\title{
44. NEOGENE CARBONATE SEDIMENTATION ON ONTONG JAVA PLATEAU: HIGHLIGHTS AND OPEN QUESTIONS ${ }^{1}$
}

\author{
W.H. Berger, ${ }^{2}$ R.M. Leckie, ${ }^{3}$ T.R. Janecek, ${ }^{4}$ R. Stax,${ }^{5}$ and T. Takayama ${ }^{6}$
}

\begin{abstract}
Neogene ocean history is dominated by the theme of stepwise global cooling (with occasional reversals); the main trends of carbonate sedimentation on the Ontong Java Plateau show the regional response of productivity, dissolution, winnowing, and redeposition to this overall climatic change. The relative importance of these processes in controlling accumulation rates and carbonate content is difficult to assess for any given place and time. Thus, the outstanding feature of the carbonate record, the Tortonian-Messinian accumulation rate peak centered in the latest Miocene (maximum sedimentation rate $>60 \mathrm{~m} / \mathrm{m}$.y.), is the product of a complex interplay of a general late Miocene to early Pliocene productivity maximum combined with increased mechanical and chemical erosion before and after the peak. The mix of erosional factors depends on the depth level considered and changes with time. Increased productivity apparently derives from high nutrient content in Pacific deep waters, caused by increased production of North Atlantic Deep Water (NADW) in the latest Miocene and basin-basin fractionation. Enhancement of the thermocline strength is indicated at that time from an increase in planktonic foraminifers living at intermediate depths. A fundamental change in the mode of productivity (toward pulsed productivity?) is indicated by changes in the coccolith flora.

The main focus of this study is the definition of major patterns of sedimentation and associated open questions, as follows:

1. Carbonate records are parallel over a wide depth range. Does this mean that dissolution is also important on the upper plateau? Or is there a "conspiracy" of separate factors acting in concert?

2. Dissolution of carbonate cannot explain both carbonate and sedimentation rate patterns. The "loss paradox" arises from the fact that carbonate percentages at different depths are so similar that the differences in carbonate are insufficient to account for differences in sedimentation rate, assuming that dissolution produces these differences.

3. Equatorial crossings have little or no effect on carbonate content or sedimentation rate. "Equatorial insensitivity" indicates that equatorial upwelling is of subordinate importance in biogenic sedimentation on the plateau in the late Neogene (as is the case today).

4. There is evidence for a general insensitivity of both carbonate and sedimentation rate records with regard to global changes in conditions, as seen in commonly used proxies. Changes in $\delta^{18} \mathrm{O}$ of benthic foraminifers, for example, and sea-level changes (as mapped by sequence stratigraphy) are not clearly correlated with the main parameters of Neogene carbonate sedimentation on the plateau. Correspondence to the $\delta^{13} \mathrm{C}$ record is somewhat better, however. Proxies may be ill defined, or the regional overprint may obscure global relationships.
\end{abstract}

The issues listed above are of a very general nature. Without a successful attack on these questions, the major patterns of carbonate sedimentation on the plateau will remain enigmatic, as will many phenomena associated with them, such as acoustic reflectors and hiatus formation. We tentatively put forward the hypothesis that the "master modulator" is the production of NADW, which affects productivity and carbonate dissolution simultaneously, through basin-basin fractionation. As NADW production is a nonlinear response to climatic forcing in a particular region (the Nordic realm), strong correlation with global proxies of change is not necessary. Other important ingredients of sedimentation history on the plateau are stepwise closure of tropical Pacific gateways (Indonesian and Panamanian) and the evolution of east-west asymmetry (warm water pileup in the western Pacific from increased strength of trade winds).

\section{INTRODUCTION $^{7}$}

A central goal of the Ocean Drilling Program (ODP) Leg 130 was the recovery of Neogene carbonate sections at several water depths from the Ontong Java Plateau in the western equatorial Pacific for the purpose of studying the evolution of global ocean dynamics and climate during the last $25 \mathrm{~m}$.y. The Ontong Java Plateau, the world's

\footnotetext{
'Berger, W.H., Kroenke, L.W., Mayer, L.A., et al, 1993, Proc. ODP, Sci. Results, 130: College Station, TX (Ocean Drilling Program).

${ }^{2}$ Geological Research Division, Scripps Institution of Oceanography, University of California, San Diego, La Jolla, CA 92093, U.S.A.

${ }^{3}$ Department of Geology and Geography, University of Massachusetts, Morrill Science Center, Amherst, MA 01003, U.S.A.

${ }^{4}$ Ocean Drilling Program, 1000 Discovery Drive, Texas A\&M University, College Station, TX 77845, U.S.A.

${ }^{5}$ Alfred-Wegener Institute for Polar and Marine Research, Columbusstrasse, D-2850 Bremerhaven, Federal Republic of Germany.

${ }^{6}$ Geology Department, Kanazawa University, 1-1 Marunouchi, Kanazawa 920, Japan.

${ }^{7}$ Another article by Berger et al. that synthesizes the Leg 130 results in a general way may be found by readers in the Geological Society of America Bulletin, Vol. 104, No. 8 (August 1992), pp. 954-972.
}

largest basaltic edifice, presumably originated as a flood basalt province within a relatively short period in the early Aptian, as the result of the outpourings from a mantle plume head (Kroenke, Berger, Janecek, et al., 1991; Tarduno et al., 1991; Mahoney et al., this volume). The plateau has an unusually thick crust (Hussong et al., 1979) and therefore has provided a stable platform for pelagic sedimentation since its origin. It is well known for its excellent record of ocean history from several earlier drilling expeditions (DSDP Leg 7, Winterer, Riedel, et al., 1971; DSDP Leg 30, Andrews, Packham, et al., 1975; DSDP Leg 89, Moberly, Schlanger, et al., 1986). During Leg 130 the JOIDES Resolution drilled 16 holes at 5 sites on the northeastern flank of the plateau (Sites 803 through 807). All sites are close to the equator, at depths ranging from 2500 to $3900 \mathrm{~m}$ (Fig. 1).

The Leg 130 campaign was highly successful, recovering complete Neogene sections at several depths, and providing abundant materials for detailed biostratigraphic and paleoceanographic studies. In addition to sediments of late Tertiary age, early Tertiary and Cretaceous sections were recovered, and basement was penetrated twice, once to $26 \mathrm{~m}$ and once to $149 \mathrm{~m}$ below the basalt-sediment contact. A substantial portion of the Neogene sections were recovered by multiple hydraulic piston coring, providing an opportunity for high 


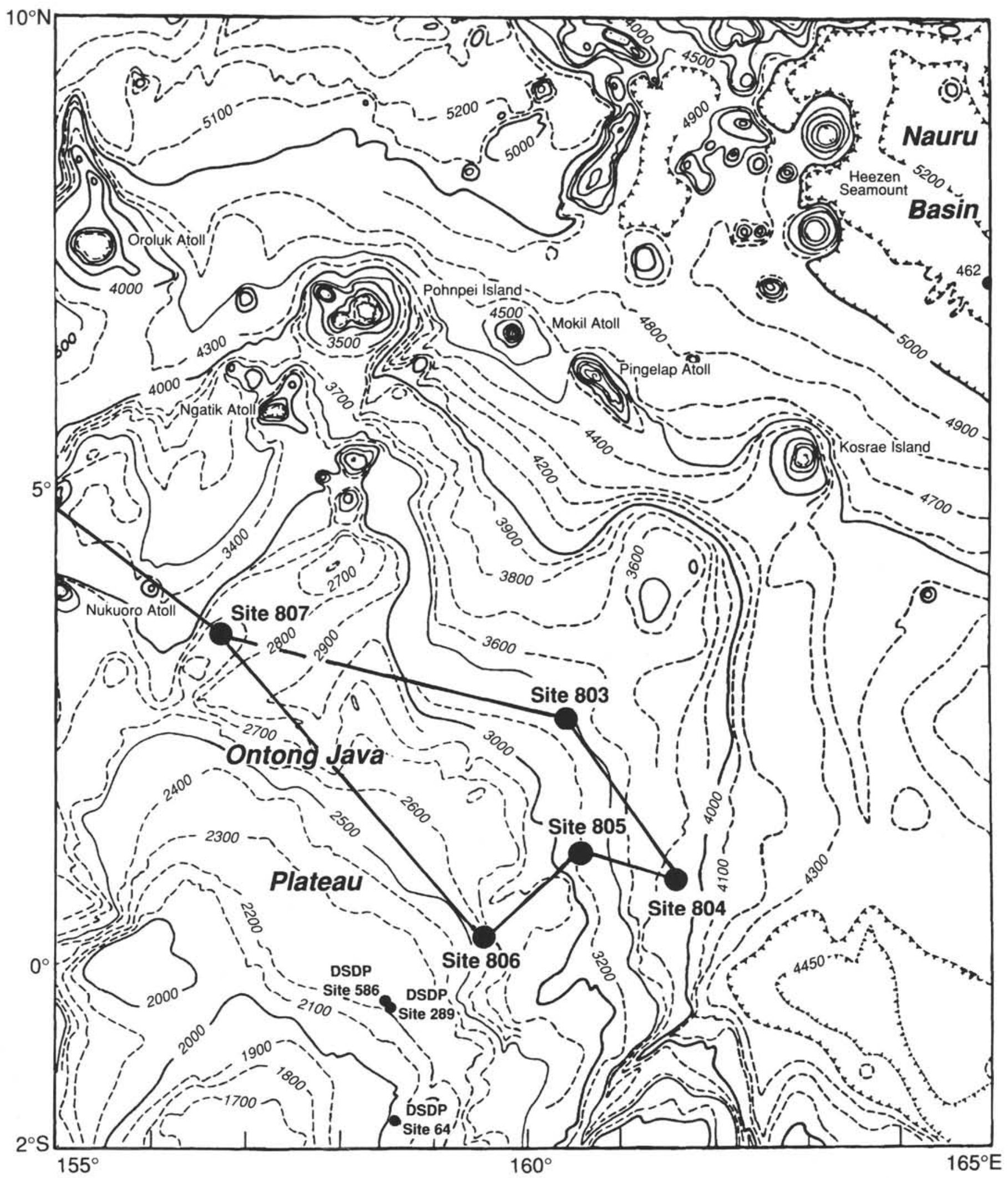

Figure 1. Site locations (from Kroenke, Berger, Janecek, et al., 1991). Contour intervals in meters. 
Table 1. Leg 130 site locations and drilling statistics.

\begin{tabular}{|c|c|c|c|c|c|c|c|c|c|c|c|}
\hline Hole & $\begin{array}{l}\text { Latitude } \\
\text { (north) }\end{array}$ & $\begin{array}{l}\text { Longitude } \\
\text { (east) }\end{array}$ & $\begin{array}{l}\text { Water } \\
\text { depth } \\
(\mathrm{m})\end{array}$ & $\begin{array}{l}\text { Cores } \\
(N)\end{array}$ & $\begin{array}{l}\text { Maximum } \\
\text { penetration } \\
\text { (m) }\end{array}$ & $\begin{array}{l}\text { Interval } \\
\text { cored } \\
(\mathrm{m})\end{array}$ & $\begin{array}{l}\text { Core } \\
\text { recovered } \\
\text { (m) }\end{array}$ & $\begin{array}{l}\text { Recovered } \\
\text { with APC } \\
\text { (m) }\end{array}$ & $\begin{array}{l}\text { Recovered } \\
\text { with XCB } \\
\text { (m) }\end{array}$ & $\begin{array}{l}\text { Recovered } \\
\text { with } \mathrm{RCB} \\
\text { (m) }\end{array}$ & $\begin{array}{l}\text { Time } \\
\text { (days) }\end{array}$ \\
\hline $803 \mathrm{~A}$ & $02^{\circ} 26.0$ & $160^{\circ} 32.5$ & 3410 & 6 & 55.5 & 55.50 & 57.99 & $57.99(104.5 \%)$ & 0 & 0 & \\
\hline 803B & $02^{\circ} 26.0$ & $160^{\circ} 32.5$ & 3410 & 7 & 61.3 & 61.30 & 58.18 & $58.18(94.9 \%)$ & 0 & 0 & \\
\hline $803 \mathrm{C}$ & $02^{\circ} 26.0$ & $160^{\circ} 32.5$ & 3410 & 23 & 237.5 & 218.50 & 226.31 & $226.31(105.4 \%)$ & 0 & 0 & \\
\hline 803D & $02^{\circ} 26.0$ & $160^{\circ} 32.5$ & 3412 & 71 & 656.0 & 656.0 & 494.96 & $228.88(103.6 \%)$ & $248.47(62.9 \%)$ & $17.61(40.0 \%)$ & \\
\hline 803 & $02^{\circ} 26.0$ & $160^{\circ} 32.5$ & 3410 & 107 & 656.0 & 991.3 & 837.44 & 571.36 & 248.47 & 17.61 & 9.7 \\
\hline $804 \mathrm{~A}$ & $01^{\circ} 00.3$ & $161^{\circ} 35.6$ & 3862 & 6 & 48.7 & 48.7 & 50.52 & $50.52(103.7 \%)$ & 0 & 0 & \\
\hline $804 \mathrm{~B}$ & $01^{\circ} 00.3$ & $161^{\circ} 35.6$ & 3861 & 15 & 137.7 & 137.7 & 141.61 & $141.61(102.8 \%)$ & 0 & 0 & \\
\hline $804 C$ & $01^{\circ} 00.3$ & $161^{\circ} 35.6$ & 3861 & 33 & 312.5 & 312.5 & 273.78 & $120.27(100 \%)$ & $153.51(79.9 \%)$ & 0 & \\
\hline 804 & $01^{\circ} 00.3$ & $161^{\circ} 35.6$ & 3861 & 54 & 312.5 & 498.9 & 465.91 & 312.40 & 153.51 & & 3.1 \\
\hline $805 \mathrm{~A}$ & $01^{\circ} 13.7$ & $160^{\circ} 31.8$ & 3189 & 6 & 50.5 & 50.5 & 52.22 & $52.22(103.4 \%)$ & 0 & 0 & \\
\hline $805 \mathrm{~B}$ & $01^{\circ} 13.7$ & $160^{\circ} 31.8$ & 3187 & 50 & 473.3 & 473.3 & 444.89 & $271.30(103.1 \%)$ & $173.59(82.6 \%)$ & 0 & \\
\hline $805 C$ & $01^{\circ} 13.7$ & $160^{\circ} 31.8$ & 3188 & 64 & 611.0 & 611.0 & 495.46 & $236.34(100.2 \%)$ & $259.12(69.1 \%)$ & 0 & \\
\hline 805 & $01^{\circ} 13.7$ & $160^{\circ} 31.8$ & 3188 & 120 & 611.0 & 1134.8 & 992.57 & 559.86 & 432.71 & & 6.2 \\
\hline $806 \mathrm{~A}$ & $00^{\circ} 19.1$ & $159^{\circ} 21.7$ & 2521 & 9 & 83.7 & 83.7 & 85.95 & $85.95(102.7 \%)$ & 0 & 0 & \\
\hline $806 \mathrm{~B}$ & $00^{\circ} 19.1$ & $159^{\circ} 21.7$ & 2520 & 78 & 743.1 & 743.1 & 666.36 & $335.20(104.8 \%)$ & $331.16(78.3 \%)$ & 0 & \\
\hline $806 \mathrm{C}$ & $00^{\circ} 19.1$ & $159^{\circ} 21.7$ & 2520 & 62 & 776.4 & 587.6 & 523.62 & $320.61(103.6 \%)$ & $203.01(73.0 \%)$ & 0 & \\
\hline 806 & $00^{\circ} 19.1$ & $159^{\circ} 21.7$ & 2520 & 149 & 776.4 & 1414.4 & 1275.93 & 741.76 & 534.17 & & 7.9 \\
\hline $807 \mathrm{~A}$ & $03^{\circ} 36.4$ & $156^{\circ} 37.5$ & 2804 & 86 & 822.9 & 822.9 & 716.74 & $263.11(103.4 \%)$ & $453.63(79.8 \%)$ & 0 & \\
\hline $807 \mathrm{~B}$ & $03^{\circ} 36.4$ & $156^{\circ} 37.5$ & 2806 & 30 & 278.6 & 278.6 & 280.18 & $280.18(100.6 \%)$ & 0 & 0 & \\
\hline $807 \mathrm{C}$ & $03^{\circ} 36.4$ & $156^{\circ} 37.5$ & 2806 & 93 & 1528.4 & 748.4 & 252.84 & 0 & 0 & $252.84(33.8 \%)$ & \\
\hline 807 & $03^{\circ} 36.4$ & $156^{\circ} 37.5$ & 2805 & 209 & 1528.4 & 1849.9 & 1249.76 & 543.29 & 453.63 & 252.84 & 24.3 \\
\hline \multicolumn{4}{|c|}{ Grand totals } & 639 & 3884.3 & 5889.3 & 4821.58 & 2728.67 & 1822.49 & 270.45 & 51.2 \\
\hline
\end{tabular}

Note: From Berger et al. (1991).

resolution work (Table 1). Also, extensive logging created a large data base for detailed correlation. Of special interest is the apparent continuity of records in several sites, with only relatively minor hiatuses at the deep sites (Fig. 2).

A number of fundamental paleoceanographic questions are being addressed using these materials, as well as others recovered from Ontong Java Plateau (DSDP Sites 289 and 586). These questions are of two kinds: those concerning processes producing the record, and those dealing with the role of the ocean in climatic change. These questions are not independent, of course. The role of the ocean cannot be assessed unless the record can be properly read, and the record cannot be read unless the processes making it are understood. The attempt to reconstruct processes from the record faces the danger of circular reasoning: it is not possible to provide the evidence on changes in conditions independent from the response seen in the sediment, a response that is to be discovered rather than assumed.

Here we attempt to cope with this fundamental difficulty by comparing results based on different approaches (physical measurements and biostratigraphy) and exploring the implications for paleoceanographic reconstruction. We concentrate on the changes in accumulation rates and carbonate content of the sediments deposited during the Neogene. Stratigraphic resolution is rather coarse, approximately 0.5 m.y., and we refer mainly to the large trends in sedimentation during this time interval. We are interested in how well present understanding of processes can cope with the patterns of Neogene sedimentation observed for the Leg 130 sites. Our working hypothesis is that changes in the production of North Atlantic Deep Water (NADW), in the Nordic realm, strongly modulate carbonate sedimentation on the plateau by controlling productivity and dissolution intensity, through basin-basin fractionation. However, we are mindful of the many other factors which potentially play important roles at one time or another: sea-level change and introduction of materials from erosion of continents (or removal to shelves), changes in temperature structure of the water, and changes in current strength and upwelling.

\section{MAJOR PATTERNS OF SEDIMENTATION AND CLIMATIC CHANGE}

\section{Main Factors and Sediment Thickness}

It is generally appreciated that a limited number of factors are responsible for producing the carbonate record: the supply of calcareous particles from surface waters, the supply of dilutants (that is, noncarbonate matter), the dissolution of carbonate, the dissolution of dilutants (e.g., siliceous fossils), and the mechanical removal and redeposition of particles on the seafloor by winnowing, scouring, sloughing (that is, creep of surficial sediment layers), or mass flow. Supply is mainly a function of productivity of overlying sunlit waters, and dissolution depends on the state of saturation of deep and bottom waters. Both change greatly through time in the equatorial Pacific (Arrhenius, 1952; Hays et al., 1969; Berger, 1973; van Andel et al., 1975; Farrell and Prell, 1989; Theyer et al., 1989; Herguera and Berger, 1991).

Mechanical removal is known to be important on top of the plateau, where it produces a thinning of the sediment cover: the maximum sediment thickness appears between 2000 and $2500 \mathrm{~m}$ depth (Berger and Johnson, 1976) rather than in the shallowest parts. Dissolution effects take over at depths greater than this, providing for a rapid thinning downslope (about $100 \mathrm{~m}$ of sediment for each $200 \mathrm{~m}$ depth increase; see Figs. 2-3). At depths below the lysocline, and more so on approaching the carbonate compensation depth (CCD), there is much evidence for "ooze flow," ascribed to a weakening in shear strength of sediments and an increase in slope. Clearly, if flow and other redeposition processes are important, they must interfere with the record of productivity and dissolution.

\section{Acoustic Stratigraphy}

Concerning large-scale features, Leg 130 especially focussed on the origin of the ubiquitous seismic reflectors within the sediment 


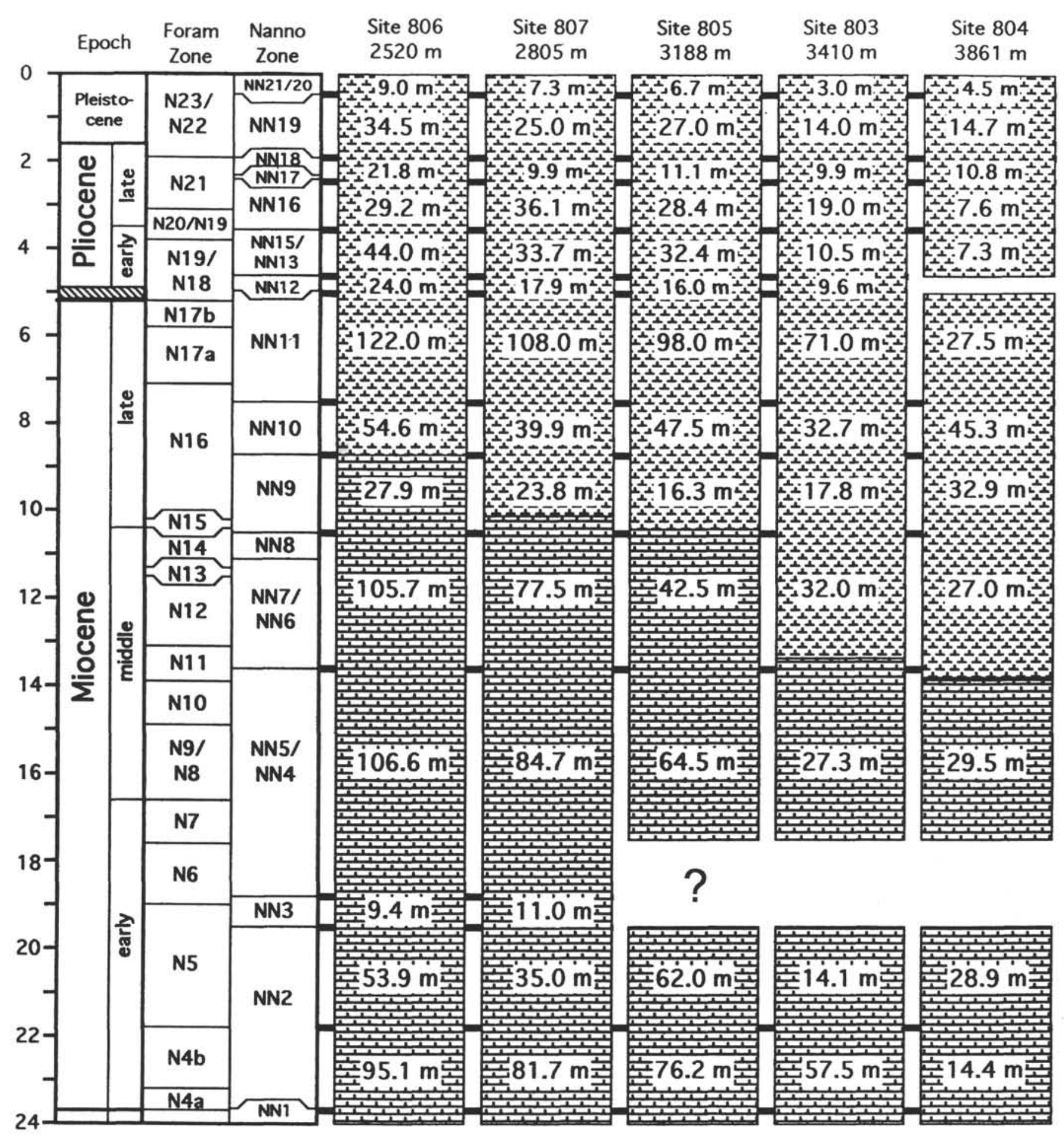

Nannofossil ooze to foraminifer nannofossil ooze

Figure 2. Overview of drilling results. Schematic time- stratigraphic representation of Neogene sediments of Sites 803-807 on the flank of Ontong Java Plateau. The sites are arranged according to depth. Sediment thicknesses for biostratigraphically defined intervals along the depth transect show a more or less regular decrease with depth, with the exception of a thickening in Zone N16 at Site 804 (see text). The hiatus at Site 805 (comprising most of Zone N6) is hypothetical (in the text we assume a condensed section). Zonation mainly after Berggren et al. (1985; see "Explanatory Notes" chapter in Kroenke, Berger, Janecek, et al., 1991). 


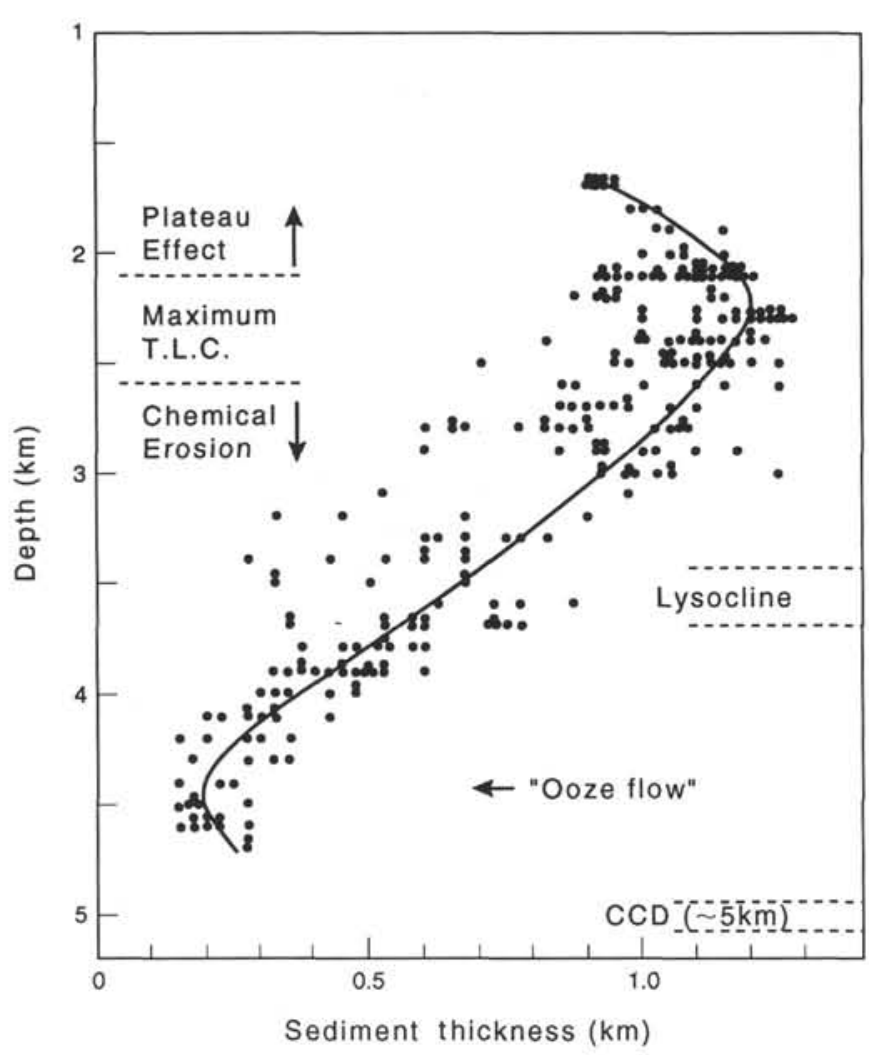

Figure 3. Thickness of acoustically transparent sediment layer on Ontong Java Plateau. Plateau effect $=$ presumably mechanical removal of sediment. T.L.C. $=$ transparent layer of carbonate. Chemical erosion zone $=$ depth range at times at or below lysocline. Lysocline $=$ approximate present position (should be near $3.3 \mathrm{~km}$ ). Ooze flow $=$ evidence for debris flow (which deepens the CCD as observed). From Berger and Johnson (1976).

stack on the Ontong Java Plateau. Individual reflectors, or groups of strong reflectors, have long been linked to times of changing conditions of sedimentation, and hence to paleoceanographic events (Schlanger and Douglas, 1974; Berger and Mayer, 1978; Mayer et al., 1986). Many of the reflectors on the plateau appear to correlate well along seismic profiles, over long distances. This is true even on the flanks of the plateau, where the increase of dissolution effects considerably alters the conditions of sedimentation along the depth gradient.

A group of major reflectors (labeled "C" in Fig. 4) marks the earliest Neogene, which is characterized by profound changes in the ocean environment, as seen in plankton evolution. Other prominent reflectors also appear to indicate major changes in paleoceanographic conditions. These, it is surmised, effected changes in the physical properties of the sediment and hence provide for impedance changes within the section (Mosher et al., this volume). Note that, on the whole, the depth gradient of sediment thickness is much stronger in the Neogene than in the underlying section (Fig. 4), suggesting increased undersaturation of deep waters after the Oligocene.

The variation in physical sediment properties which is responsible for reflectors again must be closely tied to the above mentioned processes of supply, dissolution, and mechanical displacement of sediments. Thus, to understand reflectors, these processes have to be studied in their relation to climatic change.

\section{Stable Isotopes and Sea-level Change}

Overall guidance to the sense of environmental change is provided by the oxygen isotope record of benthic foraminifers (Fig. 5), and a generalized sea-level curve (Fig. 6). Unfortunately, both curves have severe limitations. The oxygen isotope curve (based mainly on studies of Woodruff et al., 1981, on Site 289, and of Whitman and Berger, 1992, on Site 586) lacks detail because sampling intervals are too large to resolve Milankovitch fluctuations. The sea-level curve (generalized from Haq et al., 1987) is an interpretation of the geometry of sediment bodies in passive margins. Such interpretation depends on a number of assumptions, some of which have been questioned. Alternative models based on different lines of evidence have been proposed (e.g., see Moore et al., 1987; Prentice and Matthews, 1988). Given these uncertainties, the curves must be used with discretion. Nevertheless, they do provide valuable guidance to overall trends.

The general consensus is that a major cooling of deep waters occurred in the middle Miocene, a cooling that was accompanied (or perhaps rather followed) by a substantial drop in sea level (Savin et al., 1975; Shackleton and Kennett, 1975; Keigwin, 1979; Woodruff et al., 1981; Loutit et al., 1984; Miller and Fairbanks, 1985; Kennett et al., 1985; Vincent and Berger, 1985; Kennett, 1986a, 1986b; Miller et al., 1987, 1991; Woodruff and Savin, 1991). Major regression as a dominant theme of the Neogene is indicated by the rapid change of strontium isotopes in foraminiferal tests, toward continental values, indicating increased erosion on land (DePaolo and Ingram, 1985; Elderfield, 1986; Hess et al., 1986; Richter and DePaolo, 1988). However, although the mid-Miocene regression event is represented (DePaolo, 1986), apparently it is not dominant in the $\mathrm{Sr}$ record: the rate of change is greater in the early Miocene (DePaolo, 1986; Hodell et al., 1991). A number of factors beside regression determine the $\mathrm{Sr}$ trends, such as climatic conditions on land and type of materials eroded, and intensity of volcanic activity. The amplitude of cyclic change may be more important than the amplitude in overall regression in stimulating input from land. Short-lived episodes of major warming may punctuate the Neogene record (McGowran, 1986), and this would further complicate interpretation of the $\mathrm{Sr}$ isotope record.

The mid-Miocene event or series of events (as seen in $\delta^{18} \mathrm{O}$ change and sequence stratigraphy) separates the Neogene into two large periods: a warm one with high sea level ("C" in Fig. 6), and a cold one characterized by present-day sea level ("A" in Fig. 6). In addition to this dominating feature, there is agreement on the existence of an early Pliocene warm period (which is not, however, strongly reflected in the benthic isotopes), and on a sharp climatic deterioration roughly $3 \mathrm{~m} . \mathrm{y}$. ago (seen in both isotope and sea-level records). This cooling step (or series of steps) dominates late Neogene climatic trends, especially in the North Atlantic (Berggren, 1972; Backman, 1979; Shackleton et al., 1984; Jansen et al., 1990; Jansen and Sjøholm, 1991). Large-amplitude fluctuations in isotopes (and in inferred sea level) follow, leading into the Milankovitch-type cycles seen in oxygen isotopes of foraminifers (Shackleton and Opdyke, 1973, 1976).

Additional clues to global environmental change are contained in the carbon isotope record of planktonic and benthic foraminifers on the plateau (Fig. 7). The dominant features of this record are the Monterey Carbon Isotope Excursion in the latest early Miocene to early middle Miocene (marked MoCE), the decrease of values in the late middle Miocene to early late Miocene, the peak in the Tortonian preceding the (initial-) Messinian Carbon Shift to light values (marked $\mathrm{MeCS}$ ), and the low values since. The significance of these excursions and shifts has been interpreted in terms of mass flux of carbon between organic carbon reservoirs on land and in the sea, and the dissolved inorganic carbon of the ocean (Vincent et al., 1980; Loutit and Keigwin, 1982; Shackleton, 1985; Vincent and Berger, 1985; summarized in Berger and Vincent, 1986).

The curve labeled "carbon flux" shows the results from such an interpretation in term of mass flux, using the formula of Vincent and Berger (1985) and assuming that equilibrium $\delta^{13} \mathrm{C}$ of the ocean is the Neogene average. (Other assumptions give quantitatively different results, although the sense of change remains the same). The Monterey Carbon Excursion is seen as a buildup of organic carbon (given in Ocean Carbon Mass per million years) lasting for about $4 \mathrm{~m}$.y. The 


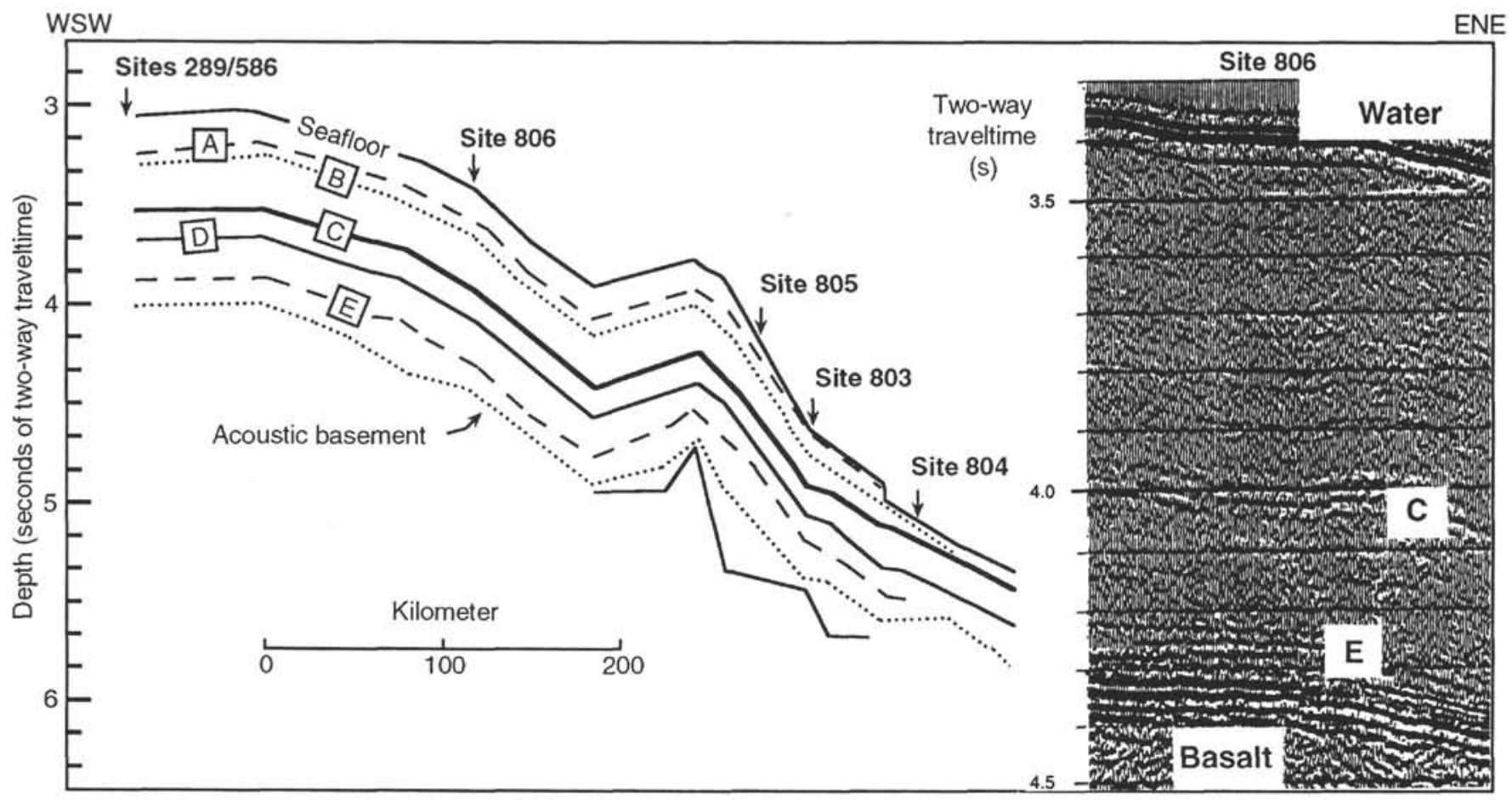

Figure 4. Prominent acoustic reflectors on Ontong Java Plateau appear to be synchronous and allow the reconstruction of depth gradients of sedimentation rates. Reflector Groups A, B, and C are in the Neogene ( $\mathrm{C}$ is in the early Miocene). Reflector Group E is near the Eocene/Oligocene boundary. From Mayer et al. (1991).

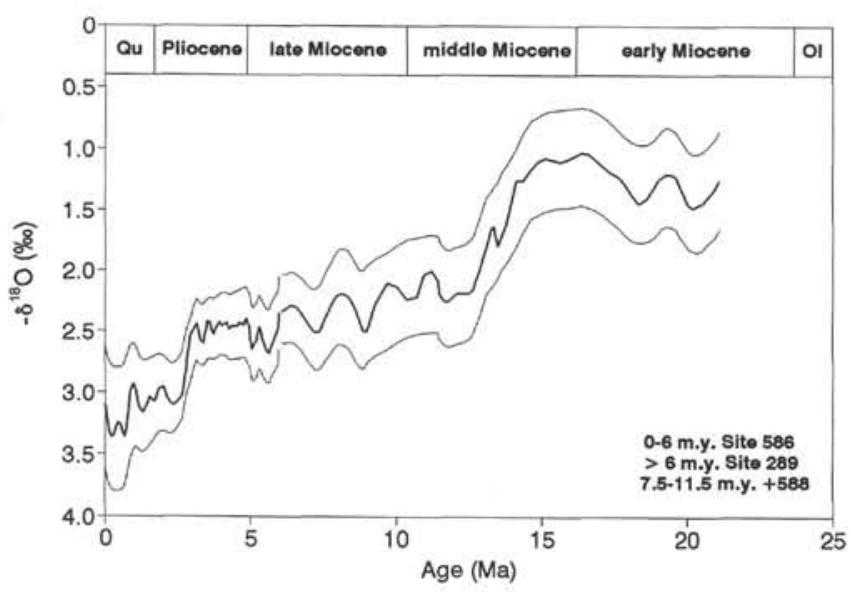

Figure 5. Oxygen isotope composition of benthic foraminifers at DSDP Sites 289 (Woodruff et al., 1981) and 586 (Whitman and Berger, 1992), Ontong Java Plateau (based on analysis of Planulina wuellerstorfi and closely related forms). Generalized by smoothing. Range of variation shown determined by eye. For the section from 7.5 to 11.5 m.y., adjustments have been made based on results from DSDP Site 588 to the south of Ontong Java Plateau (Kennett, 1986a).

late middle Miocene regression (Fig. 6) is seen to result in a major shift of carbon from organic carbon reservoirs to the ocean. An analogous correspondence between overall sea-level change and carbon isotope record is not seen in the late Neogene, which is puzzling. The sea-level curve may be at fault, or else large-scale cycles (associated with moderate sea-level drop: Hodell et al., 1986) are responsible for the organic carbon input producing the isotopic shift. Major input from land is indicated by a marked strontium isotope step at the end of the Miocene (DePaolo, 1986; Hodell et al., 1989, 1991). Regression is also indicated by the buildup of evaporites in the Mediterranean (see McKenzie and Oberhänsli, 1985, and references therein).

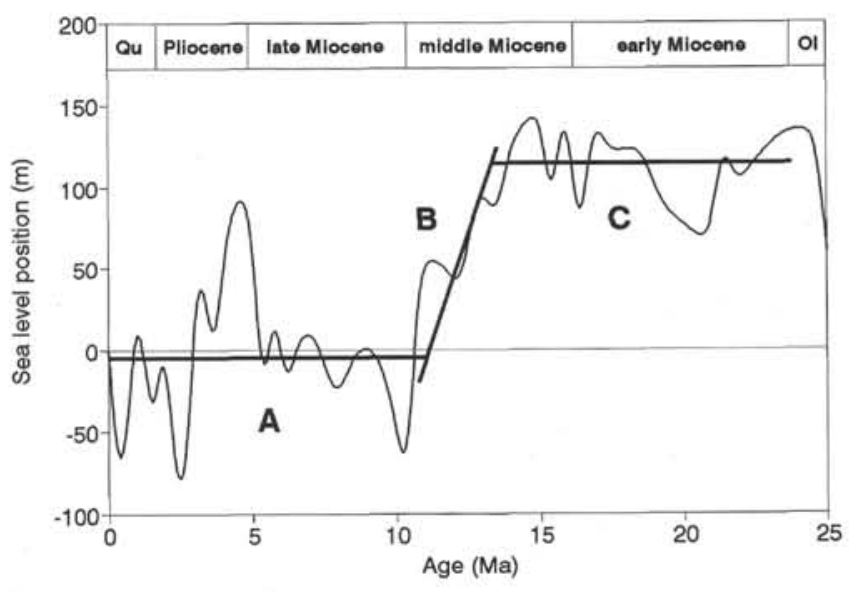

Figure 6. Sea-level change in the Neogene, estimated from sequence stratigraphy. From Haq et al. (1987), greatly smoothed. Major Subdivisions A and C emphasize the Neogene dichotomy of high and low sea-level stands before and after the late middle Miocene cooling event (marked B) (see text).

\section{Trends of Accumulation Rates and Carbonate Content}

The broad patterns of Neogene carbonate sedimentation on the plateau were established onboard during Leg 130 (Berger et al., 1991; see Fig. 8). Trends in sedimentation rates are dominated by a distinct low in the late early Miocene to early middle Miocene and a prominent high centered in the late Miocene to early Pliocene. Interestingly, the position of each site relative to the equator apparently has little or no influence on the accumulation rate (crossings are shown as open squares straddling the respective curves). The period of low rates is characterized by hiatus formation at Sites 803 and 804 , suggesting sporadic sediment removal as a factor in accumulation rate reduction (presumably in the shallower sites as well). Nevertheless, the strati- 


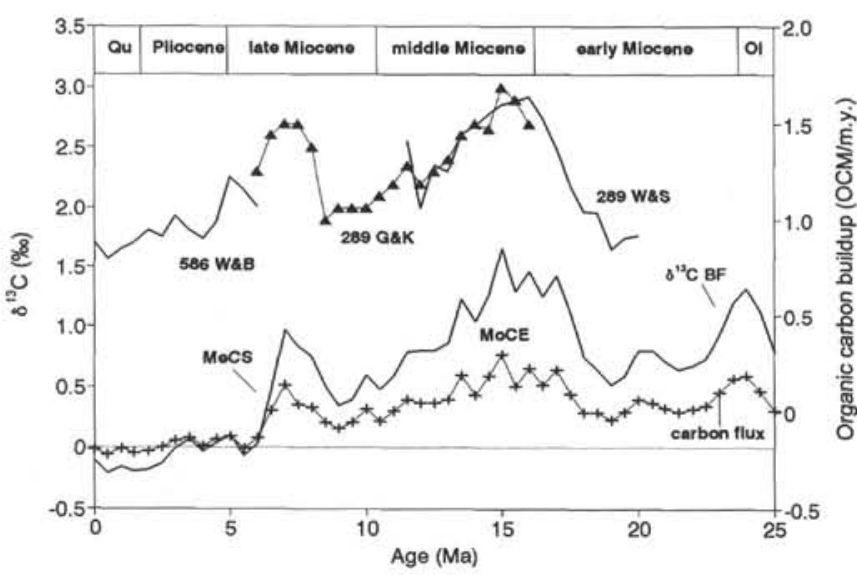

Figure 7. Carbon isotope record on Ontong Java Plateau. The record contains data from DSDP Sites 289 and 586, from the following publications: benthic foraminifers, Woodruff et al. (1981; $6 \mathrm{Ma}$ and older) and Whitman and Berger (this volume; 0-6 Ma); planktonic foraminifers, Woodruff and Savin (1991; $12 \mathrm{Ma}$ and older), Gasperi and Kennett (1992; 6-15 Ma), and Whitman and Berger (this volume; $0-6 \mathrm{Ma}$ ). Time-series data were smoothed and resampled at steps of $0.5 \mathrm{Ma}$. The planktonic data points derived from the work of Gasperi and Kennett are based on spot sampling (see Gasperi and Kennett, this volume) and are educated guesses. The overlap with the series of Woodruff and Savin is shown to provide a sense of reliability. MoCE $=$ Monterey Carbon Excursion, centered on N9 (Vincent and Berger, 1985), here peaking at ca. 15.5-15 Ma; MeCS $=$ Messinian Carbon Shift, dated at $6 \mathrm{Ma}$ (Haq et al., 1980).

graphic sequences at Sites 805,806 , and 807 appear to be complete, based on the biostratigraphy (with some doubt for Site 805 ; see Fig. 2). Comparing the overall trend in sedimentation rates (Fig. 8A) with the overall climatic trends (Figs. 5-6), we note that, on the whole, high sea level corresponds to low accumulation rates, and vice versa. This could be explained, for example, by assuming a competition for carbonate between shelves and the deep seafloor.

The inferred general correspondence between carbonate accumulation and sea level does not hold up when considering the late Neogene alone. The interval centered near $7 \mathrm{Ma}$ displays some of the highest rates $(>50 \mathrm{~m} / \mathrm{m} . \mathrm{y}$.) yet recorded in open-ocean pelagic sediments. (Similarly high rates are seen in the central equatorial Pacific [DSDP Site 572, Theyer et al., 1989], and even higher ones have now been reported for this period from the eastern equatorial Pacific [ODP Site 849, Leg 138, Mayer et al., 1992].) The timing suggests a strong relationship to the closing of the Tethys, and to major phases in mountain building (e.g., McKenzie and Oberhänsli, 1985; Raymo et al., 1988). An increase in trade-wind strength and hence in productivity may be indicated; optimal preservation of diatoms in this interval supports this interpretation. If we follow this line of thought, we would again expect a strong association between lowered sea level and increased accumulation. It is somewhat disconcerting to note, therefore, that the main peak in accumulation seems more closely associated with the early Pliocene transgression, than with the low stands of the early late Miocene or the Quaternary.

The remarkable drop in carbonate production in the Pliocene, which culminates in minimum values in the Quaternary, is accompanied by increasing sand content and decreasing diatom and radiolarian preservation. This suggests increased winnowing on the seafloor as one factor and decreased productivity as another. Why, if trade-winds increased in response to a stronger planetary temperature gradient in the late Neogene, should this now lead to reduced productivity? Two factors, working in concert, could be responsible: the closing of the Indonesian and Panamanian seaways and the increase in surfacewater transport, which resulted in a pileup of warm water in the western tropical Pacific (Kennett et al., 1985). The resulting thicken-

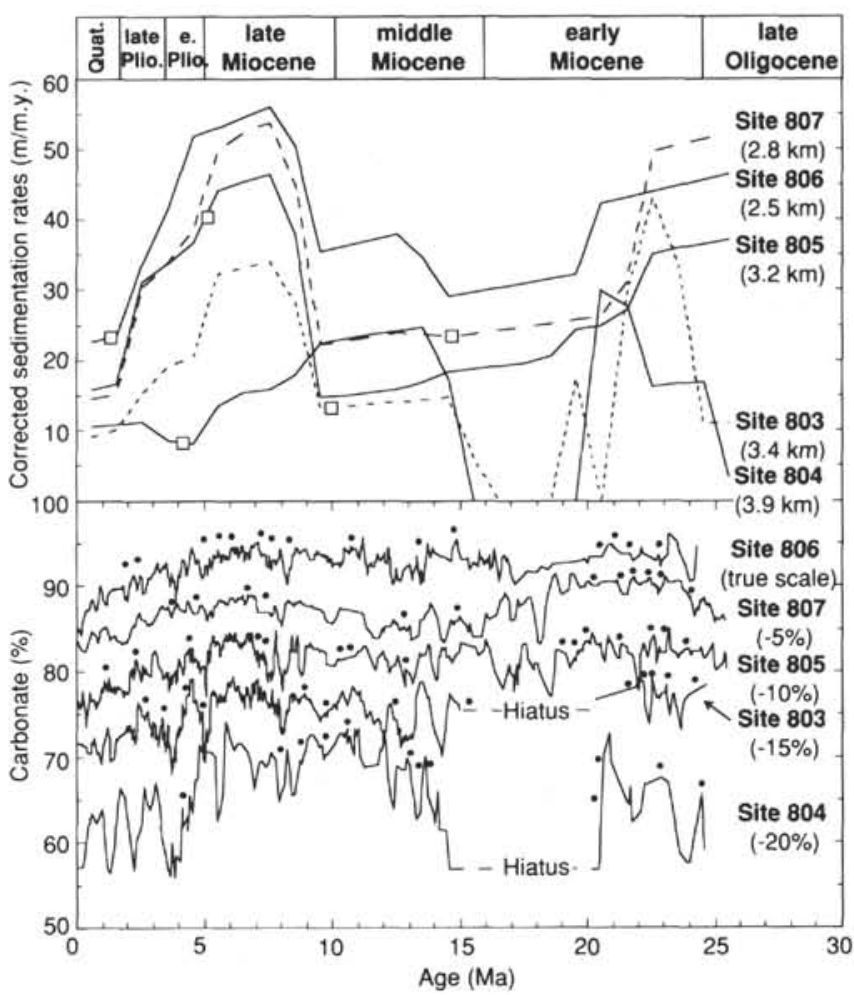

Figure 8. Sedimentation rates and carbonate percentages for the Leg 130 sites, based on shipboard studies. Sedimentation rates have been corrected for compaction, that is, they were expanded to the density of Pleistocene sediments $\left(1.5 \mathrm{~g} / \mathrm{cm}^{3}\right)$. Boxes on the sedimentation rate curves indicate the time when the site crossed the equator. Carbonate percentages were shifted as indicated to facilitate graphical presentation. The dots associated with the carbonate curves indicate the approximate positions of individual acoustic reflectors. From Berger et al. (1991).

ing of the mixed layer would have greatly reduced access to nutrients in the thermocline (Barron and Baldauf, 1989, and references therein). In addition, the thermocline might have been somewhat depleted in nutrients, due to the increase in upwelling in the coastal ocean belt, all through the late Neogene (Berger and Wefer, 1991).

The clear separation of accumulation rates at different sites since the early late Miocene, according to depth of deposition, suggests a strong carbonate saturation gradient, established by an increasing influence of cold deep-water formation. The ordering influence of this gradient is also seen in the carbonate stratigraphies (Fig. 8B), which show high correlation between sites for the last $12 \mathrm{~m}$.y. One outstanding problem is why the carbonate values of even the deeper sites differ so little from the high values of the shallower sites. As we shall see, carbonate removal by dissolution alone cannot explain both the differences in sedimentation rates between the sites and the differences in carbonate content.

\section{Can We "Explain" the Reflectors?}

One important objective, as mentioned, was to obtain data on the origin of the acoustic reflectors which characterize the layer-cake stratigraphy on the plateau (Fig. 4). The approximate position of prominent reflectors is indicated by small dots along the carbonate curves in Figure 8B. One can see that many of the reflectors line up with sharp changes in carbonate content. However, the pattern is not strictly predictive. Other changes in properties (e.g., grain size, porosity) must be considered, with important clues to their significance being hidden in the fossil content. 
Reflectors correlate extremely well between different sites on the plateau, on the upper flank (Fig. 9), and also downslope (Mosher et al., this volume). Major reflectors are synchronous within the biostratigraphic resolution available (Berger et al., 1991). Biostratigraphic age assignment to the main reflectors (based on finding depths from sound velocity profiles recovered by logging, and fossil identification) shows that the great climatic change in the middle Miocene has the strongest reflectors of the last 20 m.y. (middle of "Antarctic Series"; see Fig. 9). Also, the climate step near $3 \mathrm{Ma}$ apparently is associated with reflectors (middle of "Panama Series"). Thus, the hypothesis of climatic origin (Mayer et al., 1986) is supported. However, many other correlative reflectors exist. The difficulty is not to find a reflector matching some identified event, but to explain the presence of reflectors in the apparent absence of such events elsewhere in the section.

Knowing the isotope and carbonate stratigraphy, can we, in principle, predict the presence and strength of reflectors? At this point, this question is not resolved. If our working hypothesis (that much of the carbonate sedimentation is modulated by NADW production) is correct, many of the reflectors are long-distance messages from the Nordic realm, involving changes in productivity and carbonate dissolution. If so, basin-wide correlation of reflectors would result.

\section{Some Major Puzzles of Carbonate Sedimentation}

From this overview of major patterns emerges a set of major puzzles, with regard to carbonate sedimentation: (1) What is the reason for the inter-site similarity in accumulation rate pattern (except for the depth-related offset)? Why is the (presumed) distance to the equator so unimportant? (2) What caused the remarkable peak in sedimentation rates near the end of the Miocene, and the precipitous decrease toward the present? (3) Why are differences in carbonate content between the various sites so small, despite the substantial differences in rates of accumulation? If carbonate dissolution cannot produce both these differences, what does? (4) What are the correlations, if any, between the accumulation rate patterns, the carbonate content, and climatic conditions as recorded in oxygen isotopes? What processes determine the degree of correspondence (or lack thereof) between these parameters?

Several of these questions arose early in the investigation, and are listed in the site chapters and synthesis of the Leg 130 Initial Reports volume (Kroenke, Berger, Janecek, et al., 1991; Berger, Kroenke, Mayer, et al., 1992); the evidence provoking them is by no means subtle.

\section{AGE MODEL AND SEDIMENTATION RATES}

\section{Biostratigraphic Basis}

The basis of age assignments is biostratigraphic correlation; for the pelagic carbonates under discussion we rely on dating by nannofossils and foraminifers. Unfortunately, the hoped-for tie-in to magnetic stratigraphy, in the Neogene section, was frustrated because of severe loss of remanent magnetic intensity resulting from reduction of sulfate and concomitant chemical reaction of sulfur species with iron-containing minerals. The precipitation of magnetic iron sulfide carrying high-coercivity overprint may be largely responsible for the difficulties encountered (Musgrave et al., this volume).

Two issues must be considered when reconstructing sedimentation rates: the accuracy of correlation between sites and the assignment of ages to the datums. (A third issue, differential compaction, is comparatively unimportant here.) How consistent is datum recognition from one site to the other, and how reliable is the age in million years attached to each datum?

Some appreciation for the errors involved in correlating between sites can be attained by comparing results from different attempts at building age models. The errors arising from age assignments are separate from the errors of correlation. Age models imply sedimentation rates. We shall attempt to check on such rates by applying Fourier analysis to physical property records, assuming that the main periods of the Milankovitch spectrum should appear at 100 k.y. (eccentricity) and 41 k.y. (obliquity), if the sedimentation rate is correctly estimated. In the interval considered (the last $10 \mathrm{~m} . \mathrm{y}$.), changes in the length of these fundamental periods are negligible, for our purposes (Berger, Loutre, and Laskar, 1992).

The stratigraphic scheme adopted for Leg 130 is reproduced in Figure 10, which is taken from the Initial Reports volume (Kroenke, Berger, Janecek, et al., 1991, "Explanatory Notes" chapter). Datum levels for nannofossils and foraminifers for Hole 806B are shown in Table 2. These are based on post-cruise studies. For all other datums used here, see the original listings in the Leg 130 Initial Reports chapter (Kroenke, Berger, Janecek, et al., 1991) and the chapters by Takayama (this volume) and by Chaisson and Leckie (this volume). Fornaciari et al. (this volume) offer determinations for the early Miocene. Their identification of the first appearance datum (FAD) of Discoaster druggii level differs substantially from that of Takayama (this volume); we have not used either datum in the calculation of sedimentation rates.

\section{Age-depth Relationships}

The biostratigraphic data listed in Table 2, and additional ones from Takayama (this volume), allow the construction of a detailed age-depth plot for the five sites of Leg 130 (Fig. 11). Control for Site 806 is especially detailed. These data fully confirm the strikingly high sedimentation rates within the late Miocene that were based on the shipboard biostratigraphy of Leg 130, as well as the rapid drop in rates within the Pliocene (Fig. 8). Other major features, going downward in the record, are a slow-down of rates near $10 \mathrm{Ma}$ (possibly approaching a hiatus in the deep Sites 803 and 804), moderate sedimentation rates (?) in the poorly resolved section between $14 \mathrm{Ma}$ and $17 \mathrm{Ma}$, and hiatus formation and condensation between $17 \mathrm{Ma}$ and $19.5 \mathrm{Ma}$. In the sections older than $20 \mathrm{Ma}$, resolution is poor and the differences in the age models need to be resolved before rates can be discussed. The profile as drawn (based on foraminifers) is hypothetical.

\section{"Best-guess" Age Model for Site 806 and Corollaries}

For paleoceanographic purposes, the determination of sedimentation rates for relatively short intervals (in the following called "instantaneous" sedimentation rates [ISR]) is desirable: this information is most useful for the discussion of changes in productivity and preservation of carbonate. The retrieval of ISRs is fraught with difficulties, as is well known. Both the depth level and the age of a datum have uncertainties. If two datum levels differ by, say, $20 \mathrm{~m}$, with an uncertainty of $3 \mathrm{~m}$, the range in the difference is 14 to $26 \mathrm{~m}$. If the difference in ages is, say, 1 m.y., with an uncertainty in the age assignments of $0.2 \mathrm{~m}$.y., the range in the difference is 0.8 to $1.2 \mathrm{~m} . \mathrm{y}$. The range of the ratio (i.e., the sedimentation rate) then is $26 / 0.8$ to $14 / 1.2$, which comprises a factor of 2.8 . The numbers given in the example are more or less typical. Ironically, if errors in age assignments to datum levels are large, this will greatly improve correlations of sedimentation rates from one site to another. Such agreement, however, stems from the agreement in the errors, not from correspondence in the patterns of sedimentation.

The best studied site, from the point of view of stratigraphy, is Site 806 . We have three age models for this site, which are rather independent from each other. Two of these models result from the data listed in Table 2, which can be taken separately for foraminifers and nannofossils (Figs. 12A-12B). The third (Fig. 12C) is a model based on the nannofossil stratigraphy given in the Initial Reports volume (Kroenke, Berger, Janecek, et al., 1991, "Site 806" chapter), smoothed and adjusted for carbonate-based correlation into Sites 805 and 807 (Berger and Stax, unpubl. data; carbonate profiles in Fig. 8). Adjustments were less than $10 \mathrm{~m}$ for each datum. For each of the three models, the cumulative ("average" sedimentation rates [ASR]) and the differ- 


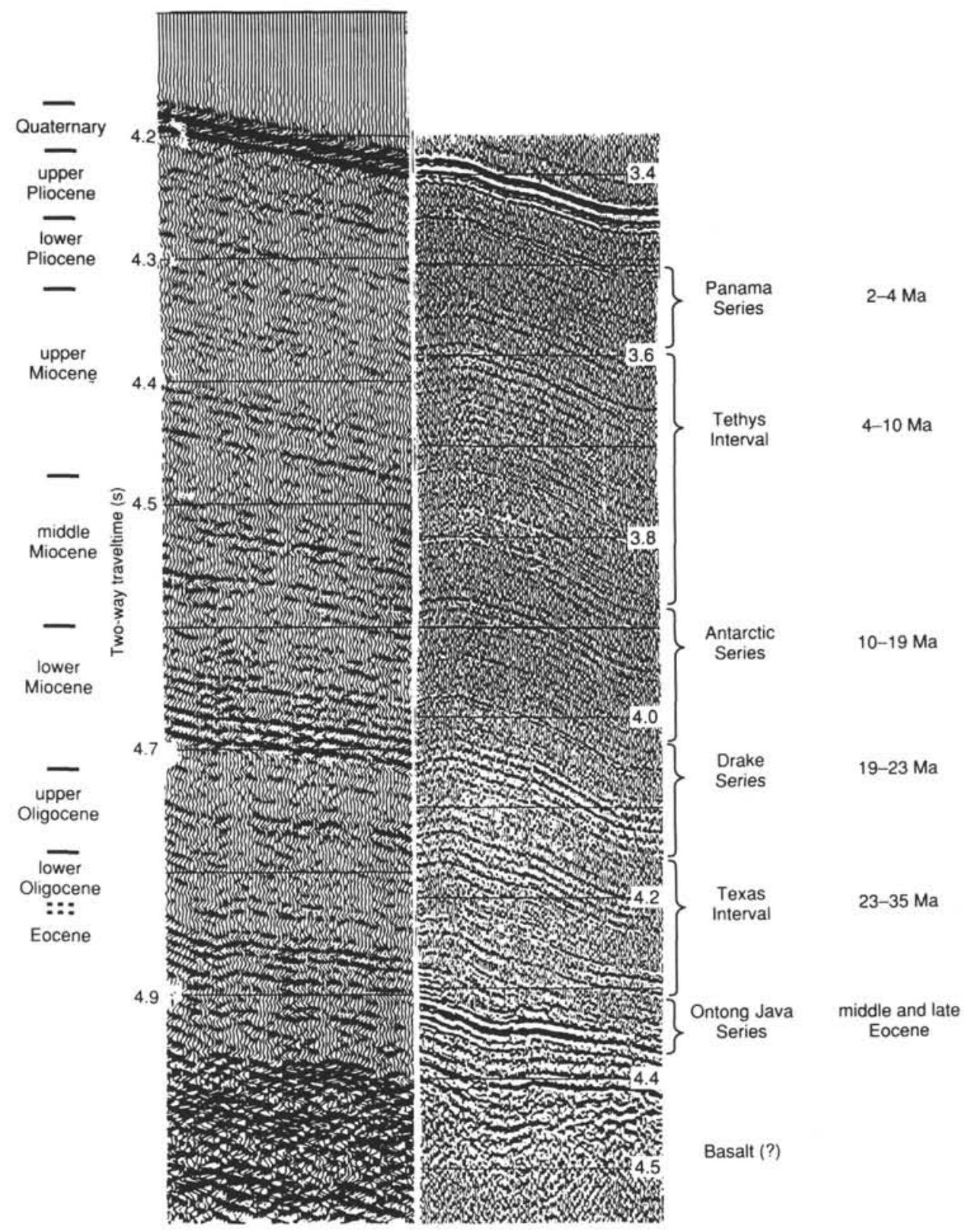

Figure 9. Correlation of seismic reflectors at Sites 805 and 806. Profiles taken by Thomas Washington on Roundabout Cruise 11, with the time scale assigned from drilling and logging results and biostratigraphy. Names to the right refer to groups of reflectors ("series") and to zones with no distinct groups ("intervals"). The scale for Site 806 was reduced by a factor of 0.73 with respect to that of Site 805 to obtain an approximate match for the reflectors of the Drake Series (lower Miocene). This procedure also had the effect of producing a good line-up between reflector groups elsewhere (e.g., Ontong Java Series). From Berger et al. (1991).

ential ("instantaneous" sedimentation rates [ISR]) are shown. Comparing the patterns, we note that they agree in the broad features, but differ considerably in detail. In each of the models, there is a late Miocene sedimentation rate maximum, for example, although the position of the peak varies somewhat. In both the foraminifer-based and nannofossil-based plots a spike appears in the ISR in the middle Miocene. However, the position of this spike differs by 2 m.y. Thus, these features do not substantiate each other and may well be spurious. Overlaying the several age models and their differentials certainly suggests that short-lived spikes (2-m.y. duration or less) are not well substantiated (Figs. 13A-13B).
The "best-guess" age scale from this comparison is found by averaging the interpolated cumulative sedimentation rates (that is, the depth/age ratios). This was done for intervals of $0.1 \mathrm{Ma}$ (Fig. 13A). The resulting smooth age model curve (ASR) is shown in Figure 13C, together with its difference curve (ISR). This is the age model used in the discussions that follow.

\section{Correlation from Site 806 to Other Sites}

Correlation between sites, that is, the determination of depth levels thought to contain contemporaneous sediments, is based on the nanno- 


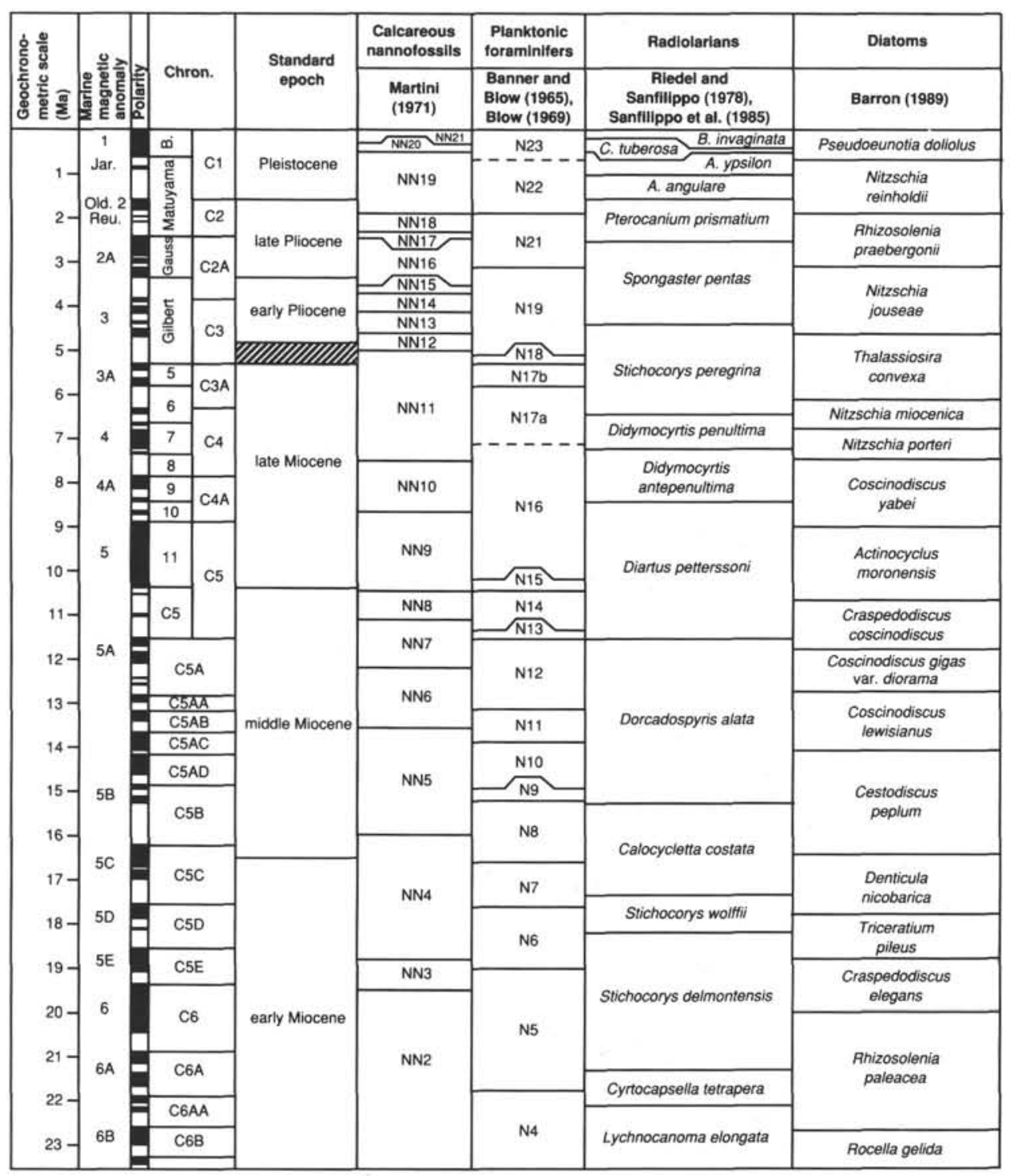

Figure 10. Correlation of Neogene chronostratigraphy, biostratigraphy, and magnetostratigraphy used during Leg 130 (see "Explanatory Notes" chapter in Kroenke, Berger, Janecek, et al., 1991). Correlation of magnetic polarity record, epoch boundaries, and planktonic foraminifer zones as in Berggren et al. (1985); nannofossil zonal boundaries as listed in the Initial Reports volume for Leg 130.

fossil stratigraphy of Takayama (this volume). The resulting matrix of equivalent depths was checked for internal consistency to identify likely "weak" correlations and to make corresponding adjustments. Resulting initial correlations are shown in Table 3. In this table, "weak" correlations are inferred to occur at those levels for which substantial adjustments are indicated in the initial analysis. For example, "7.5" is such a level as well as "13.6". These are correlations that produce sudden jumps in the ratios of instantaneous sedimentation rates.

To construct an algorithm for goodness of correlation, we reasoned as follows: Each correlation consists of assigning a depth in the "target" site to a given depth in the "standard" site, where "standard" and "target" are chosen arbitrarily. The target depth level, chosen on the basis of matching a datum from standard to target, can be checked against expectations based on adjacent correlations between standard and target from a younger or an older datum. The expected depth is given by:

$$
X_{\mathrm{DEP}}=\mathrm{Dat}_{\mathrm{DEP}}(\text { target }) / \mathrm{Dat}_{\mathrm{DEP}}(\text { standard }) \cdot \mathrm{Cor}_{\mathrm{DEP}}(\text { standard }),
$$

where Dat ${ }_{\text {DEP }}$ denotes the respective depth levels of a datum other than the one used for correlation. The closer this datum is to the one to be matched, the better the estimate $X_{\mathrm{DEP}}$ (i.e., the more weight it should be given when using several averages). Cor $_{\text {DEP }}$ is the depth of the currently selected datum in the standard.

Another way of estimating the expected depth of a datum in a target site is from sedimentation rate (based on adjacent datums) and the assigned age of the datum:

$$
X_{\mathrm{DEP}}=\mathrm{ASR}(\text { target }) \cdot \text { Age }(\text { datum }),
$$

Given an age model (such as the one for Site 806), then, at least three $X_{\text {DEP }}$ estimates can be made profitably, using datums immediately above and below the currently selected target datum, and using the age of this selected datum. If the proposed match is seriously out of line with these estimates, adjustment may be indicated (or else disturbance, such as redeposition or erosion). 
Table 2. Biostratigraphic datums used in dating Neogene sediments of Hole 806B.

\begin{tabular}{|c|c|c|c|c|c|c|c|}
\hline Biostratigraphic & Age & Nannos & Forams & Biostratigraphic & Age & Nannos & Forams \\
\hline Datums & $(M a)$ & $(806 \mathrm{~B})$ & $(806 \mathrm{~B})$ & Datums & $(M a)$ & (806B) & $(806 \mathrm{~B})$ \\
\hline FO E. huxdeyi & 0.28 & 3.67 & & LO G. dehiscens & 5.30 & & 167.05 \\
\hline LO P. lacunosa & 0.46 & 9.01 & & FO G. tumida & 5.20 & & 172.04 \\
\hline LO R. asanoi & 0.83 & 18.16 & & FO P. primalis & 5.80 & & 206.15 \\
\hline FO G. perallela & 0.90 & 21.91 & & FO D. quinqueramus & 7.50 & 284.50 & \\
\hline PO R. asanoi & 1.06 & 24.91 & & FO G. plesiotumida & 7.10 & & 296.75 \\
\hline LO Gephyrocapsa (large) & 1.10 & 26.03 & & LO D. hamatus & 8.70 & 339.15 & \\
\hline LO H. sellii & 1.19 & 30.66 & & LO Catinaster spp. & 8.80 & 344.91 & \\
\hline FO Gephyrocapsa (large) & 1.36 & 32.16 & & FO N. acostaensis & 10.20 & & 354.68 \\
\hline LO C. macintyrei & 1.45 & 34.41 & & FO C. calyculus & 10.00 & 362.81 & \\
\hline FO G. oceanica & 1.57 & 35.08 & & LO P. mayeri & 10.40 & & 364.37 \\
\hline FO G. caribbeanica & 1.66 & 35.13 & & FO D. hamatus & 10.50 & 367.04 & \\
\hline LO G. fistulosus & 1.60 & & 36.06 & FO C. coalitus & 11.10 & 375.36 & \\
\hline LO D. brouweri & 1.89 & 43.51 & & FO G. nepenthes & 11.30 & & 378.00 \\
\hline FO G. truncatulinoides & 1.90 & & 51.98 & LO G. fohsi s.l. & 11.50 & & 411.29 \\
\hline LO D. pentaradiatus & 2.35 & 54.53 & & LO C. nitescens & 12.80 & 425.46 & \\
\hline LO D. surculus & 2.41 & 65.31 & & Fo G. fohsi s.l. & 13.10 & & 449.89 \\
\hline LO D. altispira & 2.90 & & 69.04 & LO C. floridanus & 13.10 & 463.73 & \\
\hline PO G. fistulosus & 2.90 & & 72.04 & LO S. heteromorphus & 13.60 & 472.79 & \\
\hline LO Sphearoidinellopsis spp. & 3.00 & & 75.54 & FO G. praefohsi & 13.90 & & 483.51 \\
\hline FO G. tosaensis & 3.10 & & 75.54 & LO P. sicana & 14.90 & & 497.80 \\
\hline LO G. margaritae & 3.40 & & 78.54 & FO G. peripheroacuta & 14.90 & & 500.37 \\
\hline LO Sphenolithus spp. & 3.45 & 86.51 & & PO P. sicana & 16.60 & & 558.21 \\
\hline LO R. pseudoumbilica & 3.56 & 94.51 & & LO C. dissimilis & 17.60 & & 575.16 \\
\hline Pulleniatina coiling change & 3.80 & & 102.55 & FO S. heteromorphus & 18.60 & 579.08 & \\
\hline LO P. spectabilis & 3.90 & & 109.40 & LO S. belemnos & 18.80 & 579.43 & \\
\hline LO G. nepenthes & 3.90 & & 111.90 & PO G. insueta & 19.00 & & 580.33 \\
\hline LO G. cibaoensis & 4.40 & & 135.54 & LO T. carinatus & 19.50 & 588.78 & \\
\hline FO C. rugosus & 4.60 & 138.51 & & Fo S. belemnos & 20.00 & 601.01 & \\
\hline LO C. acutus & 4.60 & 138.51 & & RO D. druggii & 23.60 & 627.63 & \\
\hline FO C. acutus & 4.90 & 151.51 & & LO P. kugleri & 21.80 & & 642.67 \\
\hline LO $T$. rugosus & 4.90 & 153.01 & & FO G. dehiscens & 23.20 & & 728.87 \\
\hline LO D. quinqueramus & 5.00 & 162.51 & & Fo P. kugleri & 23.70 & & 737.75 \\
\hline
\end{tabular}

Notes: Calcareous nannofossil datums from Takayama (this volume); planktonic foraminifer datums from Chaisson and Leckie (this volume). 
A

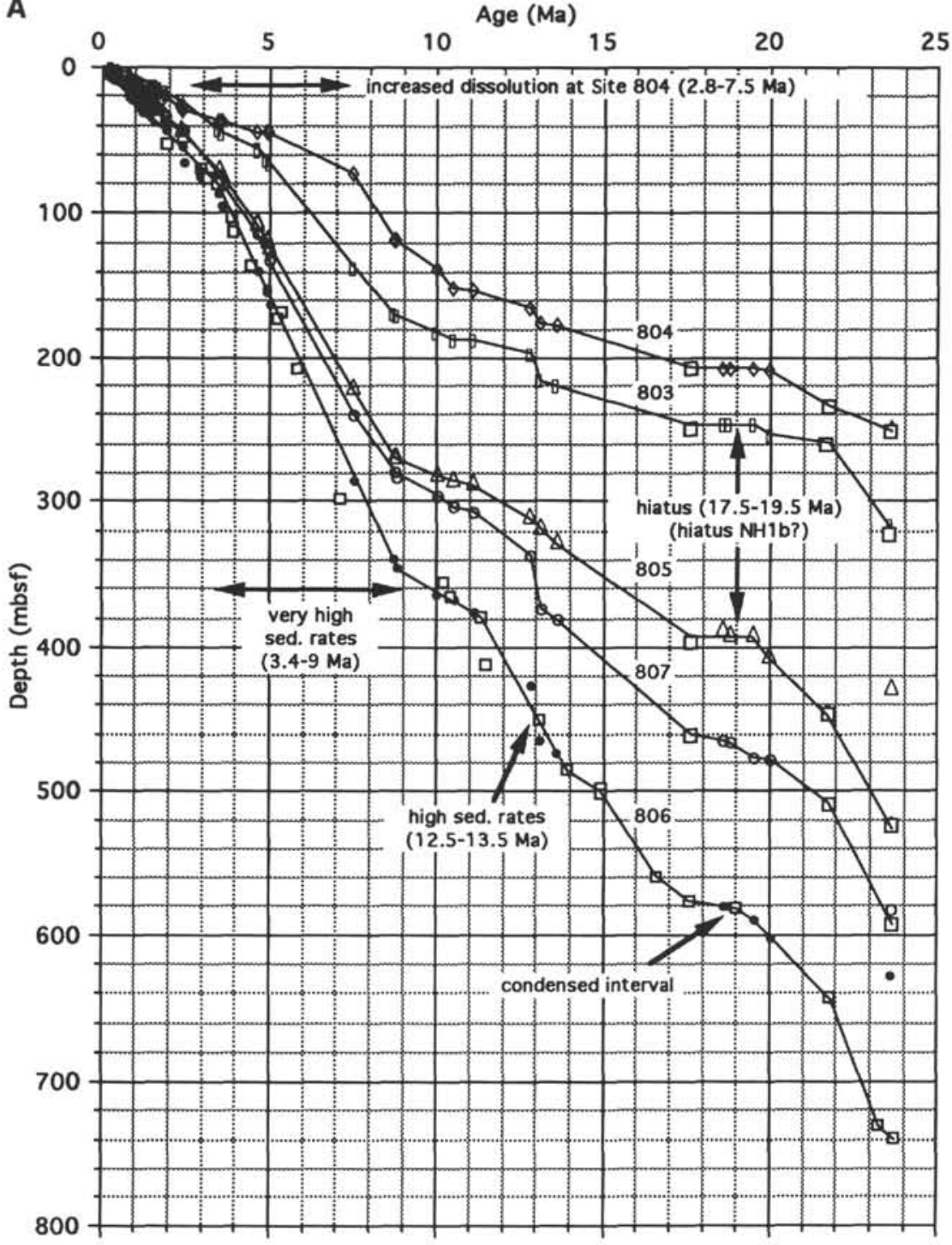

Figure 11. Age vs. depth plots for sites drilled along a depth transect on the flanks of Ontong Java Plateau during Leg 130. Depths uncorrected for compaction. Data for Site 806 from Takayama (this volume; calcareous nannofossil datums, solid circles) and from Chaisson and Leckie (this volume; foraminiferal datums, open squares). Data for Sites $803,804,805$, and 807 are based on the nannofossil datums of Takayama (this volume) with the exception of three foraminiferal datums from the lower Miocene of each site (open squares) based on shipboard results (see Kroenke, Berger, Janecek, et al., 1991). A. 0-25 Ma. B. 0-6 Ma.

To find the adjustment, an arbitrary decision has to be made about the allowable discrepancy between the expected match and the one observed from lining up a given datum. We designed a function that uses two estimates (in the present case, the average $X_{\mathrm{DEP}}$ from using adjacent datums and the $X_{\mathrm{DEP}}$ from age assignment). This function (1) lets stand the observation in the case where either expectation is close to the proposed match, (2) bases its magnitude on the smaller difference of the two estimates of $X_{\mathrm{DEP}}$, and (3) makes no adjustment if differences to expectations are large but of opposite sign. Such a function has to contain the following terms ("Dif" stands for the difference between expected and observed depth level):

Term 1, for Conditions (1) and (2): ABS[Dif(corr) · Dif(age)] Term 2, for Condition (3): Dif(corr) + Dif(age).
Also, to suppress a runaway effect from the first term, a negative feedback is needed:

$$
[1-k \cdot(\text { Term } 1)]
$$

The following equation was found to be useful for differences between expected and observed levels of up to $20 \mathrm{~m}$ in each of the two independent estimates:

$$
\begin{aligned}
& \operatorname{Adj}_{\mathrm{DEP}}=\mathrm{ABS}[D(c) \cdot D(a)] \cdot[D(c)+D(a)] / 200 \\
& \cdot\left(1-\{\mathrm{ABS}[D(c) \cdot D(a) / 800]\}^{0.2},\right.
\end{aligned}
$$

where $\operatorname{Adj}_{\mathrm{DEP}}$ is the proposed adjustment to the datum level in the target site, $D(c)$ is Dif(corr), and $D(a)$ is Dif(age). Application of this 


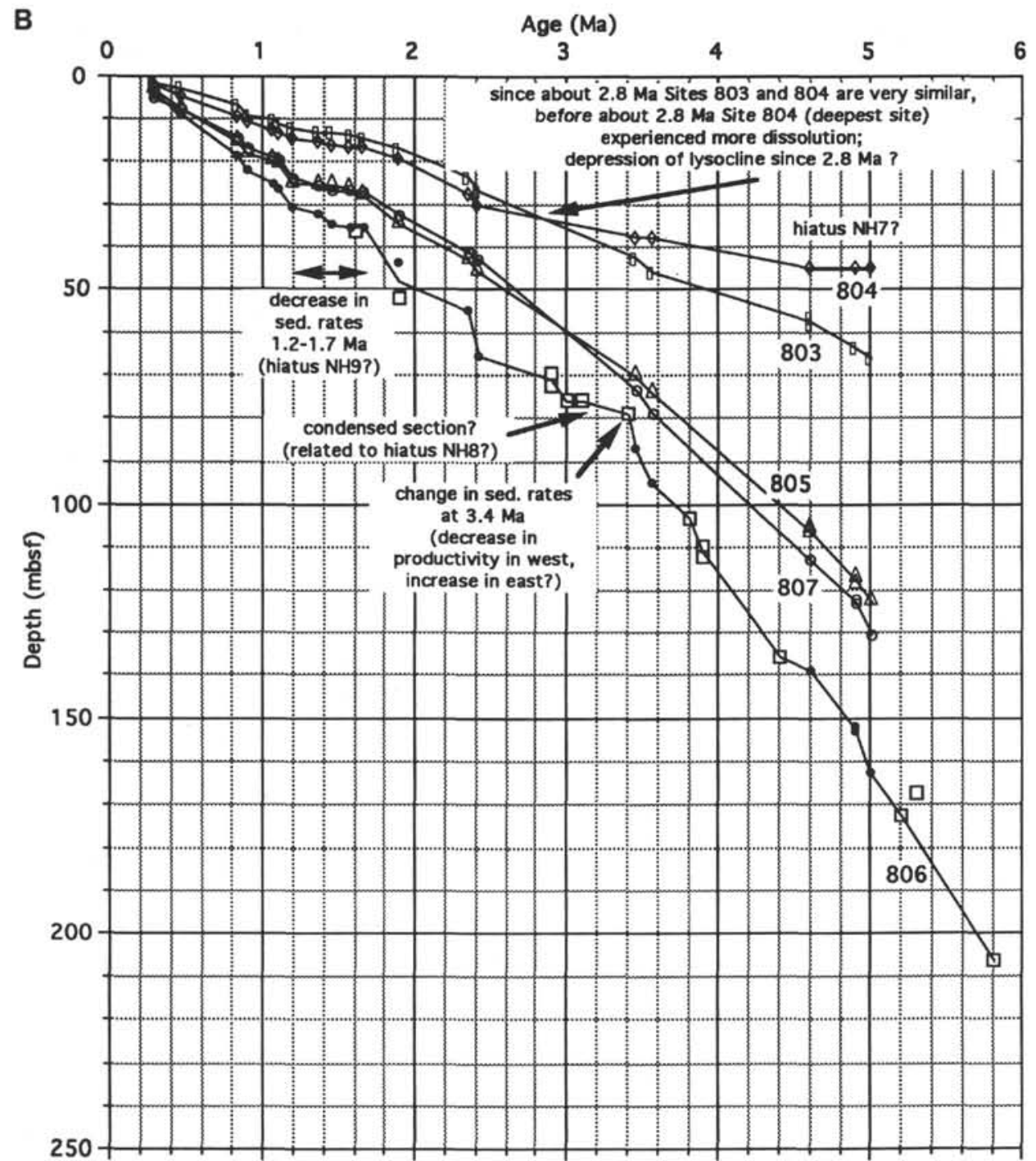

Figure 11 (continued).

formula is especially easy in a spreadsheet, where multiple adjustment can be made until the system stabilizes. Adjustments larger than 10 $m$ should not be attempted with this equation, but they can be made individually on case-by-case analysis, or by rescaling the depth units where appropriate. The performance of this function is shown in Figure 14. Note the broad area of low sensitivity to differences between observed and expected datum levels; as long as one of the estimators is close to the mark, no adjustment is proposed.

Final Age Assignments

\section{and Instantaneous Sedimentation Rates}

The correlations in Table 3 were used for age assignments in $0.5-\mathrm{m} . y$. steps, by interpolation. The resulting matrix was compared, point for point, with the nannofossil stratigraphy of Takayama (this volume), and slight adjustments were made where discrepancies exceeded a few meters (except for ages older than $20 \mathrm{Ma}$ ), to bring the final matrix back to optimum agreement with the original data base, without however losing the sense of changes in sedimentation rates (derived from the correlation procedure). The resulting agedepth matrix for the five sites is shown in Table 4, together with the age-depth matrix derived previously and independently on the basis of shipboard data only. The agreement is excellent for the last $10 \mathrm{~m} . \mathrm{y}$.
It deteriorates in places before that time, reflecting the lack of stratigraphic control (cf. Table 2).

The instantaneous sedimentation rates resulting from the agedepth matrix in Table 4 are plotted in Figure 15. This graph may be compared with a similar one based solely on shipboard nannofossil stratigraphy (Fig. 8A). Agreement for the last $8 \mathrm{~m}$.y. is excellent, confirming not just the sense but the magnitude of the rates reported previously. Additional detail emerges for earlier times. There is a hint of condensed sections (even a hiatus) positioned between 10 and $11 \mathrm{Ma}$. A similar event centered between 18 and $19 \mathrm{Ma}$ is more extensive, but the hiatuses in Sites 803 and 804 may comprise a smaller interval than originally envisaged (cf. Figs. 15 and 8).

How reliable are the curves shown in Figure 15? As mentioned, two ingredients determine the shape of these curves: (1) age assignments to biostratigraphic markers and (2) precision of correlation between sites. Both can be checked for consistency with physical properties, for which a large amount of data is available. Correlations between sites using logging results have been done in considerable detail by Lyle et al. (this volume). Spot checks indicate that their table of equivalent depths agrees well with ours, especially for the last $10 \mathrm{~m} . y$. (typically, differences are less than $3 \mathrm{~m}$, in correlative depths among Sites 806, 807 , and 805). For older sediments, correlations do not agree well; discrepancies from 5 to $15 \mathrm{~m}$ are not uncommon. This implies that 

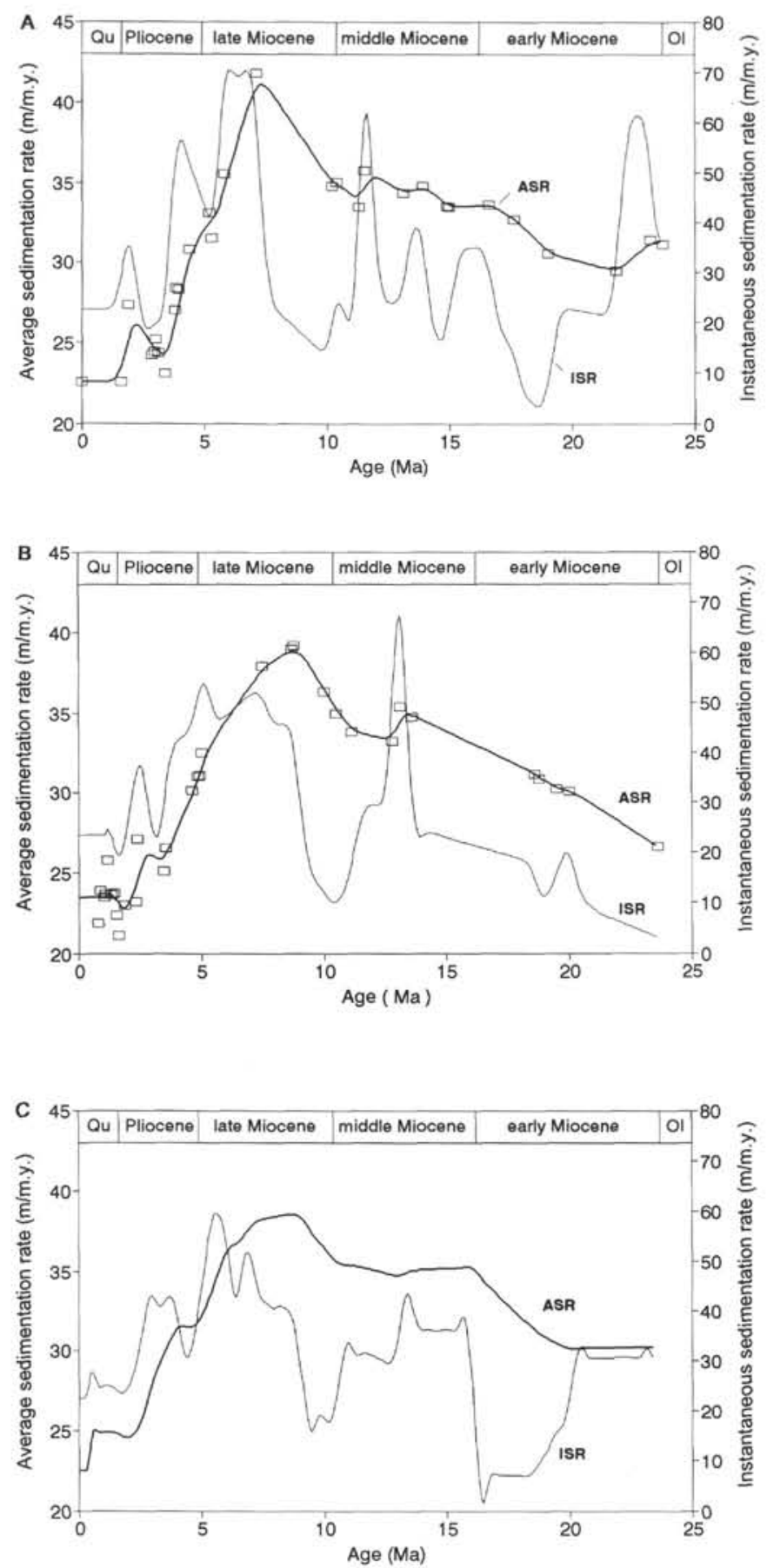

Figure 12. Profiles of cumulative sedimentation rate ("average rate" [ASR]) and differential sedimentation rate ("instantaneous rate" [ISR]) for Site 806, based on three different age models. A. Data of Chaisson and Leckie (this volume). B. Data of Takayama (this volume). C. Nannofossil data from Initial Reports (Kroenke, Berger, Janecek, et al., 1991; see text) combined with the matching of carbonate records (Berger and Stax, unpubl. data). Open squares in Figures 12A and 12B are datums given in the reports cited.

instant sedimentation rates of these older sediments would have quite different values, in places, if based on the correlations of Lyle et al. (this volume) rather than the ones given in Table 4.

Physical properties also contain information about absolute ages, in conjunction with independent time markers. As previously demonstrated (Mayer, 1991; Herbert and Mayer, 1991), the GRAPE record contains evidence for astronomically induced climatic cyclicity. The density variations are most likely related to changes in grain size (that is, the relative abundance of foraminifers within the calcareous ooze; Mayer et al., this volume). Regardless of the mechanism responsible, the signal is potentially useful as a check on instantaneous sedimentation rates. Spectral analysis of the GRAPE records of the first three cores of Hole 805B, for example, shows that dominant spectral lines appear at the expected astronomical frequencies (Fig. 16).

The first core shows a strong eccentricity component ( 100 k.y., or 10 cycles per m.y.); the second likewise (although with a split, suggesting changing sedimentation rate); and the third one shows power in the vicinity of the period of changes in obliquity ( $41 \mathrm{k} . \mathrm{y}$. , or 24.4 cycles per m.y.). This switch-over from obliquity-dominated to eccentricity-dominated cyclicity is well-known from oxygen isotope records (Shackleton and Opdyke, 1976; Ruddiman et al., 1986, 1989; Shackleton et al., 1988, 1990), including the ones from Leg 130 (Berger et al., this volume), and is also the main feature in the GRAPE record (Mayer et al., this volume). Thus, these results are fully compatible with the biostratigraphically based sedimentation rates as shown in Figure 15.

We next check the peak in sedimentation rate in the latest Miocene for consistency with the GRAPE cyclicity. This peak is the dominant feature of late Neogene sedimentation in the western equatorial Pacific (Figs, 8 and 15). Cores 130-805B-15H, $-16 \mathrm{H}$, and $-17 \mathrm{H}$ are within the relevant time interval, between 5 and $6 \mathrm{Ma}$ (Fig. 17). The spectra show strong obliquity peaks for Cores $130-805 \mathrm{~B}-15 \mathrm{H}$ and $-17 \mathrm{H}$, assuming sedimentation rates close to those given in Figure 15. These results support the high sedimentation rates postulated, and thus support the biostratigraphic age assignments back to this time. Interestingly, there is little or no evidence for obliquity variations in Core $130-805 \mathrm{~B}-16 \mathrm{H}$, although there is some indication of eccentricity signal. The apparent sudden change in response to astronomical forcing suggests that a systematic search for such "response revolutions" throughout the Neogene could be rewarding.

A similar peak in sedimentation rate in the latest Miocene was recently reported from the eastern equatorial Pacific by Leg 138 scientists (Mayer et al., 1992). However, relatively low rates are indicated before $6.5 \mathrm{Ma}$, in contrast to our results. To check for the possibility that rates shown in Figure 15 are too high for the time around $8 \mathrm{Ma}$, we analyze the GRAPE data of Cores $130-805 \mathrm{~B}-27 \mathrm{H}$ and $-28 \mathrm{H}$ (Fig. 18). A strong eccentricity-related variability appears in Core $130-805 \mathrm{~B}-27 \mathrm{H}$ (Fig. 18A) when assuming a rate of $40 \mathrm{~m} / \mathrm{m}$.y. (well above the one of about $30 \mathrm{~m} / \mathrm{m}$.y. shown in Fig. 15). This interpretation seems preferable to the one that assumes a rate of $23 \mathrm{~m} / \mathrm{m}$.y. (Fig. 18B). Core 130-805B-28H yields good results for $26 \mathrm{~m} / \mathrm{m}$.y. (Fig. 18C), which compares favorably with the $30 \mathrm{~m} / \mathrm{m}$.y. postulated in the age model used. The various estimates of instantaneous sedimentation rate are summarized in Table 5.

One can see that the spectral estimates support the biostratigraphically derived values. However, the fact that different interpretations are possible, given the same spectral data, makes it clear that such analyses cannot provide a first estimate that is reliable to within a factor of 2. Such an initial estimate must be made based on other stratigraphic evidence. Spectral analysis of physical properties can then refine the age model considerably and increase resolution.

Core $130-805 \mathrm{~B}-28 \mathrm{H}$ is the deepest of the hydraulic piston cores in Hole $805 \mathrm{~B}$. Because recovery drops sharply when using the extended core barrel (XCB), we have not attempted to analyze GRAPE records from below that level. Instead, to check on sedimentation rate estimates in sediments older than $9 \mathrm{Ma}$, we use logging data. Visual examination of different types of logs suggest that resistivity may be a suitable parameter for cyclicity checks ("Site 806" chapter in Kroenke, Berger, Janecek, et al., 1991). Of interest is the existence of low sedimentation rates between 9 and $11 \mathrm{Ma}$, moderately high rates between 12 and $14 \mathrm{Ma}$, and very low rates between 17 and $20 \mathrm{Ma}$, as shown in Figure 15. Spectral analysis of resistivity logs in Site 806 provides modest support for these postulated patterns (Fig. 19). 

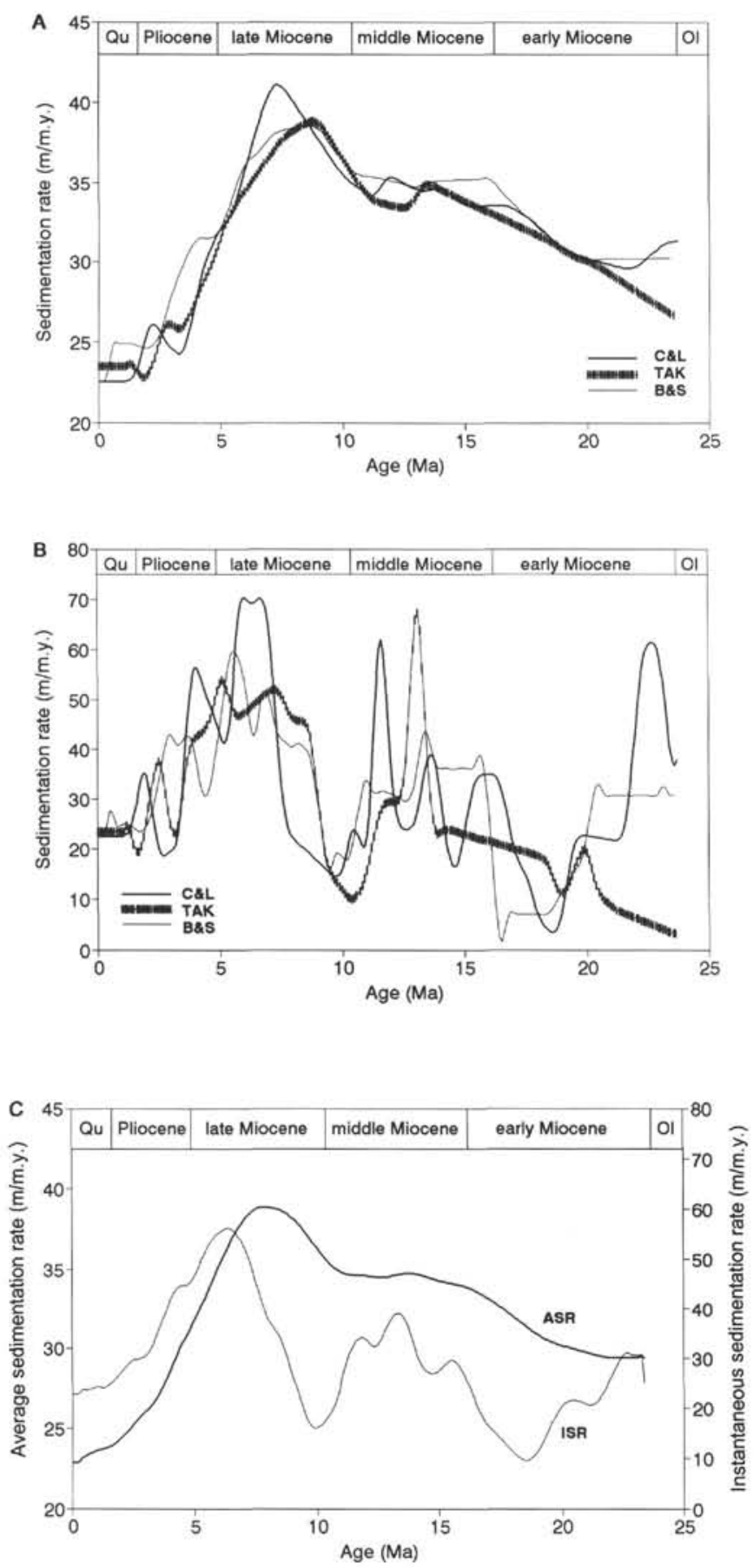

Figure 13. Derivation of "best-guess" age model from averaging the results from three independent estimates. A. Three age models shown in Figure 12, as ASR. B. Superposed ISR curves for these models. C. Overall average age model used in this work. $C \& L=$ Chaisson and Leckie data (this volume); TAK $=$ Takayama data (this volume); B\&S = Berger and Stax (unpubl. data).

Comparison is with the record of "peak rate time" (6 to $7 \mathrm{Ma}$ ), which is set at $55 \mathrm{~m} / \mathrm{m}$.y. This puts a prominent spectral line at $200 \mathrm{k} . \mathrm{y}$. ( 5 cycles per m.y.), a preferred harmonic of eccentricity-related variations. (Interpreting this spectral peak as eccentricity proper would imply a rate of $110 \mathrm{~m} / \mathrm{m} . \mathrm{y}$. !)

Three sections of the Site 806 logging record are compared with the one from "peak rate time" (200-260 mbsf): "9-11 Ma," 330-390 mbsf; "12-14 Ma," 420-480 mbsf; and "17-20 Ma," 565-605 mbsf.
Postulated sedimentation rates for these intervals (Fig. 15) are near 22,33 , and $13 \mathrm{~m} / \mathrm{m} . \mathrm{y}$. The "fit" for the "9-11 Ma" interval is plausible both for 22 and $40 \mathrm{~m} / \mathrm{m}$.y (Figs. 19A-19B). There is neither much support or opposition regarding the proposed rate. For the "12-14 Ma" interval, a plausible peak position suggests $27 \mathrm{~m} / \mathrm{m}$.y. in preference to the $33 \mathrm{~m} / \mathrm{m}$.y. derived from Table 4 . For the "17-20 Ma" interval, a (rather poor) match for $19 \mathrm{~m} / \mathrm{m}$.y. argues for somewhat higher rates than those given in Figure 15 (Fig. 19D). In summary, the resistivity analysis here attempted provides little or no help in judging the reality of the lows and highs in sedimentation rates for periods before $9 \mathrm{Ma}$. Many more logging data are available that could be tested for the purpose; time constraints prevented us from doing so for this overview.

\section{Sedimentation Rate and Color Banding}

Additional support for the reality of the general pattern of sedimentation rates here proposed comes from the abundance of color bands. Lind et al. (this volume) have argued that the origin of most of these bands is to be sought in volcanic ash falls (as did Gardner et al., 1986b). If this is correct, we infer that the abundance of color bands should be correlated with sedimentation rate. The magnitude of ash falls, like those of other episodic events surrounding volcanism, varies greatly. In general, abundance tends to increase exponentially with decrease in size for such events. Thus, if we assume that small ash falls will be better preserved in expanded sections with a high sedimentation rate, we should find

$$
N=f\left(e^{x}\right),
$$

where $N$ is the number of layers, and $x$ is the sedimentation rate. Also, there is probably a minimum magnitude, below which ash fall will not produce a band, that is, there is an upper limit to the abundance of bands no matter how great the sedimentation rate. From this requirement, we obtain an expression $(1-x / K)$ in the exponent, which describes a negative feedback on the increase of the number of bands as the limit is reached. Variable $K$ is the sedimentation rate beyond which no additional bands are preserved. Finally, we postulate a minimum sedimentation rate (the "base" rate) below which effectively all ash layers are destroyed by benthic mixing or redeposition processes, on the scale considered here. This requirement suggests an exponent of $(x / b-1)$ to replace $x$ in Equation 4, where $b$ is the base rate. Thus, we obtain an equation of the form

$$
N=f\left[e^{(x / b-1)(1-x / K)}\right],
$$

which is valid for the sedimentation rates between $b$ and $K$.

From comparing our sedimentation rate data with the abundance of color bands in Site 807 (as given in the "Site 807" chapter in Kroenke, Berger, Janecek, et al., 1991, p. 386), we set $b=7$ and $K=80$, and write

$$
N=e^{0.5(x / b-1)(1-0.5 x / \max )}-1,
$$

which produces a tolerably good fit between accumulation rate and color band abundance (Figs. 20-21).

The abundance predictions for the various sites compare favorably with the results from counting (see Lind et al., this volume). In particular, the agreement supports the reduction of sedimentation rates around $10 \mathrm{Ma}$. In the earliest Miocene, low color band counts support the low sedimentation rates that result from the nannofossil stratigraphy (Takayama, this volume) rather than the high rates that result from foraminifer stratigraphy (Chaisson and Leckie, this volume).

The relationship proposed here assumes that volcanism producing ash falls remains at a steady level of activity over long periods. Clearly, this is not necessarily so (see Gardner et al., 1986b, and Kroenke et al., this volume). If the color band abundance is a function of changing intensity of volcanic sources (as assumed by Lind et al., 
Table 3. Initial correlation of sites, based on nannofossil datums, and adjusted according to the correlation procedure described in text.

\begin{tabular}{|c|c|c|c|c|c|c|c|c|c|c|}
\hline \multirow{2}{*}{$\begin{array}{l}\text { DATUM } \\
\text { *"AGE" }\end{array}$} & \multicolumn{4}{|c|}{ DEPTH IN SITES (MBSF) } & \multirow[b]{2}{*}{804} & \multicolumn{5}{|c|}{ ADJUSTMENT TO DEPTH (M) } \\
\hline & 806 & 807 & 805 & 803 & & 806 & 807 & 805 & 803 & 804 \\
\hline "0.00" & 0.0 & 0.0 & 0.0 & 0.0 & 0.0 & 0.0 & 0.0 & 0.0 & 0.0 & 0.0 \\
\hline "0.28" & 3.7 & 4.6 & 2.2 & 1.7 & 1.8 & 0.1 & -0.0 & 0.0 & 0.0 & 0.0 \\
\hline "0.46" & 9.0 & 7.3 & 6.7 & 3.0 & 4.5 & -0.0 & 0.0 & -0.0 & 0.0 & 0.0 \\
\hline "0.83" & 18.2 & 14.0 & 14.5 & 6.8 & 9.3 & 0.0 & 0.0 & 0.0 & 0.0 & -0.0 \\
\hline "0.90" & 21.9 & 16.3 & 17.2 & 9.0 & 10.4 & -0.0 & 0.0 & 0.0 & -0.0 & 0.0 \\
\hline "1.06" & 24.9 & 18.3 & 18.8 & 10.5 & 12.3 & 0.0 & 0.0 & 0.0 & 0.0 & 0.0 \\
\hline "1.10" & 26.0 & 19.0 & 19.5 & 11.3 & 13.0 & 0.0 & 0.0 & 0.0 & 0.0 & 0.0 \\
\hline$" 1.19 "$ & 30.7 & 23.5 & 24.0 & 12.5 & 14.5 & -0.0 & -0.0 & -0.1 & 0.0 & 0.0 \\
\hline "1.36" & 32.2 & 25.0 & 24.8 & 13.3 & 15.3 & 0.0 & 0.0 & 0.0 & 0.0 & 0.0 \\
\hline "1.45" & 34.4 & 26.3 & 24.8 & 13.3 & 15.8 & -0.0 & 0.0 & 0.0 & 0.0 & 0.0 \\
\hline "1.57" & 35.1 & 26.3 & 25.5 & 14.0 & 16.5 & 0.0 & 0.0 & 0.0 & 0.0 & 0.0 \\
\hline "1.66" & 35.1 & 26.5 & 26.9 & 14.8 & 16.5 & 0.0 & 0.0 & 0.0 & 0.0 & 0.0 \\
\hline "1.89" & 43.5 & 32.3 & 33.8 & 17.0 & 19.1 & -0.0 & 0.0 & -0.0 & 0.0 & 0.1 \\
\hline "2.35" & 54.5 & 40.7 & 41.8 & 23.9 & 27.3 & 0.4 & 0.0 & 0.0 & 0.0 & -0.0 \\
\hline "2.41" & 65.3 & 42.2 & 44.9 & 26.9 & 30.0 & -3.2 & 1.5 & 0.1 & 0.0 & -0.1 \\
\hline "3.45" & 86.5 & 72.9 & 69.2 & 42.9 & 37.5 & 2.5 & -1.5 & -0.2 & -0.1 & 0.1 \\
\hline "3.56" & 94.5 & 78.3 & 73.3 & 45.9 & 37.5 & 0.3 & 0.0 & 0.0 & -0.2 & -0.0 \\
\hline "4.60" & 138.5 & 112.0 & 105.7 & 56.4 & 44.8 & -0.7 & -0.1 & -0.2 & 0.5 & 0.3 \\
\hline "4.60" & 138.5 & 112.0 & 104.2 & 58.0 & 44.8 & -0.0 & -0.0 & 0.3 & 0.0 & -0.0 \\
\hline "4.88" & 151.5 & 121.5 & 116.2 & 63.7 & 44.8 & -0.0 & -0.0 & -0.1 & -0.0 & 0.0 \\
\hline "4.92" & 153.0 & 122.4 & 117.7 & 63.7 & 44.8 & 0.1 & 0.0 & 0.0 & 0.0 & 0.0 \\
\hline "5.00" & 162.5 & 129.9 & 121.7 & 66.0 & 44.8 & 0.4 & 1.2 & 2.4 & 3.6 & 0.1 \\
\hline "7.50" & 284.5 & 237.9 & 219.7 & 137.0 & 72.3 & -1.2 & -6.7 & -1.0 & -4.8 & 6.7 \\
\hline "8.70" & 339.2 & 277.8 & 267.2 & 169.7 & 117.5 & -0.1 & -0.1 & -2.2 & -1.9 & -9.3 \\
\hline "8.80" & 344.9 & 280.8 & 267.2 & 170.5 & 117.5 & -1.3 & -0.4 & -0.4 & -0.1 & 0.4 \\
\hline "10.0" & 362.8 & 295.2 & 279.9 & 183.0 & 137.4 & 0.5 & 0.6 & 0.5 & 0.0 & 0.0 \\
\hline "10.5" & 367.0 & 301.6 & 283.5 & 187.5 & 150.5 & 0.1 & -0.1 & -0.1 & -0.3 & -2.0 \\
\hline "11.1" & 375.4 & 306.3 & 286.5 & 187.5 & 152.0 & 0.5 & -0.1 & -0.6 & -0.2 & -0.0 \\
\hline "12.8" & 425.5 & 334.9 & 309.8 & 198.2 & 164.5 & 2.0 & 9.0 & 0.4 & 6.6 & 2.0 \\
\hline "13.1" & 463.7 & 372.2 & 316.5 & 216.0 & 176.2 & -8.3 & -3.2 & 0.5 & -1.5 & -0.6 \\
\hline "13.6" & 472.8 & 379.1 & 326.0 & 219.5 & 177.5 & -7.8 & -0.8 & -6.5 & -7.4 & -2.3 \\
\hline "18.6" & 579.1 & 462.3 & 387.0 & 246.8 & 206.9 & 7.1 & 2.3 & 7.6 & 5.6 & 3.7 \\
\hline "18.8" & 579.4 & 463.9 & 390.5 & 246.8 & 206.9 & 6.8 & 0.7 & 4.1 & 5.6 & 3.7 \\
\hline "19.5" & 588.8 & 474.9 & 390.5 & 246.8 & 206.9 & 0.3 & -0.3 & 1.8 & 1.2 & 0.1 \\
\hline "20.0" & 601.0 & 476.1 & 404.7 & 254.2 & 208.5 & -10.1 & 8.1 & -6.7 & 1.4 & 0.6 \\
\hline "23.6" & 627.6 & 580.6 & 427.5 & 316.9 & 250.1 & 53.9 & -9.0 & 32.5 & -8.7 & -0.1 \\
\hline "25.2" & 763.0 & 616.0 & 558.0 & 327.5 & 270.0 & -26.3 & 6.0 & -38.0 & 5.8 & 0.0 \\
\hline
\end{tabular}

Notes: Nannofossil datums are labeled with their assigned ages as shown in Table 2. Adjustments are listed to the right; they are minor back to $5 \mathrm{Ma}$. "AGE" represents identification of datums used, not age assignments.

this volume), then it would appear that sedimentation rate of carbonate is positively correlated with volcanic activity. No explanation for such a correlation is obvious to us. The fact that there is an abundance gradient with depth, which is reproduced by our equation, suggests that our interpretation in terms of preservation of volcanic ash layers rather than source modulation is reasonable, as a first approximation.

\section{SEDIMENTATION RATE VS. CARBONATE CONTENT: THE LOSS PARADOX}

\section{The Loss Paradox Defined}

When comparing sedimentation rates and carbonate content in the major intervals of the Neogene we note a striking discrepancy: The difference in sedimentation rates between sites at different depths is substantial but the difference in carbonate content between these same sites is rather modest. Under the assumption that the decrease in sedimentation rates with depth (Fig. 15) is due to increasing dissolution, we should expect much lower carbonate values in the deeper sites than we in fact find. The paradox is pervasive throughout the Neogene, as illustrated in Table 6, where sedimentation rate ratios are compared to losses of sediment expected from the difference in carbonate content.

The sedimentation rate ratios (which are simply thickness ratios of corresponding depth intervals) are given relative to the values in Site 806 , using that column as a standard. The presumption is that differences from the standard, in the deeper sites, indicate sediment loss at those deeper sites. Ratios in Site 807, for example, range from 0.70 to 0.88 , which translates into a loss of between $30 \%$ and $12 \%$ under the hypothesis ("actual losses," fourth section in Table 6). The carbonate contents do not agree with this apparent loss. For Site 807, values typically are the same as those in Site 806. The same kind of incongruity is seen in all other sites; in each case the change in car- 


\begin{tabular}{|c|c|c|c|c|c|c|c|c|c|c|c|c|}
\hline & 30 & 20 & 10 & 5 & 2 & 0.5 & -0.5 & -2 & -5 & -10 & -20 & $-3 c$ \\
\hline 30 & & & 10.69 & 7.47 & 3.88 & 1.25 & 1.21 & 3.40 & 5.33 & 5.34 & & \\
\hline 20 & & 0.36 & 7.26 & 4.25 & 1.98 & 0.60 & 0.57 & 1.62 & 2.55 & 42 & & \\
\hline 10 & 10.69 & 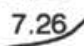 & 3.40 & 1.60 & 0.63 & 0.17 & 0.15 & 0.42 & 0.53 & 0 & 2.42 & 7 \\
\hline 5 & 7.47 & 4.25 & 1.60 & 0.63 & 0.20 & 0.05 & 0.04 & 0.09 & 0 & -0.53 & -2.55 & 5.3 \\
\hline 2 & 3.88 & 1.98 & 0.63 & 0.20 & 0.05 & 0.01 & 0.01 & 0 & -0.01 & -0.42 & -1.62 & 3.4 \\
\hline 0.5 & 1.25 & 0.60 & 0.17 & 0.05 & 0.01 & 0.00 & 0 & -0.01 & -0.04 & -0.15 & -0.57 & -1.21 \\
\hline-0.5 & 1.21 & 0.57 & 0.15 & 0.04 & 0.01 & 0 & -0.01 & -0.01 & -0.05 & -0.17 & -0.60 & -1.25 \\
\hline-2 & 3. & 1.62 & 0.42 & 0.09 & 0 & -0.01 & -0.01 & -0.01 & -0.20 & -0.63 & -1.98 & -3.8 \\
\hline-5 & 5.33 & 2.55 & 0.53 & 0 & -0.10 & -0.04 & -0.05 & -0.20 & -0.63 & -1.60 & -4.25 & . \\
\hline-10 & 5.34 & 2.42 & 0 & -0.53 & -0.42 & -0.15 & -0.17 & -0.63 & -1.60 & -3.40 & & 10.6 \\
\hline-20 & & & & -2.55 & -1.62 & -0.57 & -060 & -1.98 & 405 & & -10.36 & \\
\hline-30 & & 1.68 & 34 & 5.33 & -3.40 & -1.21 & .25 & 38 , & 7.47 & 99 & & \\
\hline
\end{tabular}

Figure 14. Matrix for datum adjustment resulting from Equation 3 (see text). Limit of use is $>20>20$ for the two estimates. To circumvent the limit, rescale the depth units (e.g., multiples of 3 or 10).

bonate content is too small to "explain" the apparent loss, assuming the dissolution hypothesis. Under the hypothesis, this loss is calculated using the formula

$$
L=1-N C_{i} / N C_{f}
$$

where $L$ is the loss of sediment, and $N C_{i}$ and $N C_{f}$ are the initial and final content of noncarbonate, respectively. In the lowermost section of Table 6, the "observed loss" from the sedimentation rate ratios is compared with the "expected loss" from this equation. The "observed loss" exceeds the "expected loss" by about $200 \%$ for Sites 805 and 803 , and by $140 \%$ for Site 804 , for the Neogene. This is the "loss paradox." It indicates that the assumption that carbonate dissolution is the sole or main factor producing both carbonate and sedimentation rate differences must be wrong. Thus, the task is to find clues to the processes that are in fact responsible for the patterns observed.

Basically, sedimentation rates and carbonate percentages are both changed by addition or removal of carbonate and noncarbonate to the seafloor. If such addition and removal is nondiscriminatory with respect to the type of particles involved, carbonate content will not change. Thus, to keep carbonate content from changing very much with depth, while reducing the sedimentation rate, we need to assume one of two things:

1. Carbonate dissolution is not important; instead, removal is by other, nonselective processes.

2. Removal of noncarbonate tends to proceed in parallel to carbonate dissolution.

The first assumption is unlikely to be correct, given the fact that carbonate saturation does decrease with depth, and given the evidence from preservation of calcareous fossils. For the second possibilityparallel removal - two modes can be envisaged:

1. Dissolution enhances wholesale removal of sediment.

2. Dissolution leads to preferential removal of noncarbonate.

Wholesale removal (but with preservation of stratigraphic continuity: "exfoliation") is suggested by the observation (in box cores) that increased dissolution decreases the strength of calcareous ooze, which leads to downhill flow in a type of solifluction process (Berger and Johnson, 1976). During earthquakes, low strength of surface sediments could conceivably lead to very-thin-sheet mass wasting and attendant resuspension. Downslope removal would be the result by gravity-driven flow. We shall refer to this hypothetical mechanism as "seismically induced catabatic flow," or "seismic catabatic flow," for short. It is similar to concepts arising in the discussion of turbidity currents, but it differs in that it postulates slow-moving dilute sediment clouds whose particles derive from the sediment surface only.

Preferential removal of noncarbonate ("purification") could be mechanical or chemical in nature. If mechanical, it would rely on the differences in settling velocities of the particles, with clays and small diatoms staying in suspension and travelling farther downhill than other particles, subsequent to resuspension events. If chemical, it would rely on increased dissolution of opal as carbonate dissolution reduces sedimentation rate and hence protection through burial.

How important are the postulated processes of "exfoliation" by "catabatic flow" and "purification" by opal dissolution? The first step in identifying and quantifying the mechanisms responsible for the "loss paradox" is to define the problem in a detailed stratigraphic framework, so that its record can be compared with those of potential driving mechanisms. To this task we turn next.

\section{Density Profiles: Clues to Productivity and Dissolution?}

To convert from sedimentation rates to mass flux rates, generalized bulk density profiles of the various sites have been extracted from the shipboard records (laboratory and logging; Kroenke, Berger, Janecek, et al., 1991). Bulk density increases more or less monotonically with depth in each site, but at different rates, depending on original conditions of sedimentation (Fig. 22). Well-preserved calcareous oozes (Sites 806, 807, 805) start out at a density of between 1.50 and $1.54 \mathrm{~g} / \mathrm{cm}^{3}$, reaching values higher than $1.8 \mathrm{~g} / \mathrm{cm}^{3}$ in the early Miocene. Interestingly, Sites 805 and 806, despite the difference in depth of deposition, show an almost congruent increase with depth, while Site 807 (which is intermediate in depth between the two) shows distinctly lower bulk density throughout the Miocene. A case can be made that it is the equatorial crossing in the early middle Miocene which reduces bulk density rapidly within the sediments of Site 807. A similar reduction is seen in Site 805 in the earliest Pliocene, when it has just crossed the equator. A plot of density anomalies (relative to a linear regression on depth) shows this response more clearly (Fig. 22B).

All three shallow sites show a density reduction for the latest Neogene. If the interpretation regarding equatorial crossings is correct, this trend would indicate increased productivity starting in the latest Miocene, between 8 and $7 \mathrm{~m} . y$. ago. Such an increase would be in agreement with the high values in sedimentation rate which are attained at the time (Fig. 15).

Densities in the two deeper sites (803 and 804), presumably, are strongly influenced by the history of carbonate dissolution, as suggested by the fact that their densities stay distinctly low throughout the record. If so, anomalously strong dissolution is indicated in Site 804 between 15 and $20 \mathrm{Ma}$ (Fig. 22B), in agreement with the 
Table 4. Final correlation between sites and age assignments.

\begin{tabular}{|c|c|c|c|c|c|c|c|c|c|c|}
\hline AGE & $\begin{array}{l}\text { THIS W } \\
806\end{array}$ & $\begin{array}{c}\text { BGSX } \\
806\end{array}$ & $\begin{array}{l}\text { THIS W } \\
807\end{array}$ & $\begin{array}{c}\text { BGSX } \\
807\end{array}$ & $\begin{array}{c}\text { THIS W } \\
805\end{array}$ & $\begin{array}{l}\text { BGSX } \\
805\end{array}$ & $\begin{array}{c}\text { THIS W } \\
803\end{array}$ & $\begin{array}{l}\text { BGSX } \\
803\end{array}$ & $\begin{array}{c}\text { THIS W } \\
804\end{array}$ & $\begin{array}{l}\text { BGSX } \\
804\end{array}$ \\
\hline 0 & 0.0 & 0.0 & 0.0 & 0.0 & 0.0 & 0.0 & 0.0 & 0.0 & 0.0 & 0.0 \\
\hline 0.5 & 11.5 & 12.4 & 10.5 & 7.4 & 8.4 & 7.5 & 4.9 & 6.4 & 5.7 & 3.2 \\
\hline 1 & 23.5 & 24.9 & 18.6 & 14.8 & 18.3 & 16.7 & 9.8 & 12.7 & 11.6 & 6.4 \\
\hline 1.5 & 35.6 & 37.3 & 27.3 & 22.2 & 27.5 & 25.5 & 14.7 & 19.1 & 16.8 & 9.6 \\
\hline 2 & 48.4 & 49.2 & 36.5 & 31.7 & 37.2 & 34.5 & 20.1 & 25.1 & 22.6 & 13.5 \\
\hline 2.5 & 62.5 & 63.7 & 46.0 & 49.1 & 46.8 & 46.6 & 27.3 & 32.5 & 29.8 & 24.7 \\
\hline 3 & 77.4 & 84.1 & 57.8 & 61.9 & 58.1 & 60.7 & 35.8 & 38.9 & 34.8 & 28.6 \\
\hline 3.5 & 93.5 & 104.6 & 74.9 & 74.6 & 72.5 & 74.8 & 44.4 & 45.3 & 38.5 & 32.5 \\
\hline 4 & 112.4 & 125.6 & 93.1 & 96.6 & 87.9 & 98.6 & 51.0 & 51.5 & 41.6 & 45.5 \\
\hline 4.5 & 134.1 & 141.5 & 110.6 & 111.4 & 103.5 & 112.7 & 57.1 & 58.1 & 45.0 & 48.8 \\
\hline 5 & 156.6 & 160.7 & 128.1 & 133.2 & 120.1 & 129.3 & 66.4 & 70.9 & 45.6 & 52.8 \\
\hline 5.5 & 181.0 & 188.0 & 148.6 & 154.2 & 139.1 & 147.0 & 79.3 & 87.6 & 48.5 & 56.1 \\
\hline 6 & 207.8 & 217.0 & 171.1 & 175.2 & 159.8 & 164.6 & 93.6 & 104.3 & 54.0 & 59.5 \\
\hline 6.5 & 235.7 & 239.0 & 193.4 & 196.2 & 180.9 & 182.3 & 108.1 & 121.0 & 59.9 & 62.8 \\
\hline 7 & 263.3 & 264.5 & 215.7 & 216.0 & 202.0 & 200.8 & 122.6 & 134.8 & 65.9 & 66.7 \\
\hline 7.5 & 288.4 & 286.8 & 236.8 & 235.0 & 222.1 & 219.9 & 136.8 & 146.7 & 72.9 & 71.1 \\
\hline 8 & 309.5 & 307.2 & 254.2 & 254.0 & 239.1 & 238.7 & 150.5 & 157.4 & 85.4 & 85.6 \\
\hline 8.5 & 327.7 & 327.7 & 269.9 & 272.9 & 254.7 & 257.4 & 163.4 & 168.0 & 102.2 & 100.2 \\
\hline 9 & 343.3 & 345.5 & 284.0 & 286.4 & 268.5 & 271.3 & 174.5 & 175.8 & 118.9 & 119.0 \\
\hline 9.5 & 355.0 & 355.0 & 292.9 & 292.7 & 276.3 & 276.3 & 181.1 & 179.0 & 131.4 & 133.0 \\
\hline 10 & 363.6 & 364.5 & 299.7 & 298.9 & 281.3 & 281.4 & 185.4 & 182.3 & 139.7 & 147.0 \\
\hline 10.5 & 372.1 & 374.0 & 306.9 & 305.2 & 285.9 & 286.4 & 188.8 & 185.5 & 149.9 & 158.0 \\
\hline 11 & 382.5 & 389.7 & 313.8 & 310.7 & 290.6 & 292.2 & 189.0 & 190.0 & 156.4 & 165.2 \\
\hline 11.5 & 397.0 & 405.4 & 323.3 & 316.3 & 297.2 & 298.1 & 190.3 & 194.5 & 158.8 & 168.3 \\
\hline 12 & 413.8 & 421.2 & 334.0 & 321.8 & 304.4 & 303.9 & 194.7 & 199.0 & 161.5 & 167.0 \\
\hline 12.5 & 430.3 & 436.3 & 345.9 & 329.3 & 311.2 & 310.6 & 200.0 & 203.4 & 164.6 & 174.7 \\
\hline 13 & 447.6 & 451.7 & 360.6 & 339.4 & 316.4 & 318.5 & 208.0 & 208.2 & 167.9 & 178.5 \\
\hline 13.5 & 466.9 & 472.9 & 376.2 & 362.0 & 321.2 & 330.3 & 218.1 & 217.8 & 171.5 & 185.0 \\
\hline 14 & 485.1 & 491.6 & 386.6 & 375.2 & 327.3 & 339.4 & 226.1 & 224.6 & 175.4 & 191.3 \\
\hline 14.5 & 499.9 & 509.7 & 394.7 & 388.4 & 334.6 & 347.8 & 231.1 & 230.8 & 179.5 & 197.6 \\
\hline 15 & 513.5 & 527.8 & 402.9 & 401.6 & 342.4 & 356.2 & 234.3 & 237.0 & 183.9 & 200.3 \\
\hline 15.5 & 527.7 & 545.9 & 411.0 & 414.8 & 350.2 & 364.6 & 237.2 & 242.1 & 188.4 & 200.8 \\
\hline 16 & 542.2 & 564.0 & 419.1 & 428.0 & 357.9 & 373.0 & 239.9 & 242.7 & 193.0 & 201.2 \\
\hline 16.5 & 554.5 & 567.6 & 427.3 & 432.1 & 365.3 & 377.4 & 242.3 & 243.3 & 197.6 & 201.7 \\
\hline 17 & 563.9 & 571.1 & 435.4 & 436.2 & 372.0 & 381.8 & 244.4 & 244.0 & 202.1 & 202.2 \\
\hline 17.5 & 571.6 & 574.7 & 443.6 & 440.3 & 377.9 & 386.2 & 245.9 & 244.6 & 206.5 & 202.7 \\
\hline 18 & 577.9 & 578.3 & 451.7 & 444.4 & 382.9 & 390.6 & 246.1 & 245.2 & 207.6 & 203.1 \\
\hline 18.5 & 583.2 & 581.9 & 459.8 & 448.5 & 386.8 & 395.0 & 246.1 & 245.8 & 207.6 & 203.6 \\
\hline 19 & 588.2 & 586.9 & 467.3 & 454.1 & 390.1 & 400.8 & 246.1 & 246.4 & 207.6 & 204.1 \\
\hline 19.5 & 594.8 & 594.0 & 473.8 & 461.8 & 394.4 & 408.8 & 246.9 & 247.0 & 207.6 & 204.5 \\
\hline 20 & 603.8 & 603.4 & 480.4 & 474.1 & 403.8 & 416.1 & 253.6 & 251.5 & 209.6 & 205.0 \\
\hline 20.5 & 614.4 & 618.8 & 488.3 & 487.0 & 414.7 & 419.6 & 262.5 & 255.0 & 214.7 & 210.7 \\
\hline 21 & 625.0 & 634.1 & 500.8 & 499.5 & 421.7 & 423.0 & 271.5 & 260.0 & 220.3 & 216.5 \\
\hline 21.5 & 635.5 & 649.5 & 516.1 & 512.0 & 428.0 & 426.5 & 280.5 & 265.5 & 225.8 & 223.0 \\
\hline 22 & 647.1 & 664.8 & 531.5 & 525.0 & 434.2 & 441.0 & 289.5 & 272.0 & 231.4 & 227.9 \\
\hline 22.5 & 661.0 & 680.2 & 546.9 & 539.0 & 440.5 & 450.0 & 298.5 & 277.0 & 237.0 & 233.7 \\
\hline 23 & 676.3 & 695.6 & 562.3 & 555.0 & 446.7 & 459.0 & 307.5 & 281.0 & 242.5 & 239.4 \\
\hline 23.5 & 690.5 & 710.9 & 577.7 & 576.0 & 453.0 & 475.0 & 316.5 & 285.0 & 248.1 & 245.1 \\
\hline
\end{tabular}

Notes: Final correlations are based on post-cruise nannofossil stratigraphy (Takayama, this volume) and other controls (including foraminifer stratigraphy of Chaisson and Leckie for Site 806; see text). Comparison is to an independently derived matrix, based on shipboard data (nannofossil stratigraphy and carbonate fluctuations; Berger and Stax, unpubl. data). Note the good agreement for the last $10 \mathrm{~m} . \mathrm{y}$. THIS W = based on post-cruise studies of T. Takayama for Site 806, including the results of Chaisson and Leckie. BGSX = based on shipboard nannofossils and carbonate matching. 


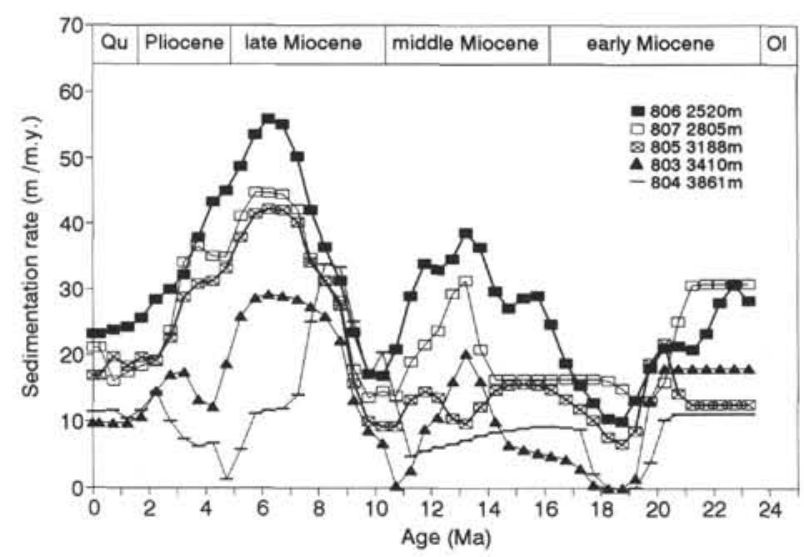

Figure 15. Instantaneous sedimentation rates (= differential depth/age ratios) for the five sites of Leg 130, based on Table 4 .
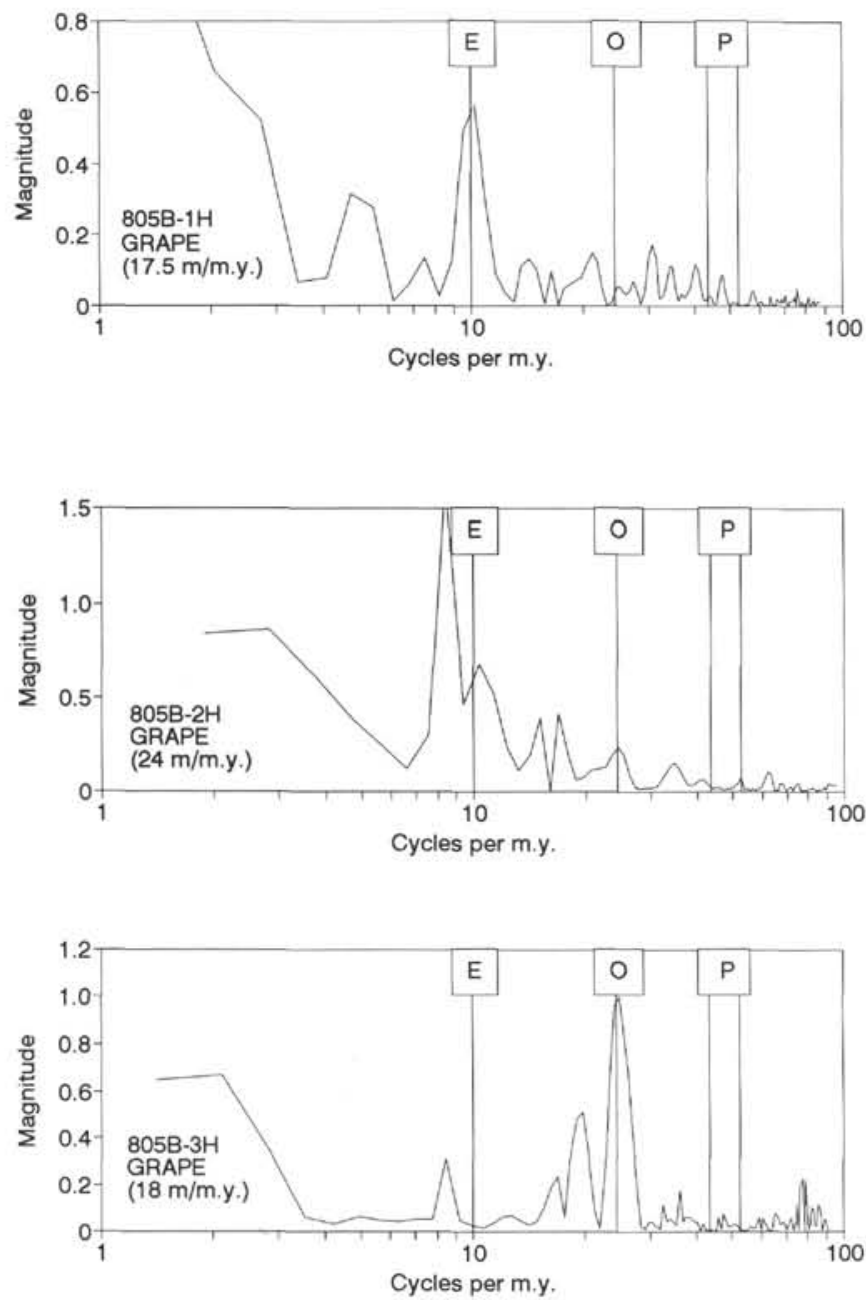

Figure 16. Spectral analysis of GRAPE records of Cores $130-805 \mathrm{~B}-1 \mathrm{H},-2 \mathrm{H}$, and $-3 \mathrm{H}$, by Fast Fourier Transform (FFT, a MathCad program), "Magnitude" = the sum of squares of real and imaginary component of each term in the expansion. E, O, $\mathrm{P}=$ expected positions of eccentricity-, obliquity-, and precession-related cycles in the record analyzed. A strong eccentricity-related signal is seen (peak at E) in Cores 130-805B-1H and -2 H, and an obliquity-related record in Core 130-805B$3 \mathrm{H}$ (as expected from previous work on Quaternary isotope stratigraphy).
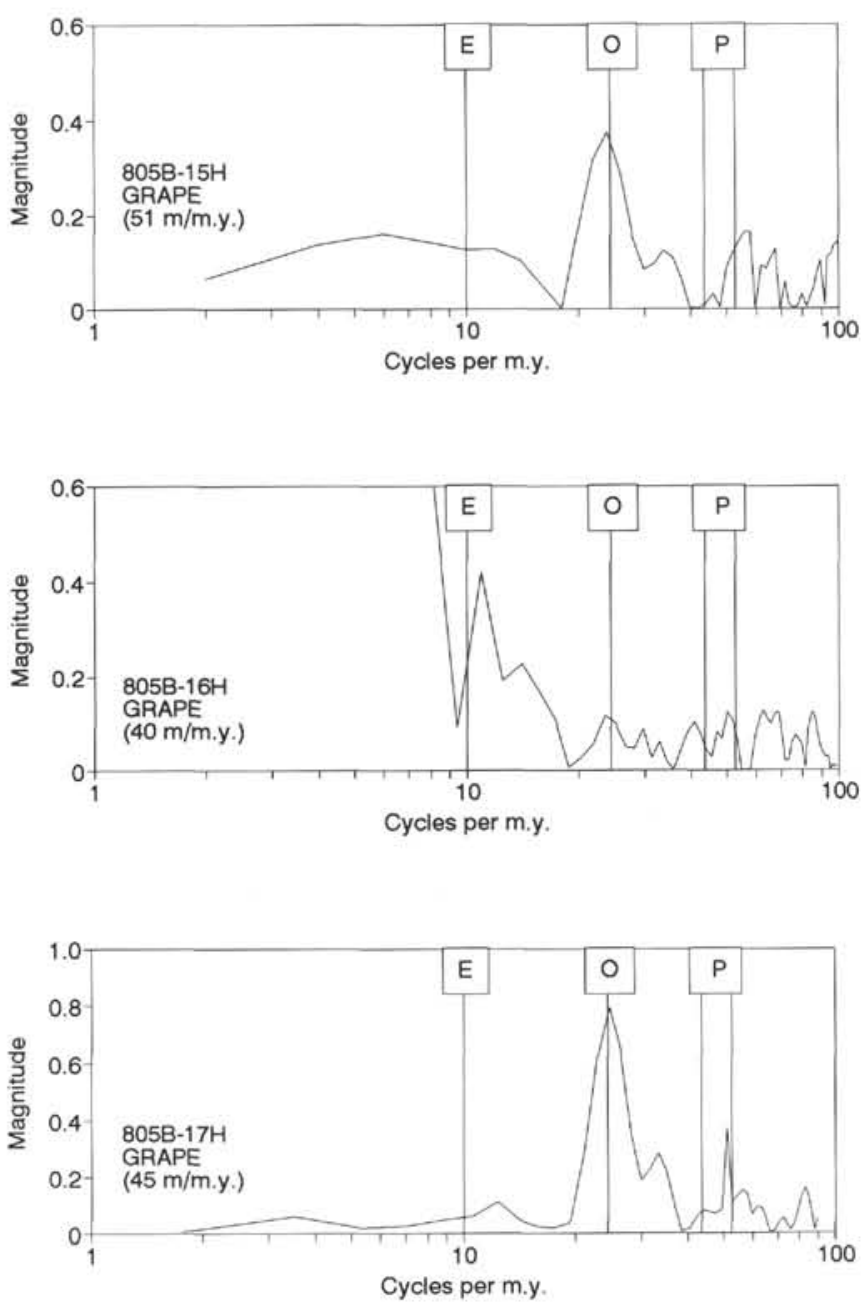

Figure 17. Spectral analysis of GRAPE records of Cores 130-805B-15H, -16H, and $-17 \mathrm{H}$ by FFT. "Magnitude" = the sum of squares of real and imaginary component of each term in the expansion. $\mathrm{E}, \mathrm{O}, \mathrm{P}=$ expected positions of eccentricity-, obliquity-, and precession-related cycles in the record analyzed. The obliquity-related signal is seen to be strong in Cores $130-805 \mathrm{~B}-15 \mathrm{H}$ and $-17 \mathrm{H}$.

sedimentation rate record. Dissolution greatly reduces sand content (Johnson et al., 1977; Wu et al., 1991), and grain-size distribution has been identified as one of the controlling factors in determining bulk density in the sediments on the Ontong Java Plateau (Johnson et al., 1977; Mosher et al., this volume). The late middle Miocene reduction in density in Site 803 may also indicate such a dissolution effect. The timing is reasonably (but not exactly) congruent with a corresponding sedimentation rate decrease (Fig. 15).

\section{Accumulation Rates as a Function of Depth}

For purposes of stratigraphic comparison, accumulation rates (that is, mass fluxes) are preferable to sedimentation rates (that is, depth/ age differentials). It should be kept in mind, however, that all errors of the age model are faithfully preserved during the conversion from one rate to the other, and that such errors are likely to be larger than those arising from substituting sedimentation rates for accumulation rates in the discussion of trends.

The mass flux of sediment is the product of sedimentation rate $\left(\mathrm{cm} / \mathrm{k} . \mathrm{y}\right.$.) and density $\left(\mathrm{g} / \mathrm{cm}^{3}\right)$; units are $\mathrm{gcm}^{-2} \mathrm{k} \cdot \mathrm{y} .{ }^{-1}$. To preserve the familiar units of meters per million years $(\mathrm{m} / \mathrm{m} . \mathrm{y}$.), we have recon- 

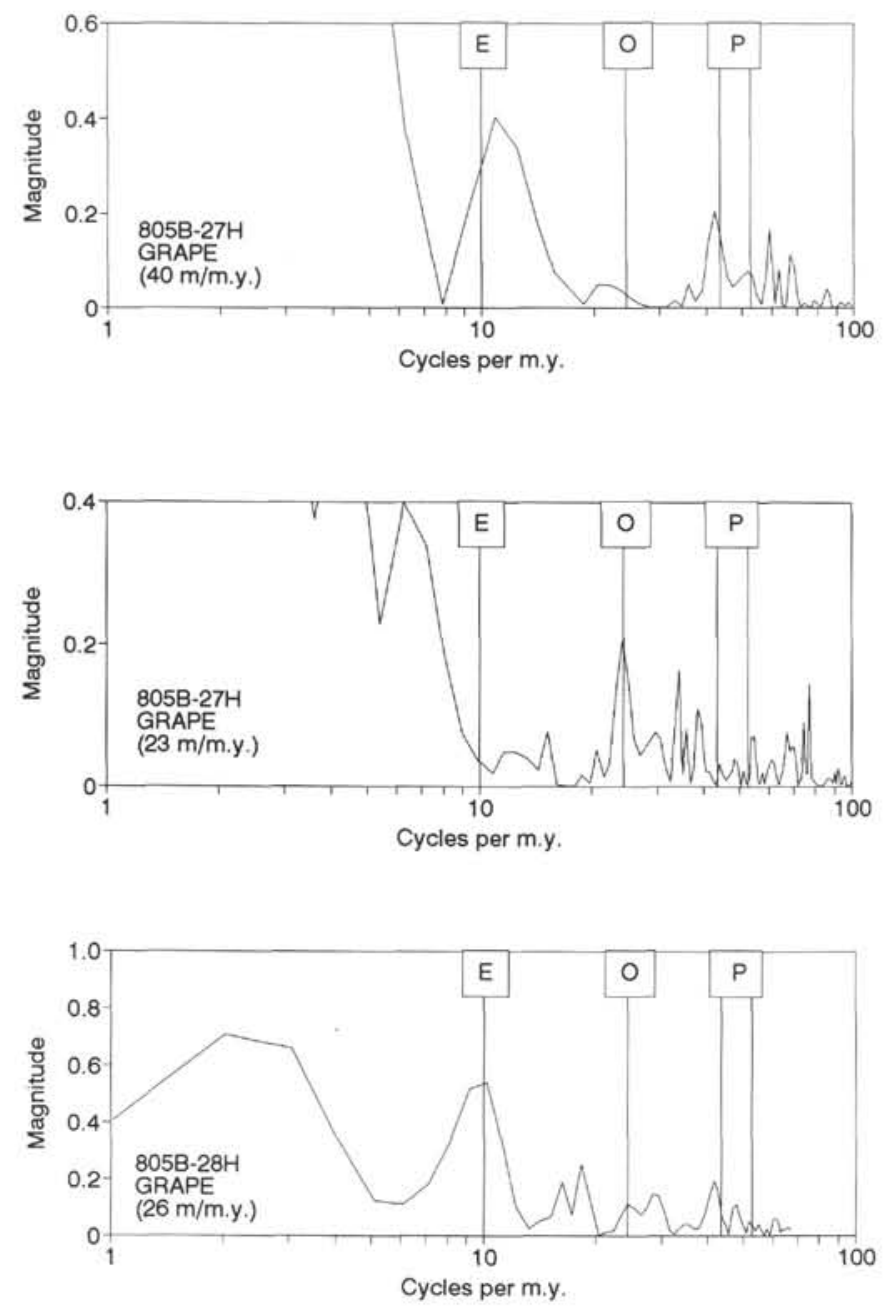

Figure 18. Spectral analysis of GRAPE records of Cores 130-805B-27H and $-28 \mathrm{H}$ by FFT. "Magnitude" = the sum of squares of real and imaginary components of each term in the expansion. $\mathrm{E}, \mathrm{O}, \mathrm{P}=$ expected positions of eccentricity-, obliquity-, and precession-related cycles in the record analyzed. Two alternative interpretations are shown for the record of Core 130-805B$27 \mathrm{H}$, one assuming that eccentricity-related cycles are dominant, the other assuming that obliquity-related cycles are dominant. Without additional data either assumption is viable. The rate for Core $130-805 \mathrm{~B}-28 \mathrm{H}$ is determined as $26 \mathrm{~m} / \mathrm{m} . \mathrm{y}$, assuming that eccentricity-related cycles are important.

verted mass flux units to sedimentation rate units, standardizing to a density of $1.5 \mathrm{~g} / \mathrm{cm}^{3}$, which is the typical density of these sediments in the late Quaternary, above the lysocline (Johnson et al., 1977). The resulting plot shows the original sedimentation rates at the time of deposition, here called "accumulation rates" (Fig. 23). The units $(\mathrm{m} / \mathrm{m} . \mathrm{y}$.) are really mass flux units, which emerge when multiplying by 0.15 . The graph reemphasizes the differences in the rates found for low-rate $(0-3,9-11$, and $17-20 \mathrm{Ma})$ and high-rate periods (5-8 and $12-14 \mathrm{Ma}$ ), and indicates a factor of 3 involved in the last $10 \mathrm{~m} . \mathrm{y}$. (the period for which these rates are reasonably reliable).

The subparallel curves of all sites except Site 804 may now be compared to obtain a sense of depth effects on accumulation rates through time. To this end, we combine the two sites above the lysocline, and the two at or below it, to generate "typical" accumu-lation stratigraphies for shallow and (moderately) deep environs (Fig. 24). Curve $\mathrm{A}$, in Figure 24, is the calculated sedimentation rate for a site between Sites 806 and 807 , at a depth of $2700 \mathrm{~m}$. Averages are geometric means. Curve B, by analogy, is the sedimentation rate at the depth of the
Table 5. Comparison of sedimentation rate estimates, Site 805.

\begin{tabular}{ccclll}
\hline Core & Depth & Age & A & B & \multicolumn{1}{c}{ C } \\
\hline $1 \mathrm{H}$ & $0-6.7$ & 0.3 & 17.5 & 17 & 17.5 \\
$2 \mathrm{H}$ & $6.7-16.2$ & 0.8 & 17.5 & 17 & 24 \\
$3 \mathrm{H}$ & $16.2-25.7$ & 1.3 & 13.2 & 19.5 & 18 \\
$15 \mathrm{H}$ & $130.2-139.7$ & 5.4 & 39 & 35.5 & 51 \\
$16 \mathrm{H}$ & $139.7-149.2$ & 5.7 & 39 & 39 & 40 \\
$17 \mathrm{H}$ & $149.2-158.7$ & 5.9 & 39 & 41 & 45 \\
$27 \mathrm{H}$ & $244.2-253.7$ & 8.2 & 38 & 32 & 40 \\
$28 \mathrm{H}$ & $253.7-263.2$ & 8.5 & 38 & 30 & 26 \\
\hline
\end{tabular}

Notes: $\mathrm{A}=$ biostratigraphy of Takayama (this volume); $\mathrm{B}=$ Table 4 and Figure 15 (this work); and C= GRAPE data spectrum (Hole 805B).

lysocline $(3300 \mathrm{~m})$ calculated by averaging the records of Sites 805 and 803 . The two curves, as expected from the input, show strong parallelism. Whatever process is responsible for the overall changes in sedimentation rates through the Neogene would appear active throughout the entire depth range.

If we wish to call on carbonate dissolution to do much of the modulation of accumulation rate, we should then be forced to have long periods of strong dissolution at depths well above that of Site 806: to affect the record at this site, the lysocline must lie above it. Chaisson and Leckie (this volume) present evidence that the severe reduction of sedimentation rate near $18 \mathrm{Ma}$ (Zone N6; Hiatus NH1 of Keller and Barron, 1983, 1987) is marked by poor preservation in Hole 806B, suggesting that in fact dissolution of carbonate is responsible for the condensation of the record at this level. Of course, since this event is recorded $600 \mathrm{~m}$ below the seafloor, the depth of deposition was not the present depth $(2500 \mathrm{~m})$, but one closer to $2800 \mathrm{~m}$ (accounting for isostatic adjustment by adding only one half the sediment thickness). More detailed preservational studies will allow an assessment of the importance of dissolution fluctuations further up in the section.

If we exclude carbonate dissolution as an important modulating factor at depths above, say, $2500 \mathrm{~m}$, we must then postulate a mix of different processes for different depths, but acting in concert such that accumulation rates stay parallel throughout. We have, then, a choice between a "shallow dissolution" hypothesis and a "conspiracy" hypothesis. In the first case, the conventional lysocline model (Berger, 1978) has to be modified to allow dissolution at shallow depth. In the second, a mechanism governing closely coordinated cooperation of different factors (production, dissolution, redeposition) must be invoked (and found).

Having noted the overall parallelism and its implications, we turn next to the differences, where the dissolution story is to be found (if anywhere). Assuming the shallow Record A represents the input, and Record B the remainder after dissolution, what is the fraction of sediment left at the depth of the present lysocline as a function of time? The answer is B/A, and it is about $60 \%-70 \%$, on average (Fig. 24B). Is there any evidence that this record of relative removal (in fact, the gradient between $2700 \mathrm{~m}$ and $3300 \mathrm{~m}$ ) is related to carbonate dissolution? Yes, there is: this gradient predicts (albeit roughly) the sedimentation rate history of deeper Site 804 (Fig. 24B). Whenever the gradient is strong, accumulation rates at Site 804 (3861 m) are low, and vice versa, exactly as expected.

If we assume, then, that the entire difference in rates is due to dissolution, we obtain a minimum removal at the deeper level (near the lysocline) of $35 \%$ of the sediment. This presumes that there is no loss at the shallower level $(2700 \mathrm{~m})$. If the calculations of Archer (1991) are correct, this shallower level in fact suffers a loss of 30 to $50 \%$ of the original calcite rain to the seafloor at that depth (that is, the saturation horizon as defined by Archer). This loss would be from dissolution in response to organic carbon oxidation. It is entirely conceivable, therefore, that the rate pattern at the shallower site is 

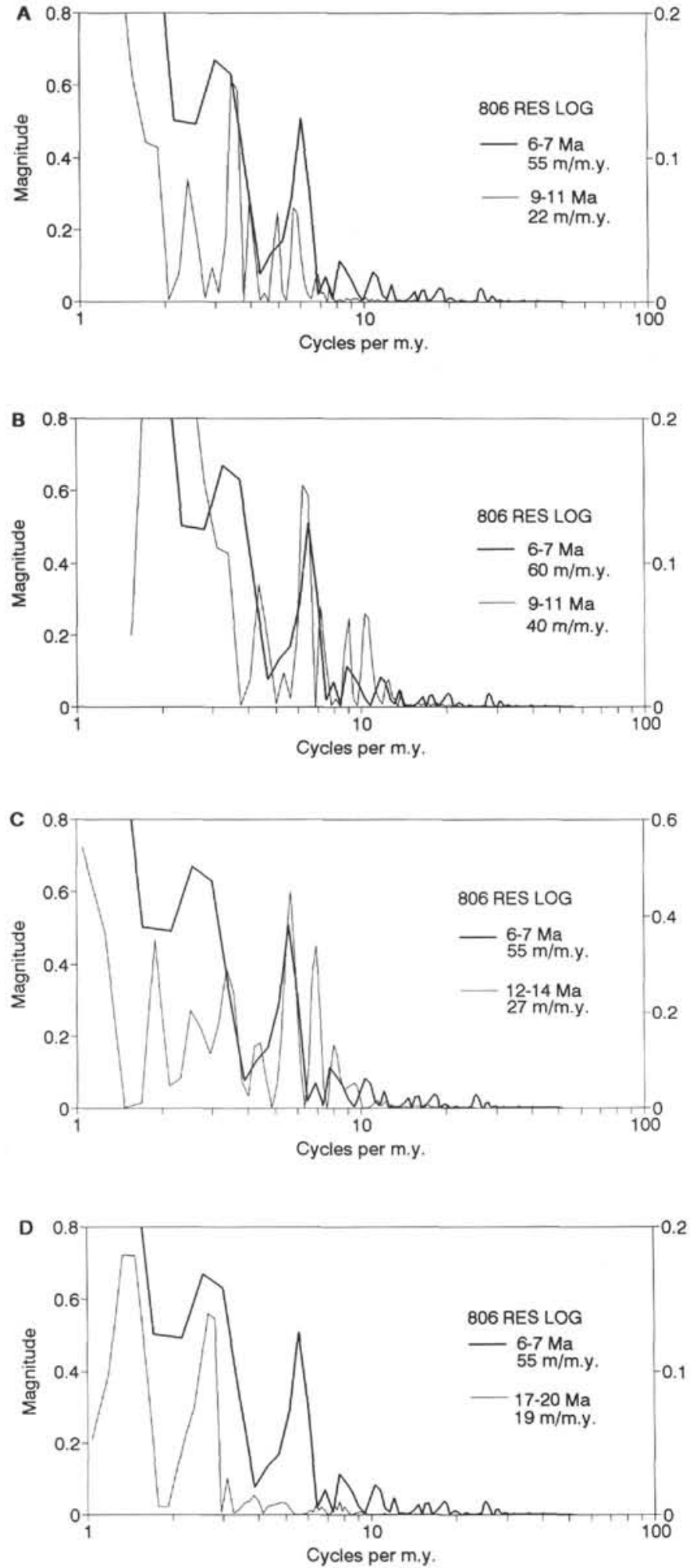

Figure 19. Spectral analyses of resistivity logs of Site 806, for the intervals shown in the window on each graph. Sedimentation rates based on biostratigraphy, adjusted for spectral "fit" to expected astronomical cycles. In Figure $19 \mathrm{~B}$, the rate of $40 \mathrm{~m} / \mathrm{m} . \mathrm{y}$. is given for illustration of uncertainty only (see text). In essence, the diagnostic cycles (E, O, P, as in Fig. 18) are missing in these records (possibly as a result of coarse sample spacing).

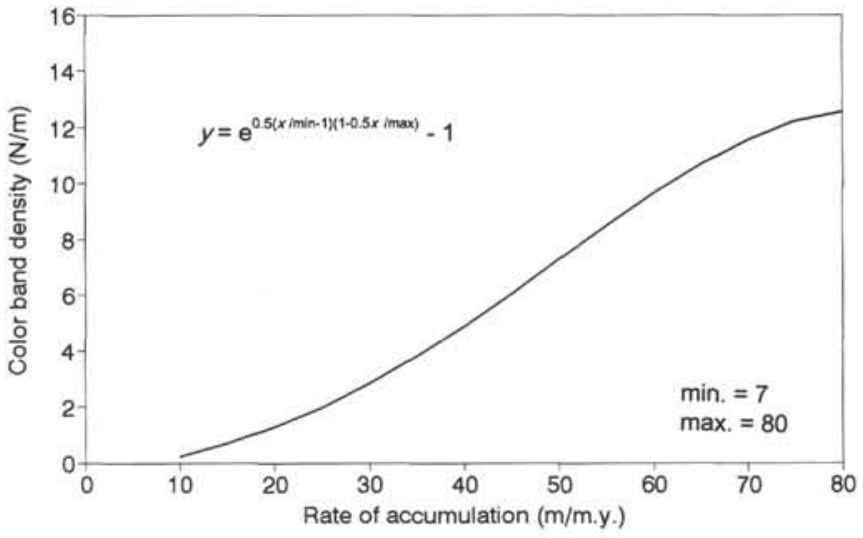

Figure 20. Postulated relationship between the rate of accumulation of carbonate sediments on Ontong Java Plateau and the abundance of color bands in the section. Based on fitting a logistic-type equation to the record of Site 807.

strongly modulated by fluctuations in background saturation, as this would change the response to organic carbon oxidation accordingly.

There is one distinct exception to the parallelism between the rate differences calculated for the depth range $2700 \mathrm{~m}$ to $3300 \mathrm{~m}$ and the rate in Site 804 (Fig. 24B), at about 10 to $11 \mathrm{Ma}$. Here the section at Site 804 is anomalously thick. Intraformational resedimentation processes must be at work. Somewhat deeper in the section (by two cores), the presence of turbidites was noted in the core descriptions (Kroenke, Berger, Janecek, et al., 1991). The anomalous thickness of the lower upper Miocene section in Site 804 is especially striking when comparing standardized units of sedimentation rates (Fig. 24C). One can see that this condition lasts for several million years; it cannot be due to an isolated event of redeposition. We suggest that it is, in fact, the result of continuous coherent redeposition, but also of decreased dissolution at depth, which goes parallel with low productivity (and hence low sedimentation rates in the shallower cores). If our interpretation is correct, this pattern would support the NADW hypothesis: a decline of the NADW source would decrease nutrient input to the Pacific and at the same time enhance preservation of carbonate at depth. This mechanism requires that the $\delta^{13} \mathrm{C}$ of deep waters moves toward heavier values, as is indeed the case (see Fig. 7).

\section{The Carbonate Record and Implications}

Carbonate stratigraphies are available for all five sites (Fig. 8). The coverage is not uniform, however, and it becomes more spotty previous to about $10 \mathrm{~m}$.y. The most striking feature of the combined carbonate record is the parallelism between the five stratigraphies (Fig. 25). Whatever factor modulates carbonate- the argument is already familiar from considering accumulation rates-must do so throughout the entire depth range studied. The correlations are so good, that one carbonate record can be closely predicted from another. Comparisons were made as follows: (1) convert both records to $\log$ (noncarbonate) (which adds variability in the high ranges of carbonate values); (2) find mean and standard deviation for both records; (3) for the record to be transformed subtract the mean and divide by the standard deviation; and (4) multiply the resulting transform by the standard deviation of the target record, and add the mean of the target record. Records, if similar, will now plot on top of each other (Fig. 26). Anomalies should identify the activity of different agencies, and the depth dependency of such anomalies in turn should give clues to the strength of dissolution effects. The data at hand probably are not good enough for such detailed work.

It seems unlikely (unless we have missed important preservational signals in the shallower cores) that the striking parallelism seen in Figure 26 is due to dissolution effects alone, or even in the main (at 

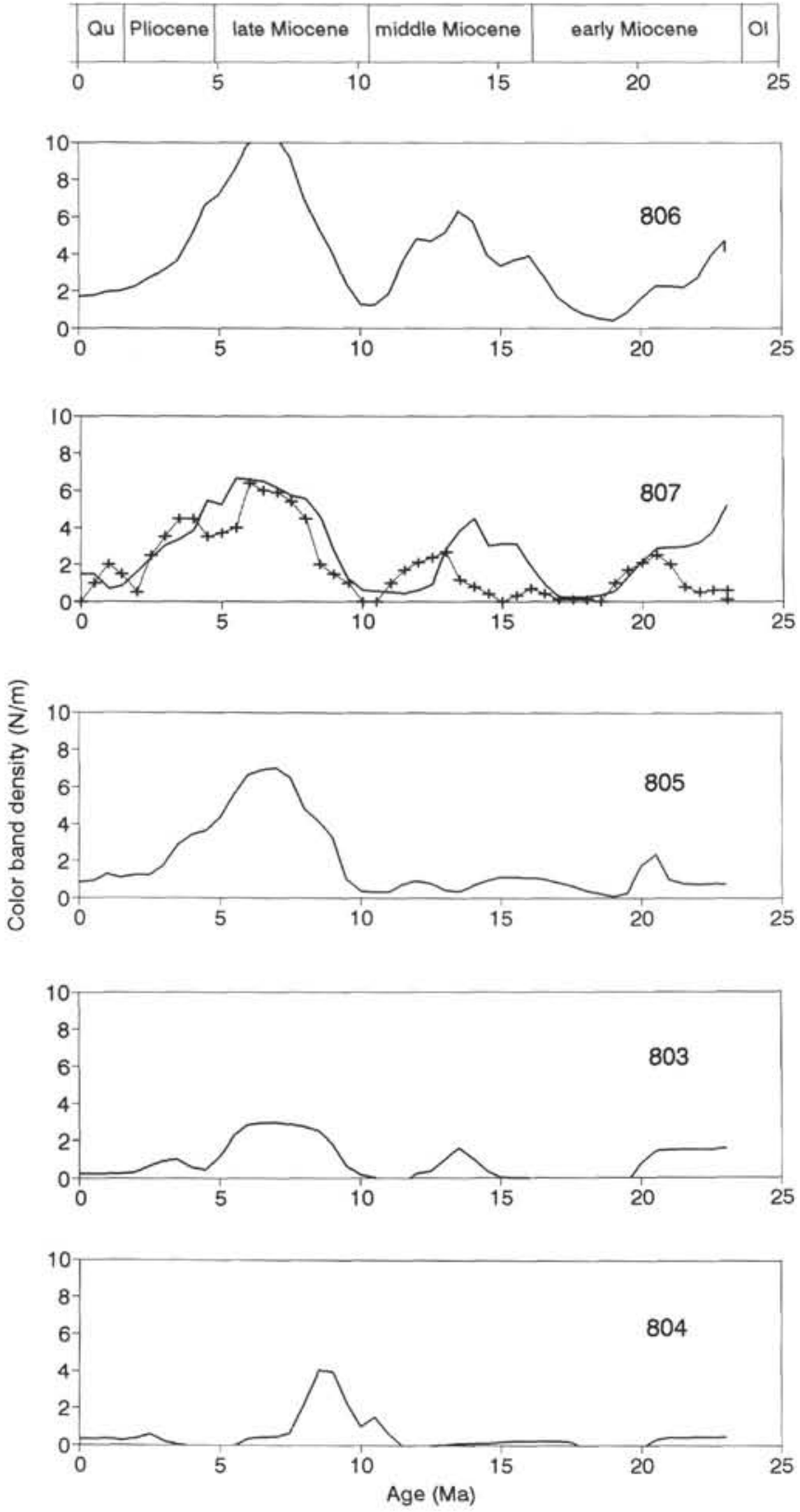

Figure 21. Abundance of color bands in Leg 130 sites predicted from relationship between sedimentation rate and color band abundance in Site 807 (as shown in Fig. 20). The patterns of the calculated abundances are similar to those observed (Lind et al., this volume).

the shallow depths). Since dissolution of carbonate must be important at depth, other factors (dilution, purification) active on the upper plateau should be working in concert with those active on the flanks to provide the correspondence. One likely scenario, from the overall thickness distributions and from detailed work on Quaternary deposits, is that mechanical sifting dominates at shallow depths, while dissolution dominates at and below the lysocline (Berger and Johnson, 1976; Wu and Berger, 1991; Mosher et al., this volume). Another scenario we could invoke is derived from the NADW hypothesis, which couples productivity and dissolution: when productivity rises, dilution by silica increases and reduces carbonate percentages; in addition, at depth the increased $\mathrm{CO}_{2}$ content of deep waters removes carbonate in parallel. These factors, then, act in concert - they conspire to produce parallel-
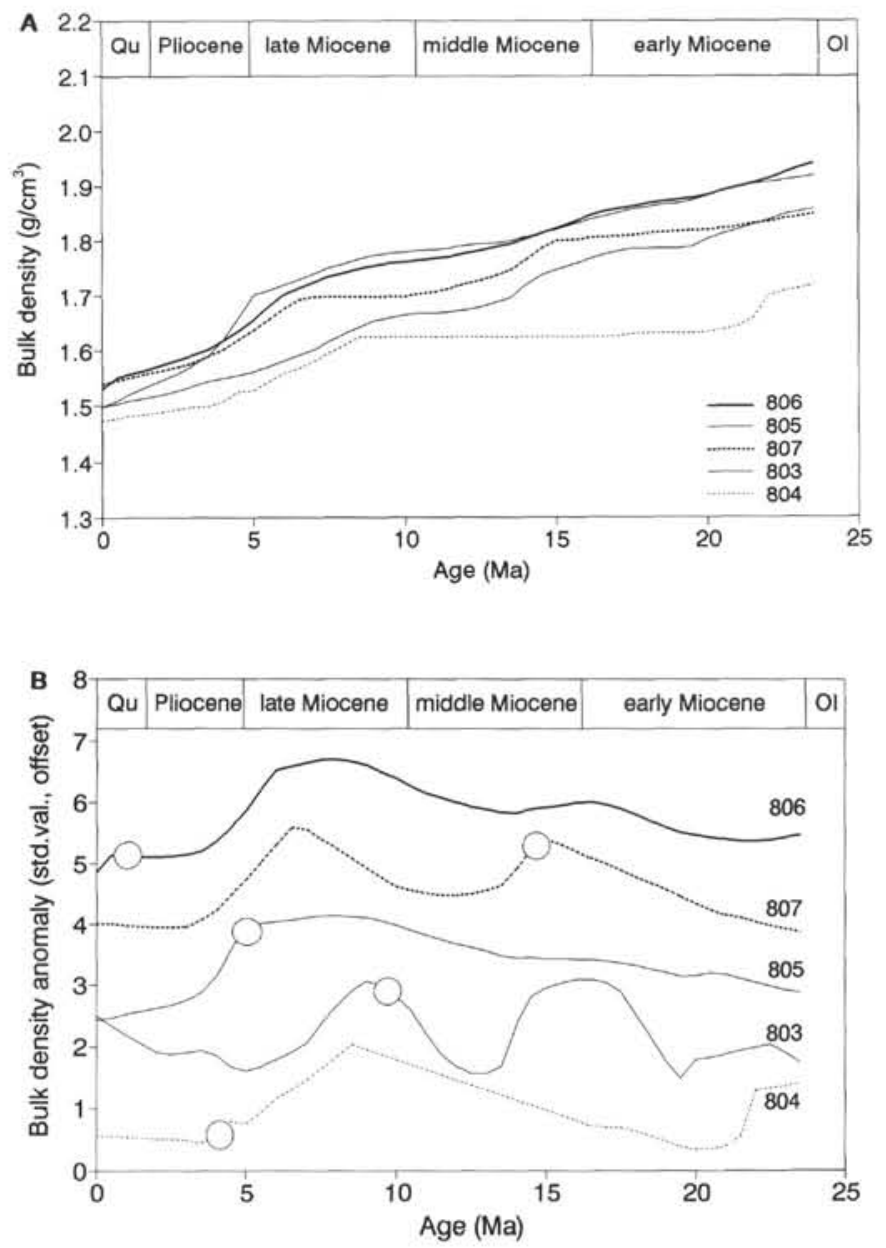

Figure 22. Bulk density of Neogene sediments, Leg 130. A. Generalized profiles for each site. B. Deviation from linear regression for each site, in standard units and offset for clarity. Figure 22A shows a steady increase of density with increasing age and illustrates that dissolution-related processes generate lowered density. Figure 22B shows that variations in the rate of density increase tend to be correlated between sites; it also illustrates the effect of crossing the equator (marked by open circle).

ism-because of being controlled by the same master modulator, NADW production.

There is a hint of an overall correlation between accumulation rates and carbonate values (Fig. 27). Sediments with low carbonate values tend to have low accumulation rates, and vice versa. The correspondence may in fact be better than that shown because of the poor resolution of the accumulation rate record (also, it may be not as good, of course). There is no problem rationalizing the correspondence if the dissolution of carbonate modulates both sedimentation rates and carbonate content. However, we have argued above that this cannot be the entire story (Table 6).

Can winnowing, in principle, produce the correspondence? No, if increased winnowing, by removing dilutant, increases carbonate content and decreases sedimentation rate. If winnowing is to be an important factor, then it should decrease carbonate content, that is, it should remove calcareous fines preferentially, to preserve the relationship between carbonate content and sedimentation rate seen (e.g., for post-Miocene time). This requirement is incompatible with having high carbonate values during glacial times, if it is assumed that winnowing is stronger during glacial periods than during interglacial ones (e.g. because more energy reaches the abyss in the absence of 


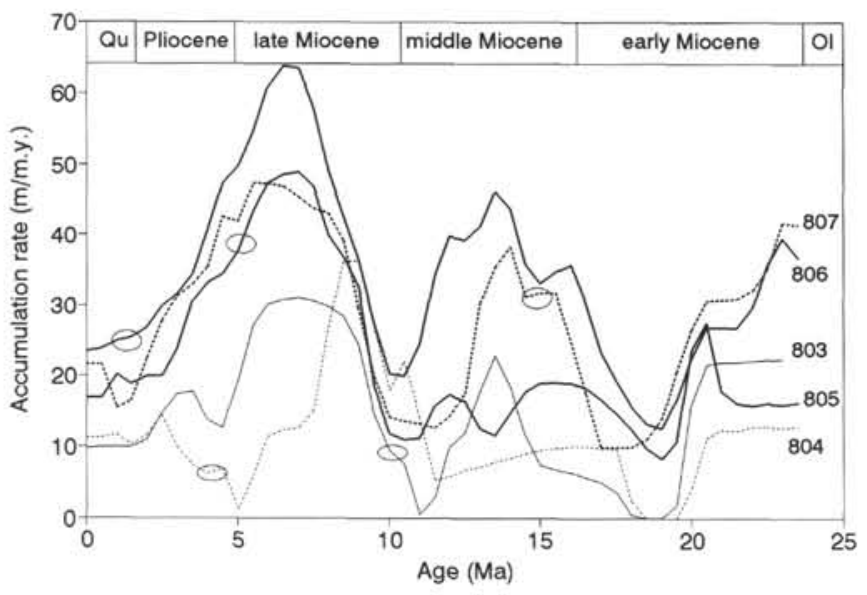

Figure 23. Sedimentation rates, converted to standard accumulation rates by setting bulk density equal to $1.5 \mathrm{~g} / \mathrm{cm}^{3}$ (the typical value for Quaternary sediments on the plateau). The graph represents the mass flux rates at the various sites. Note the peak values near the end of the Miocene, the parallelism between sites, and the quasi-contrary trends at Site 804 .

shelves where tidal energy is normally destroyed, and because of stronger storm action that produces episodic benthic currents).

Clearly, this complex of problems is not now well understood. To attack it, it is necessary to study the phase relationships between shallow and deep records. Thus, carbonate data must not be used for correlating between shallow and deep cores (as we have done). Instead, high-resolution correlation must rely on independent means. (Unfortunately, physical properties and biostratigraphy based on calcareous fossils is unlikely to be entirely independent from carbonate content.) Also, detailed comparisons will have to be made with corresponding grain-size records and with preservational data, and with proxies of input from eolian sources.

\section{Loss Stratigraphy}

The comparison between accumulation rates and carbonate content leads to the conclusion that factors other than dissolution must be at work in modulating both parameters (Table 6). The discrepancy between expected loss (from a comparison of carbonate contents; Eq. 7) and observed loss (the difference in corresponding sections) changes through time. Comparing Site 806 with the two next deeper equatorial sites ( 805 and 803 ), we find that discrepancies are at a minimum in the late Miocene, when sedimentation rates were high, and are large in the middle Miocene and in the latest Neogene, when sedimentation rates were moderate to low (Fig. 28). The minimum in discrepancy is due mainly to a decrease in the loss depth gradient (rather than an increase in the difference of carbonate values). This says, that carbonate differences, within the range considered, are not very sensitive to sediment loss. We hasten to emphasize that this conclusion is highly tentative, as it is based on a comparison of rather long-period trends, the shorter scales having entirely unreliable rate data. Again, with detailed refined correlation, using GRAPE data and logging results in combination with the detailed biostratigraphic data now available, this question can be attacked with some confidence.

\section{TORTONIAN-MESSINIAN RATE PEAK: A SEARCH FOR MECHANISMS}

\section{Emergence of the End-of-Miocene Accumulation Rate Peak}

One dominant feature of carbonate accumulation in the Neogene record of the Ontong Java Plateau is the accumulation rate peak in the uppermost Miocene, roughly spanning foraminifer Zone N17. An-
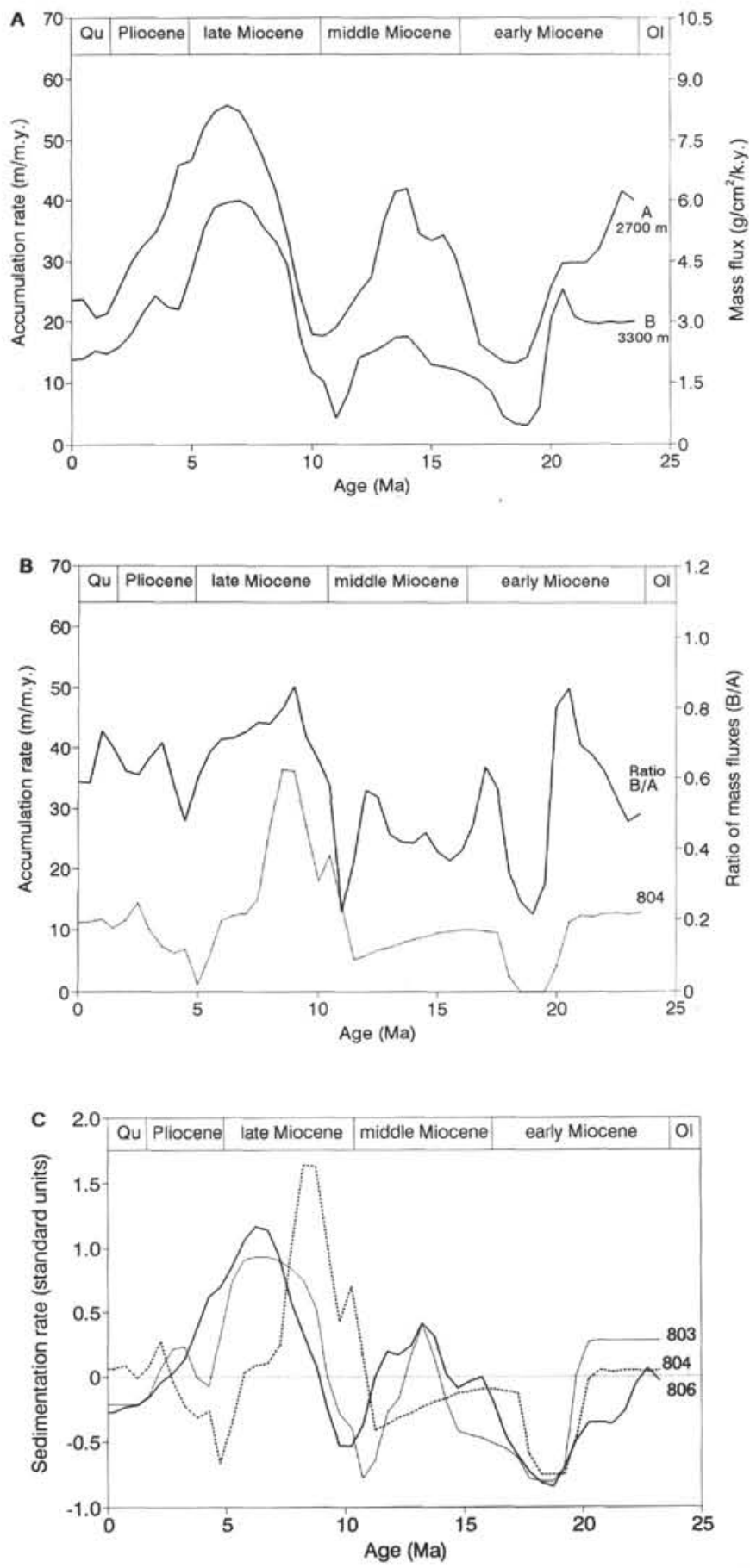

Figure 24. Depth dependency of accumulation rates. A. Comparison of the calculated rate for $2700 \mathrm{~m}$ (Record A, from averaging records of Sites 806 and 807 ) to the rate for $3300 \mathrm{~m}$ (Record B, Sites 805 and 803). Note the parallelism and changes in difference. B. Comparison of ratio B/A (depth gradient of accumulation rate) with the accumulation rate record of Site 804 . Note that $\mathrm{B} / \mathrm{A}$ is predictive for the rate at Site 804 . C. Illustration of the late Miocene accumulation rate anomaly in Site 804, using standardized values (raw values demeaned and divided by standard deviation). 


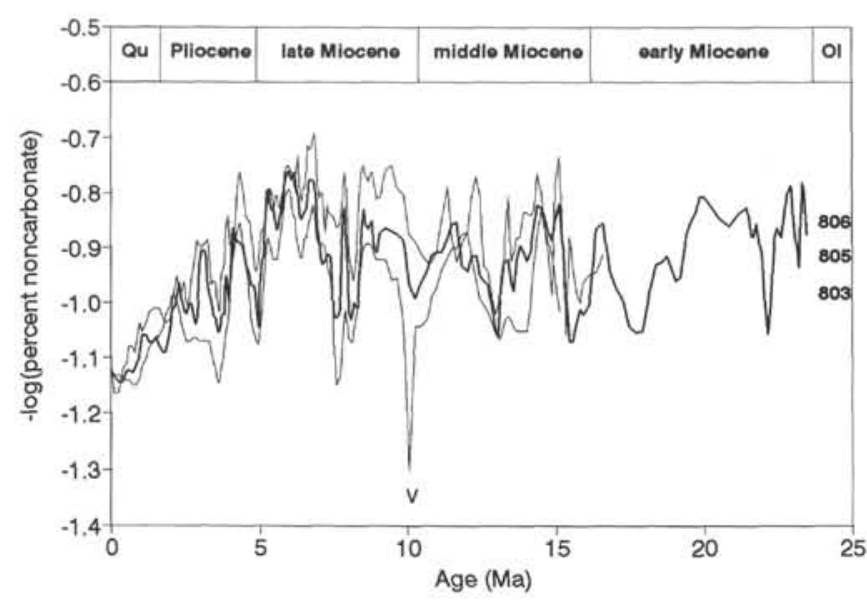

Figure 25. Topography of carbonate patterns on Ontong Java Plateau (Sites 806,805 , and 803 ), shown as $\log$ (percent noncarbonate), to emphasize variability in high carbonate ranges. The graph illustrates the striking parallelism in carbonate content over a large depth range (which implies dissolution at shallow depths, or "conspiracy" of carbonate-modifying factors; see text). V = volcanic matter present.

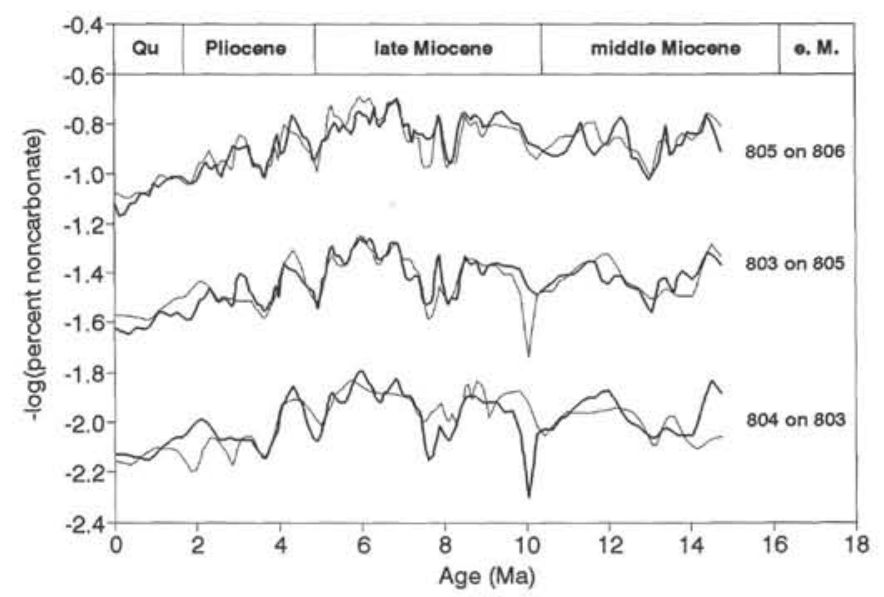

Figure 26. Comparison of carbonate records between three sites, two at a time. Match is by scaling. Transform $=$ thin line, target $=$ thick line. The graph illustrates the excellent match between carbonate stratigraphies at different depths. Profiles offset for clarity.

other is the condensed section in the upper lower to lower middle Miocene (involving nannofossil Zone NN4). These two features represent the extremes of accumulation history. We concentrate on the younger one as a target for discussion because it is easier to study an excess than a lack of materials and because information deteriorates when going back in time. Our aim is to investigate the possible roles of controlling factors: productivity, dissolution, dilution, purification, and redeposition.

Is the Tortonian-Messinian Rate Peak an artefact of age assignments? When discussing sedimentation rates, it must be kept in mind how vulnerable these data are to errors in biostratigraphic age assignments. It is sobering to read the articles in the volume on Miocene paleoceanography (Kennett, 1985), and realize the substantial differences in the age models used therein and the one adopted here (based on Berggren et al., 1985). In certain sections, in the late middle Miocene and early late Miocene, differences in datum assignments are as large as $2 \mathrm{~m}$.y. The discrepancy is due to a switch in the

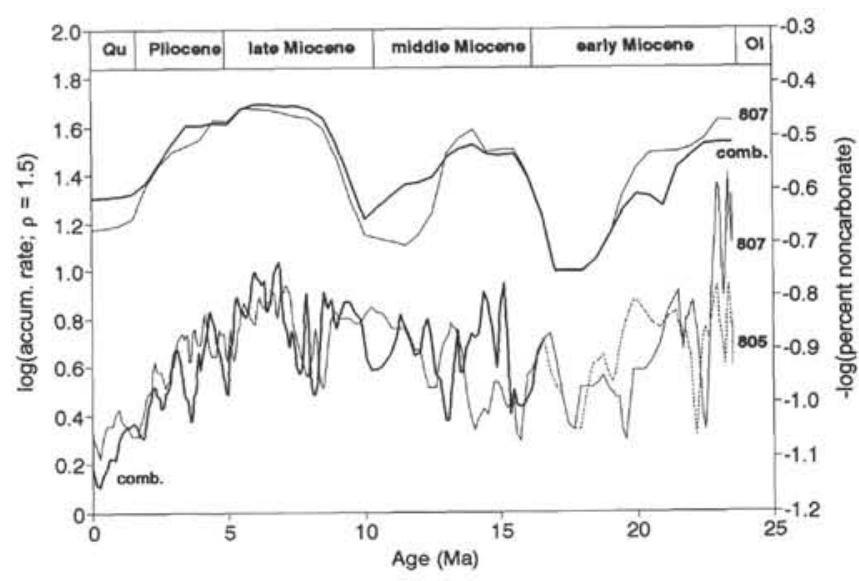

Figure 27. Comparison of carbonate record (bottom) and accumulation rate record (top). "Comb." (combined) refers to average of records for Sites 805 and 806 . The graph illustrates the overall parallelism between accumulation rates and carbonate content.

correlation of paleomagnetic Anomaly 5 to Chron 11, instead of to Chron 9 (see Barron et al., 1985, figs. 1 and 5). The impact on rate calculations of the changes in age models is profound. For example, in the middle to late Miocene our rate pattern is close to the opposite of that shown and discussed by Romine and Lombari (1985), for Site 289 on the Ontong Java Plateau. The excursions they ascribe (tentatively) to the closure of the Indo-Pacific passage (Romin and Lombari, 1985, fig. 11) are now interpreted as an artefact of the age model. We must assume that our age model produces similar artifacts, somewhere in the Neogene section.

Comparing our assignments with those of Gartner (1992), we find good agreement on the whole; but there are also some marked differences, for example, for the first occurrence (FO) D. hamatus (10.5 vs. 9.6 Ma), the last occurrence (LO) of Cyclicargolithus floridanus (13.1 vs. $11.25 \mathrm{Ma}$ ), and the FO of Sphenolithus belemnos (20.0 vs. 19.5 $\mathrm{Ma}$ ). The point is, for example, that the extremely low sedimentation rates seen in all sites near 10 Ma may be (at least in part) an artefact. On the other hand, the time scale for the last $6 \mathrm{Ma}$ or so has been rather stable; we consider it quite well established. Thus, the peak accumulation rate found for the latest Miocene, and the decline of rates in the Pliocene and Quaternary, are real phenomena in all probability. There is independent evidence that this is so from Fourier analysis of physical properties and the stable isotope record (Mayer et al., this volume; Lyle et al., this volume; Jansen et al., this volume).

There is internal evidence from the carbonate record that the time scale is reasonable from $8 \mathrm{Ma}$ to the present. Using this scale, the accumulation rate of noncarbonate varies but little in the shallow Site 806 since the late Miocene (Fig. 29A). If the scale had serious distortions, we should expect a stronger covariation of otherwise independent sediment components. Such covariation is seen, to some extent, in Site 803, which is below the lysocline (Fig. 29B). The reason why Site 806 shows a stratigraphy that is well-behaved, while Site 803 does not, is readily appreciated: biostratigraphic datums can be affected by dissolution effects, and these are much stronger in the deeper site. By the principle of least surprise, one would expect a reduction of sedimentation rate, in Site 803 , near $8 \mathrm{Ma}$, where the carbonate content is lowered substantially (Fig. 29B). Similarly, one would not expect a dip in sedimentation rate between 4 and $5 \mathrm{Ma}$, where the carbonate content is high. These discrepancies show as apparent accumulation rate excursions in the noncarbonate.

\section{Peak Supply: The Role of Productivity}

Proceeding on the well-founded assumption that the peak in accumulation rate emerging from our age model in the latest Miocene is 
Table 6. Sedimentation rate ratios ( $\mathrm{x} / \mathbf{8 0 6}$ ), carbonate contents, and loss statistics for Neogene sediments in the five sites of Leg 130.

\begin{tabular}{|c|c|c|c|c|c|}
\hline $\begin{array}{l}\text { Site } \\
\text { Depth (m) }\end{array}$ & $\begin{array}{r}806 \\
2520\end{array}$ & $\begin{array}{r}807 \\
2805\end{array}$ & $\begin{array}{r}805 \\
3188\end{array}$ & $\begin{array}{r}803 \\
3410\end{array}$ & $\begin{array}{r}804 \\
3861\end{array}$ \\
\hline \multicolumn{6}{|c|}{ Sedimentation rate ratios: } \\
\hline Quaternary & 1.00 & 0.70 & 0.73 & 0.40 & 0.38 \\
\hline late Pliocene & 1.00 & 0.88 & 0.88 & 0.51 & 0.35 \\
\hline early Pliocene & 1.00 & 0.73 & 0.71 & 0.38 & 0.14 \\
\hline late Miocene & 1.00 & 0.85 & 0.67 & 0.58 & 0.47 \\
\hline middle Miocene & 1.00 & 0.78 & 0.59 & 0.31 & 0.30 \\
\hline early Miocene & 1.00 & 0.80 & 0.87 & 0.41 & 0.35 \\
\hline Neogene & 1.00 & 0.80 & 0.72 & 0.43 & 0.35 \\
\hline \multicolumn{6}{|l|}{ Carbonate contents: } \\
\hline Quaternary & 88.19 & 88.90 & 86.96 & 86.30 & 79.00 \\
\hline late Pliocene & 90.90 & 91.22 & 90.07 & 88.44 & 82.71 \\
\hline early Pliocene & 91.84 & 92.40 & 90.70 & 88.39 & 80.72 \\
\hline late Miocene & 93.41 & 92.89 & 92.39 & 89.86 & 90.14 \\
\hline middle Miocene & 92.49 & 91.22 & 91.52 & 90.04 & 87.05 \\
\hline early Miocene & 93.90 & 94.89 & 92.15 & 91.84 & 83.20 \\
\hline Neogene & 92.64 & 92.50 & 91.45 & 89.90 & 86.27 \\
\hline \multicolumn{6}{|c|}{ Expected losses (1-NCi/NCf): } \\
\hline Quaternary & 0.00 & NA & 0.09 & 0.14 & 0.44 \\
\hline late Pliocene & 0.00 & NA & 0.08 & 0.21 & 0.47 \\
\hline early Pliocene & 0.00 & NA & 0.12 & 0.30 & 0.58 \\
\hline late Miocene & 0.00 & 0.07 & 0.13 & 0.35 & 0.33 \\
\hline middle Miocene & 0.00 & 0.14 & 0.11 & 0.25 & 0.42 \\
\hline early Miocene & 0.00 & NA & 0.22 & 0.25 & 0.64 \\
\hline Neogene & 0.00 & 0.02 & 0.14 & 0.27 & 0.46 \\
\hline \multicolumn{6}{|c|}{ Actual losses (thickness deficit): } \\
\hline Quaternary & 0.00 & 0.30 & 0.28 & 0.60 & 0.63 \\
\hline late Pliocene & 0.00 & 0.12 & 0.12 & 0.49 & 0.65 \\
\hline early Pliocene & 0.00 & 0.27 & 0.29 & 0.62 & 0.86 \\
\hline late Miocene & 0.00 & 0.15 & 0.33 & 0.43 & 0.54 \\
\hline middle Miocene & 0.00 & 0.22 & 0.41 & 0.69 & 0.70 \\
\hline early Miocene & 0.00 & 0.20 & 0.28 & 0.59 & 0.65 \\
\hline Neogene & 0.00 & 0.20 & 0.28 & 0.57 & 0.65 \\
\hline \multicolumn{6}{|c|}{ Observed/Expected (\%): } \\
\hline Quaternary & NA & NA & 290 & 433 & 143 \\
\hline late Pliocene & NA & NA & 147 & 230 & 137 \\
\hline early Pliocene & NA & NA & 234 & 209 & 150 \\
\hline late Miocene & NA & 199 & 247 & 122 & 162 \\
\hline middle Miocene & NA & 154 & 358 & 282 & 167 \\
\hline early Miocene & NA & NA & 58 & 232 & 101 \\
\hline Neogene & NA & 1081 & 205 & 210 & 140 \\
\hline
\end{tabular}

real, we need to discuss its nature. Is it an "add-on"- a result of superposing additional sediment during an unusually productive time on a low-rate background? Or is it a "remnant" resulting from increased erosion before and after that period? For the first case, we should see evidence for increased productivity during peak time; for the second, increased erosion before and after that time.

Clues to productivity history may be found in the various fossils that make up most of the sediment. In the present equatorial Pacific, there is a succession of planktonic foraminifer assemblages from east to west, with the highly productive eastern areas dominated by $N$. dutertrei and the much less productive western ones by $P$. obliquiloculata (Parker and Berger, 1971). The G. menardii-tumida complex is intermediate and is typical for the equatorial regions of the central Pacific. A shift of the $G$. menardii-tumida group to the west, then, would reasonably be interpreted as an increase in productivity in the western Pacific, and even more so an increased abundance of $N$. dutertrei. Remarkably, the one section in Site 806 where both $G$. menardii and $N$. acostaensis (forerunner of $N$. dutertrei) are abundant is that corresponding to peak rate time, between about 8 and $6 \mathrm{Ma}$. In fact, diversification patterns suggest that a strong thermocline only developed sometime in the late Miocene. The distinct rise of deep-dwelling species in the surface waters above the Ontong Java Plateau (species that cannot rely on symbionts but depend on food raining down into the dark thermocline habitat) was earlier recog-
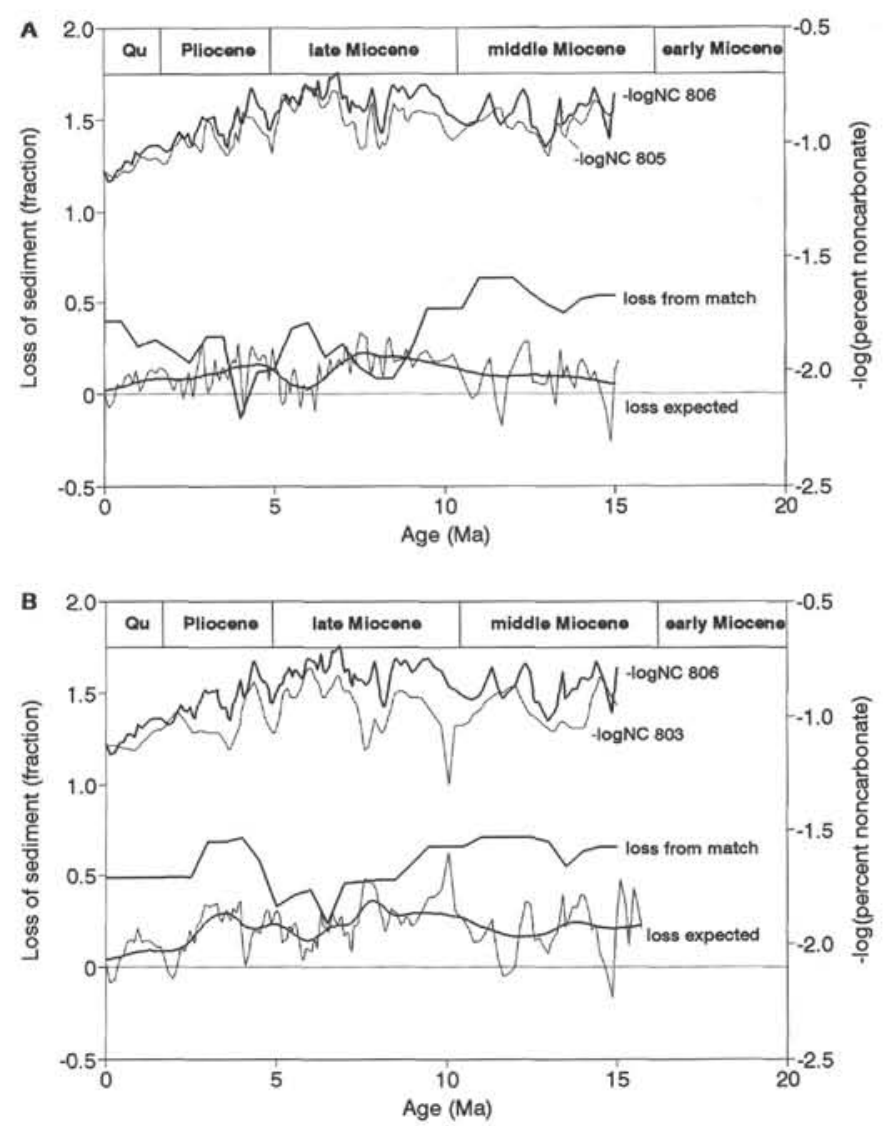

Figure 28. Loss records of two pairs of sites. Comparison of difference in corresponding sections ("loss from match") and loss calculated from carbonate difference based on the dissolution hypothesis ("loss expected"). A. Sites 805 vs. 806 . B. Sites 803 vs. 806 . The graph illustrates the distinct mismatch between the loss estimates obtained by the two methods ("loss paradox").

nized in Site 289 (Keller, 1985). Keller shows maximum abundances in Zone N17, which is the interval of peak sedimentation rate. Another indication of increased productivity is the greatly increased abundance of biserial planktonic foraminifers in the interval in question (Resig, this volume). Resig suggests that these foraminifers reflect the existence of a strong oxygen minimum, implying elevated productivity in surface waters and high nutrient concentrations in the thermocline.

Benthic foraminifers have long been recognized as potential indicators of productivity variations. Benthic data collected and analyzed by Woodruff (1985) from Site 289 indicate a marked increase in productivity beginning in the late Miocene, and culminating in the latest Miocene (her "Factor 1"). Areal distributions (her Fig. 14) show that during peak rate time the west was similar to the east, unlike during previous periods when a stronger asymmetry is in evidence. Earlier, Woodruff and Douglas (1981) proposed increased upwelling and productivity (and an intensified oxygen minimum) for the period between 5 and 9 m.y. ago, on the basis of benthic assemblages.

Some observations on benthic abundances are available for Site 803 for this interval from counts by J. Resig (Marsters et al., this volume) (see Fig. 30). Percentages of benthic foraminifers actually are not particularly high, but the pattern of high productivity emerges when multiplying percentages with the accumulation rate. This product simulates the accumulation rate of benthic foraminifers, which is thought to be a good proxy for delivery of organic matter to the seafloor (Herguera and Berger, 1991). Maximum values are centered near $6 \mathrm{Ma}$. This pattern agrees well with that found by Stax and Stein 

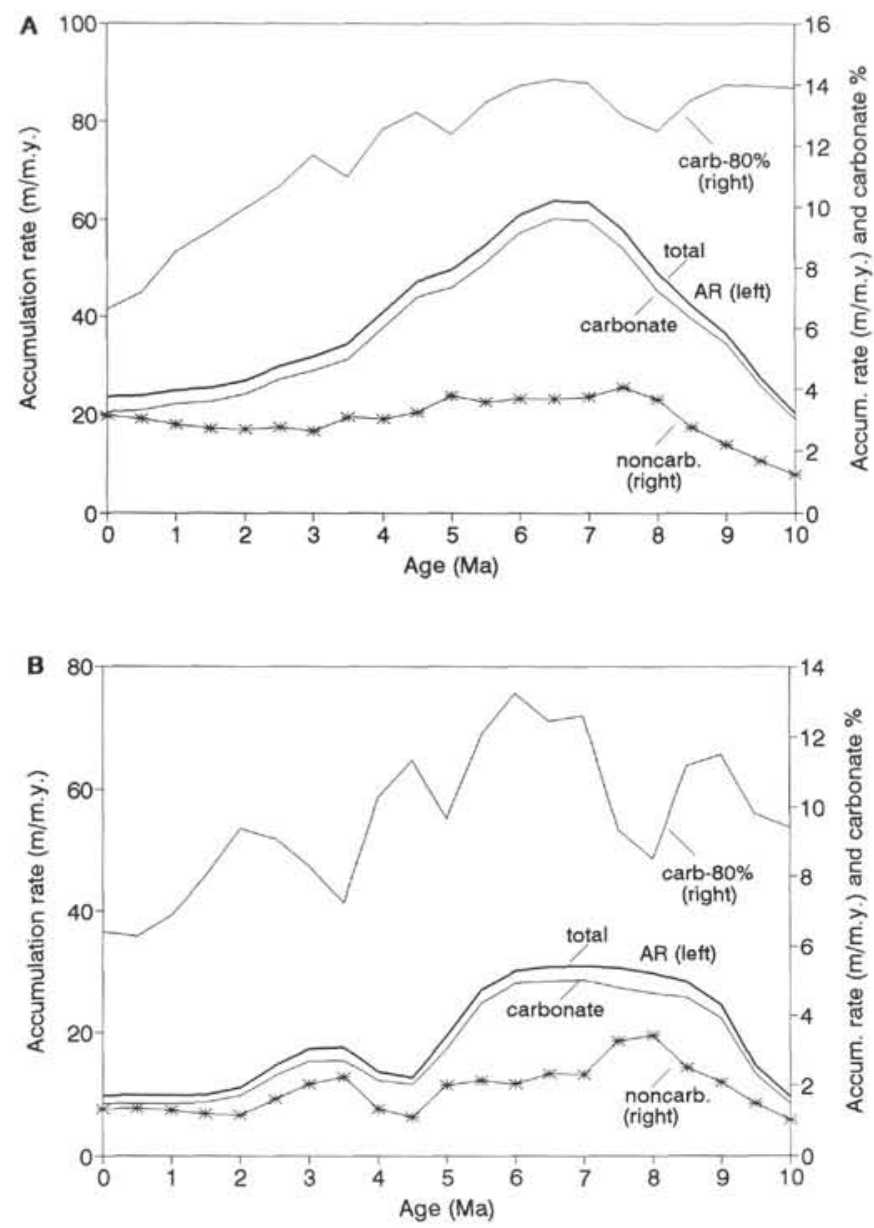

Figure 29. Comparison of carbonate content and accumulation rates of carbonate and noncarbonate on Ontong Java Plateau for the last 10 m.y. A. Site 806 at $2520 \mathrm{~m}$ depth. B. Site 803 at $3410 \mathrm{~m}$ depth. Fluctuations in noncarbonate are subdued relative to those in carbonate. After the Miocene, both carbonate content and accumulation rates show a long-term decrease.

(this volume) for the accumulation of organic matter, which peaks between 6 and $5 \mathrm{Ma}$ in the shallow sites, with a subsidiary peak near $3 \mathrm{Ma}$, and a drop after $2.5 \mathrm{Ma}$.

Siliceous fossils are commonly abundant below regions of high productivity, and are useful as paleoproductivity indicators (Barron and Baldauf, 1989). Inspection of smear slide results from Site 806 (as given in Kroenke, Berger, Janecek, et al., 1991, p. 302) shows that increased radiolarian abundances occur between 6 and $4.5 \mathrm{Ma}$, in agreement with expectations. Also, in Site 803, diatoms are relatively more abundant in the interval in question (Fig. 30).

Although the available evidence from siliceous fossils is supportive of the hypothesis of increased productivity in Tortonian-Messinian time, it is not particularly strong. In the present circumstances, siliceous fossils are unreliable as productivity proxies for several reasons. One is that the wide spacing of samples leads to spurious results, in view of large short-term fluctuations ("aliasing"). Another is illustrated by the observation that radiolarian abundances can increase in condensed sections, being concentrated by the dissolution of carbonate (e.g., Hole $804 \mathrm{C}, 200 \mathrm{~m}$; Hole $805 \mathrm{C}$, between 350 and $400 \mathrm{~m}$ ). Yet another, stressed by Lange and Berger (this volume), is that the abundance patterns of diatoms are greatly influenced by variations in preservation rather than in productivity, with the twist that these two factors may counteract each other. A fourth, finally, is related to the changes in the concentration of silica in the deep waters of the Pacific, which is a function of the Atlantic-Pacific asymmetry, and the intensity of upwelling around Antarctica and in the coastal oceans. Thus, the fact that diatoms become rare at the end of the Miocene (Fig. 30) does not necessarily reflect decreased productivity, but rather a shortage of silicate. Increased upwelling in the Southern Ocean (and in coastal systems) extracts the silica that is then no longer available for sedimentation in the equatorial Pacific (cf. Leinen, 1979; Barron and Baldauf, 1989).

Additional support for increased productivity during the latest Miocene comes from the carbon isotope record (Fig. 31). The difference in $\delta^{13} \mathrm{C}$ values of foraminifers inhabiting surface waters and those growing bathed in deep waters is a proxy for nutrient content of deep waters (Broecker, 1973). The assumption is that nutrient content in surface waters will be close to zero, and that there is a carbon deficit in surface waters corresponding to the absence of nutrients, which is the greater the more nutrients were present initially, in the upwelled deep water. This deficit is tagged by isotopic fractionation.

The difference in planktonic and benthic values indicates that the nutrient content of deep waters increased throughout the late Miocene and fell off in post-Miocene time. The late Miocene nutrient increase, presumably, is a consequence of regression (Messinian evaporites in the Mediterranean; overall $\delta^{13} \mathrm{C}$ shift toward negative values) as well as increased NADW production, as seen in increased carbonate preservation there (Berger, 1972; van Andel et al., 1977; Ehrmann and Thiede, 1985). NADW production depletes the deep Atlantic of nutrients and increases nutrient content "down-stream" in the Pacific, while increasing the contrast in $\delta^{13} \mathrm{C}$ of deep waters between the two ocean basins (e.g., Keir, 1988). A late Miocene "silica switch" from the Atlantic to the Pacific (Keller and Barron, 1983; Barron and Baldauf, 1989; Baldauf and Barron, 1990) is another indication of this process of shifting nutrients into the Pacific.

Although the peak of nutrient concentration in deep waters (as proxied by the difference in $\delta^{13} \mathrm{C}$ ) and the peak of sedimentation rate coincide tolerably well (considering the tentative nature of these curves), nutrients do not decrease in the same measure as does sedimentation rate in post-Miocene time. Either shallow waters do not "see" the deep nutrients (because of a greatly thickened mixed layer caused by a warm pool pileup), or carbonate sediment is being removed by erosional processes, or both.

\section{The Pliocene Accumulation Rate Decline: The Role of Winnowing}

The history of Neogene climate is dominated by cooling steps, and the post-Miocene period is no exception. Thus, it is surprising at first glance that accumulation rates should decrease after the Miocene, when an increasing planetary temperature gradient and an associated increase in trade-wind activity should have favored upwelling and mixing along the equator. This paradox has been noted previously, and it has been suggested that an increase in the pileup of warm surface waters in the western equatorial Pacific, from closure of the Indonesian seaway in combination with increased easterly winds, could explain the puzzle (articles in Kennett, 1985; Barron and Baldauf, 1989, and references therein). Such a pileup (which is indeed in evidence at present) thickens the warm water lid on the nutrient-rich thermocline layer, so that stirring and upwelling become ineffective in bringing up nutrients. Another possible factor responsible for a drop in sedimentation rates, in spite of increased mixing, is a depletion of nutrients in subsurface waters resulting from increased nutrient extraction in the coastal regions (Berger and Wefer, 1991).

Although there are good reasons, then, to postulate a drop in productivity after the Miocene, other factors also must be considered. In Site 803, for example, both sand content and the abundance of foraminifer fragments increase between the late Miocene and the late Pliocene (Fig. 30). An increase in sand content can be produced by several factors, of course: change in supply of foraminifers relative to nannofossils, winnowing, and improvement of preservation. The last item can be excluded because of the trend in fragmen- 


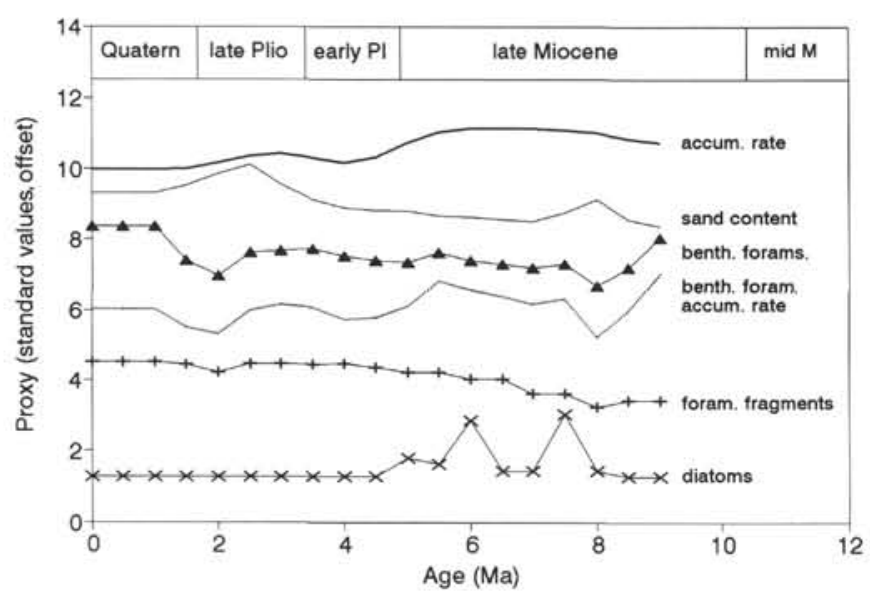

Figure 30. Accumulation rate of Site 803 compared with various proxies of productivity and erosional activity. Proxies generalized from data given in Marsters et al. (this volume) and plotted on an arbitrary scale after standardization. The decrease in accumulation rate is seen to be accompanied by a slight decrease in benthic foraminifer accumulation rate (indicating somewhat reduced productivity) and by an increase in sand content (indicating enhanced winnowing activity).

tation. A relative increase in the supply of foraminifer shells would probably be incompatible with decreasing productivity (the low-rate Sargasso Sea carbonates have a lower foraminifer content than the ones on the Ontong Java Plateau). Thus, we postulate increased winnowing as an important factor. Winnowing apparently has considerable impact in the shaping of sedimentation rate patterns on the plateau at present and during the late Quaternary, with glacial periods characterized by increased activity (Wu and Berger, 1991). Gardner et al. (1986a) suggested the possibility of cyclic winnowing activity (period of $430 \mathrm{k.y}$.) on the Ontong Java Plateau, increasing in amplitude in the Quaternary.

Under the assumption of winnowing as the controlling factor of changing sand content, the loss of sediment can be calculated in exact analogy to Equation 8, provided that sand acts as the residual (i.e., is unaffected):

$$
\text { Loss }=1-S_{o} / S_{f}
$$

Equation 9 states that the loss increases regularly with the increase in final sand content $\left(S_{f}\right)$, which is greater than the initial sand content $\left(S_{o}\right)$. We can now test whether the change in sand content is of the right order to explain the decrease in sedimentation rate in post-Miocene time. To do this, we must not use a site at or below the lysocline, since carbonate dissolution destroys sand-size shells, producing shell hash (Johnson et al., 1977). Thus, dissolution interferes with the analysis in terms of winnowing.

The shallowest site from which data are available is DSDP Site 586 , at $2218 \mathrm{~m}$, close to ODP Site 806 , and just south of the equator (Fig. 1). Sand content in the period in question spans values from 12 to 30 percent, approximately; the lowest values being found between 6 and $7 \mathrm{Ma}$, the highest in the late Quaternary (Fig. 32). From Equation 9, one can see that a factor of 3 in sand content translates into a loss of two thirds of the sediment, and hence a factor of 3 in accumulation rate. Thus, under the assumption of winnowing as controlling factor, the sand content change is compatible, in principle, with the observed range of sedimentation rate.

In detail, the model of sedimentation rate derived from Equation 9 (setting $S_{o}=10$ and the initial sedimentation rate equal to $70 \mathrm{~m} / \mathrm{m}$.y.) does not follow the rate derived from biostratigraphy (interpreted in terms of the age model adopted here). The Tortonian-Messinian Rate Peak is much more pronounced in the winnowing model than in the

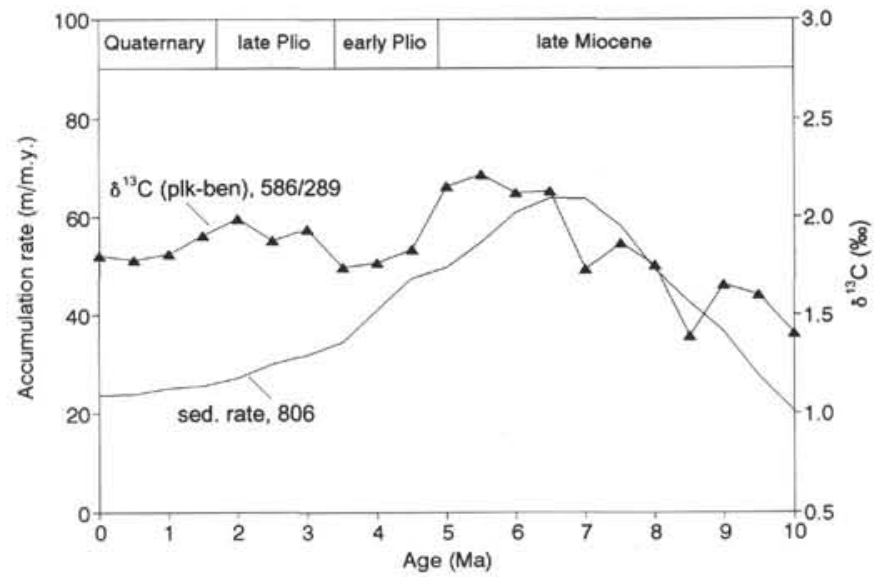

Figure 31. Comparison of difference in $\delta^{13} \mathrm{C}$ values of planktonic and benthic foraminifers (Sites 586 and 289; see Fig. 7), and the accumulation rate in Site 806 (reset to $\rho=1.5 \mathrm{~g} / \mathrm{cm}^{3}$ ). The graph illustrates that, although accumulation rate decreases in post-Miocene time are accompanied by decreases in $\delta^{13} \mathrm{C}$ contrast (suggesting lowered productivity), the $\delta^{13} \mathrm{C}$ trend is weak compared with that in the accumulation rate.

smoothed target curve. Also, the sand content would predict a sharper drop within the early Pliocene than that seen in the biostratigraphy, as well as a pronounced high in the late Pliocene. At face value (unless the analysis is quite wrong), these results suggest increased productivity in the early Pliocene (overwhelming increased winnowing), and greatly decreased productivity in the late Pliocene (making up for decreased winnowing). The record of the deep-sea nutrient proxy (Fig. 31) appears to agree with this analysis, at first glance. However, a more detailed study of the course of productivity history is warranted, considering the results of Hermelin (1989) who offers evidence for increased productivity during the late Pliocene (from 3.3 to $2.4 \mathrm{Ma}$ ), based on benthic foraminifer abundances. In any case, the sand record is compatible with the hypothesis of an important role for winnowing in shaping the Tortonian-Messinian Rate Peak.

\section{The Role of Carbonate Dissolution}

The scant data on foraminiferal preservation available (Site 803; see Fig. 30) suggest that dissolution effects increased in post-Miocene time, aiding in the observed reduction of sedimentation rates, at least in the sites close to and below the lysocline. The lysocline fluctuated through a large depth interval in the Quaternary, a range of almost $1 \mathrm{~km}$ on the Ontong Java Plateau (Berger and Keir, 1984; Hebbeln et al., 1990; Grötsch et al., 1991; Wu et al., 1991) and in the central equatorial Pacific (Farrell and Prell, 1989). Judging from the amplitude of carbonate excursions in the Pliocene in the deeper sites (Fig. 8), similarly large excursions must be postulated for the last 5 m.y.

We have presented evidence (Fig. 24) that the mass flux diminishes by $40 \%$ in going from a depth of $2700 \mathrm{~m}$ to one of $3300 \mathrm{~m}$ (present lysocline) in the late Neogene. If this depth difference is on the order of lysocline fluctuation, a range of sedimentation rates of a factor of two, at these intermediate depths, can be explained by variations in dissolution intensity. At greater depths, the factor rapidly increases because it approaches the factor by which carbonate content exceeds noncarbonate content at the CCD (ca. 10). For this reason, the pattern of the deepest site, Site 804 , is strongly dominated by dissolution history (Fig. 24B).

The problem is not whether carbonate dissolution can explain the rate patterns of the deep sites, but to what degree dissolution influences the patterns in the sites above and at the present lysocline, that is, Sites 806,807 , and 805 . We have argued above (Fig. 24) that the sedimentation rate ratio (SR-ratio) of sites in the same area but at 


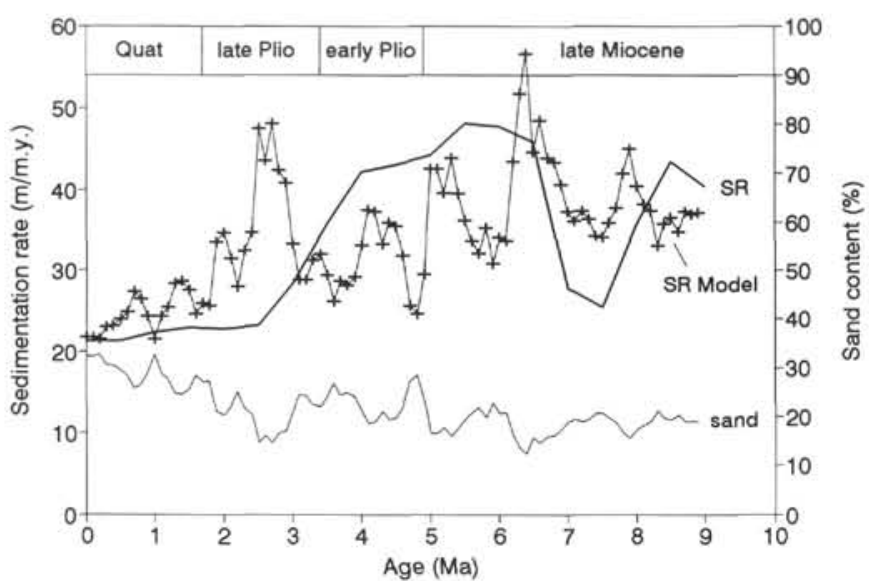

Figure 32. Evidence for winnowing as an important factor in shaping the accumulation rate peak in Tortonian-Messinian time, DSDP Site 586. Sand content (scale to right) from Whitman (1989). Sedimentation rate (SR, scale to left) based on shipboard nannofossil stratigraphy (Kennett, von der Borch, et al., 1986), adapted to present age model. SR Model (scale to left) = sedimentation rate predicted from sand content, assuming initial sand content is $10 \%$ and corresponds to a sedimentation rate of $70 \mathrm{~m} / \mathrm{m} . \mathrm{y}$. (see text). The graph shows that winnowing (as reflected in percent sand) can explain much of the trend in the post-Miocene accumulation rate. Also, it shows where mismatches exist within the Pliocene.

different depths is a measure of the record of dissolution intensity. This ratio is independent of the age model; it only depends on correlation, not on age assignment. The SR-ratio 805/806 shows only a weak relationship to the sedimentation rate patterns of either Site 805 or 806 (Fig. 33). If we assume that there is no dissolution at Site 806 (at $2520 \mathrm{~m}$ ), then the loss history at Site 805 emerges as the difference of the SR-ratio to unity. This difference is near $20 \%$ throughout; it does not diminish at peak rate time.

Thus, although dissolution decreases the sedimentation rate in Site 805 (by some $20 \%$ relative to Site 806 ), it apparently does not help shape the rate peak, unless it runs parallel in the two sites. There is evidence that Site 806 was markedly affected by carbonate dissolution at times, based on foraminifer preservation (Chaisson and Leckie, this volume). The extent of this effect can only be ascertained by studying the preservation record of foraminifers and nannofossils in some detail. Considering that a difference in a depth of $600 \mathrm{~m}$ produces a difference in accumulation rate of $40 \%$ (Fig. 24), and considering the potential for vertical excursions of the lysocline, we suggest that a loss from dissolution of $20 \%$ at Site 806 would not be an unreasonable expectation. Modulation of such a loss would produce a factor of rate change of 1.2-a small portion of the factor of 3 seen in the age model. We conclude that dissolution is probably unimportant in modulating sedimentation rates in Site 806, and that we have to call on productivity and winnowing as master variables.

\section{Other Factors: Purification and Redeposition}

Beside carbonate productivity, dissolution, and winnowing, other factors are quite likely important in changing the patterns of sedimentation on the plateau through time. Fine-scale redeposition processes apparently are pervasive in Site 586, for example, according to the Shipboard Party of Leg 89 (although the Leg 90 Shipboard Party emphasized the biostratigraphic coherency of the deposits; see reports in Moberly, Schlanger, et al., 1986, p. 220; and Kennett, von der Borch, et al., 1986; p. 33). Winnowing removes fines preferentially; as noncarbonate is mainly in the fine material, winnowing purifies the carbonate. This may be one reason why carbonate values are so high on top of the plateau. Why then does carbonate content decrease as

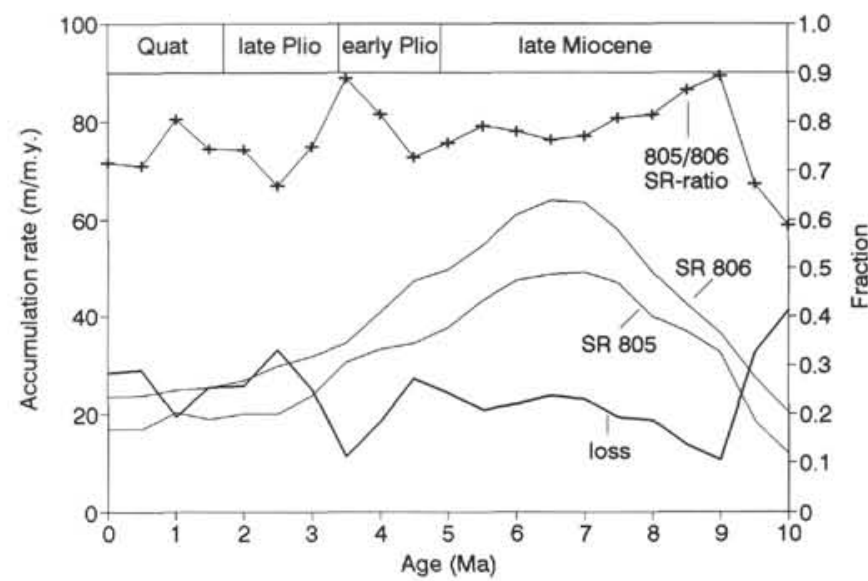

Figure 33. Sedimentation rate ratio between Sites 806 and 805 as a measure of dissolution intensity in the late Neogene, and comparison with individual sedimentation rate histories. Loss in Site 805 reckoned as the difference between the two sites. The graph suggests that dissolution plays a subordinate role in producing the marked decrease in accumulation rate during post-Miocene time.

winnowing increases in post-Miocene time? Something must change in the nature of the sediment that facilitates the removal of carbonate, in preference to noncarbonate: carbonate particles must become finer and the noncarbonate coarser. In fact, small forms of Reticulofenestra dominate the sediment in post-Miocene time (Figs. 34-35). Size distributions on lithogenous components are not available; we would expect an increase in size throughout the post-Miocene period to account for the decrease in carbonate content.

What is winnowed away in one place is transported to another. Because suspensions are heavier than clear water, all such transport has a gravity-driven component. That is, the winnowed material, the "chaff," tends to waft downslope. One effect is to increase sedimentation rates at intermediate levels (Fig. 3). Another is to deliver carbonate to depths where it dissolves.

The increased supply of fine carbonate to great depths, from winnowing, increases the alkalinity of deep and bottom waters. This has two consequences: (1) CCD and lysocline tend to move downward during times of strong winnowing, and (2) the ocean takes up a greater share of carbon dioxide. Thus, if post-Miocene winnowing at shallow depths is a general phenomenon (rather than being restricted to the Ontong Java Plateau), this process would contribute to a drop in atmospheric carbon dioxide in the late Neogene (maximally, say, $10 \%$ of atmospheric $\mathrm{CO}_{2}$, for a CCD drop of a several hundred meters; see Berger and Spitzy, 1988).

\section{SUMMARY AND CONCLUSIONS}

\section{Trends and Events}

We have attempted to integrate biostratigraphic and geochemical information to arrive at a plausible reconstruction of the history of carbonate sedimentation on the Ontong Java Plateau. A summary of major trends and events is given in Figures 34-35 for biostratigraphy and in Figures 36A-36B for geochemistry. As is well appreciated (Hsü and Weissert, 1985; Kennett, 1985; Haq, 1984; Thiede and Bleil, 1990; and authors therein), Neogene history is dominated by successive pulses of polar cooling, and its effects on the global environment. This general trend is accompanied by the closing of the circumtropical Tethys Ocean, the widening of the circumpolar Southern Ocean, and mountain building on a grand scale.

There are two outstanding periods of change within the Neogene, as seen in the paleontological record (Berggren, 1969; Cifelli, 1969; Haq, 1973; Vincent and Berger, 1981; Wei and Kennett, 1986). One is in the early Miocene, when the modern planktonic assemblage (or 


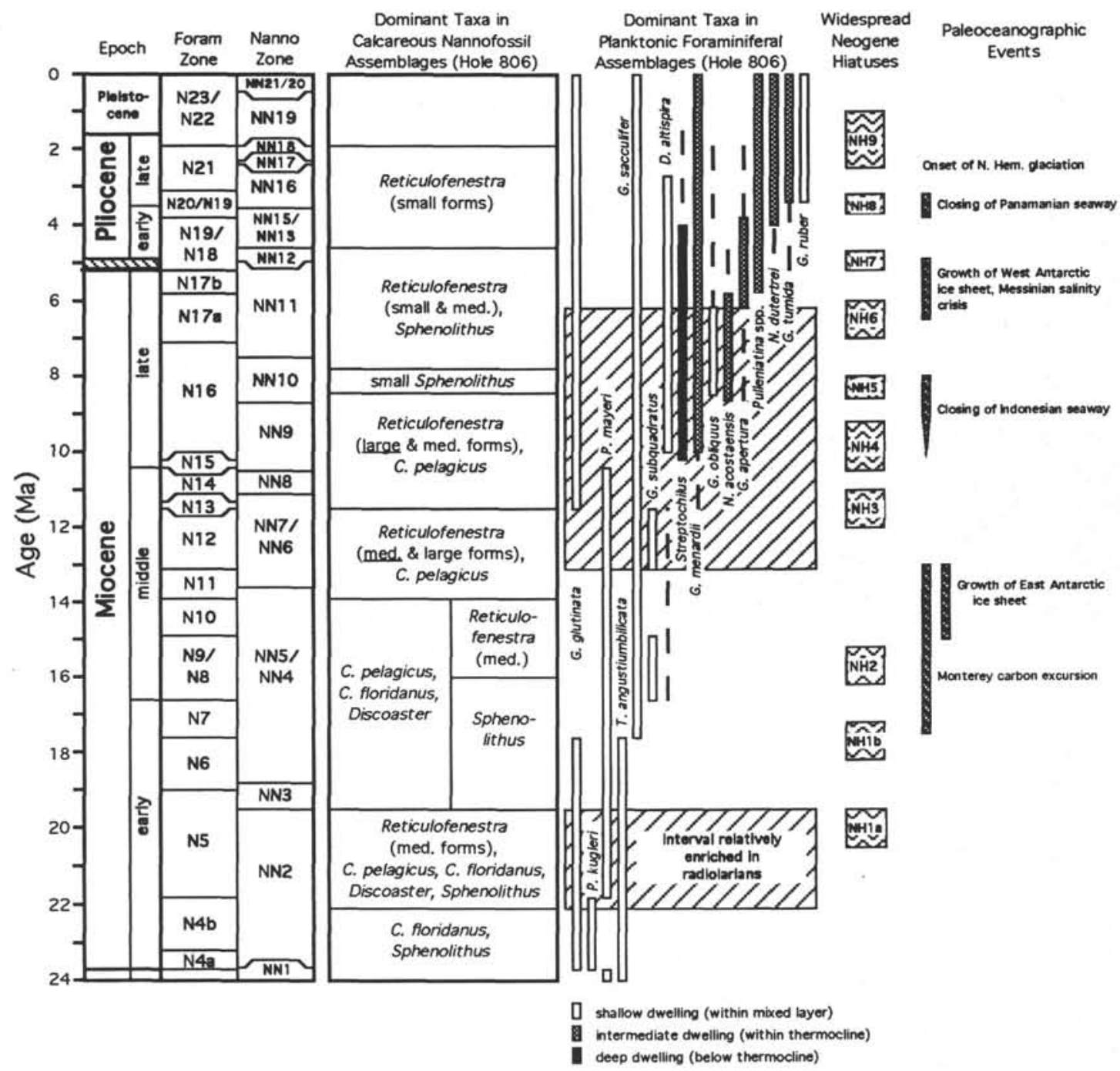

Figure 34. Major trends in calcareous plankton assemblages in the Neogene, Hole 806B. Nannofossil data from Takayama (this volume), planktonic foraminiferal data from Chaisson and Leckie (this volume). Intervals enriched in radiolarians shown as ruled pattern (very schematic). Ages of Neogene hiatuses from Keller and Barron (1987) and Barron (1989). (N.B.: Keller and Barron [1987] assign an age of 11.8-12.9 Ma for Zone NH3, whereas Barron assigns an age of 11.0-12.0 Ma.) Major paleoceanographic events summarized from Kennett et al. (1985) and Theyer et al. (1989). The marked changes in plankton assemblages near the middle to late Miocene boundary are especially noteworthy.

something like it) establishes itself. (In the benthic fauna, the main change is at the beginning of the Monterey Carbon Excursion [Thomas and Vincent, 1987].) The other, of great interest here because of the greater completeness of the record, is in the late Miocene (Fig. 34). The buildup of a strong thermocline is reflected in the increasing abundance of foraminieral species residing at intermediate water depths (that is, in the upper thermocline). Increased productivity is seen in the high abundance of siliceous fossils, and especially in the high concentration of biserial foraminifers (Streptochilus), between Zones N15 and N19. As mentioned, these forms seem to indicate low oxygen content (and hence high nutrients) in the thermocline. The continued presence, in post-Miocene time, of forms related to $G$. menardii and $N$. dutertrei suggests that productivity remains high, even though sedimentation rates decrease toward the present. Observations on the abundance of benthic foraminifers at Site 586 in sediments of Pliocene age (Hermelin, 1989) reenforce this impression.

The nannofossil assemblage shows a drastic change in the early middle Miocene: a strong decrease of Discoaster and Cyclocargolithus floridanus, and the onset of dominance of Reticulofenestra
(Fig. 35). Another important change occurs in the late Miocene, within Zone NN10 (at about $8 \mathrm{Ma}$ ). At this time, there is a rapid and steady increase in the dominance of extremely small Reticulofenestra. From the observations on planktonic foraminifers presented above (Fig. 34), we assume that small Reticulofenestra thrive because of thermocline buildup and concomitant warm-water pooling in the western equatorial Pacific.

There is a paradox here that needs to be addressed. We have used an hypothesis of increased productivity to explain the sedimentation rate maximum centered in the latest Miocene, and we have argued that productivity did not decline sufficiently to explain the greatly decreased sedimentation rate following the Tortonian-Messinian maximum (calling on winnowing to produce the decline in rate). Why should small forms of Reticulofenestra be favored under these conditions? Considering the size difference of coastal-ocean and openocean phytoplankton, would it not be more reasonable to assume that the small representatives of this taxon indicate oligotrophy? If so, it would mean that carbonate production would stay high because of episodic bursts of growth of this form, by analogy to the blooms 


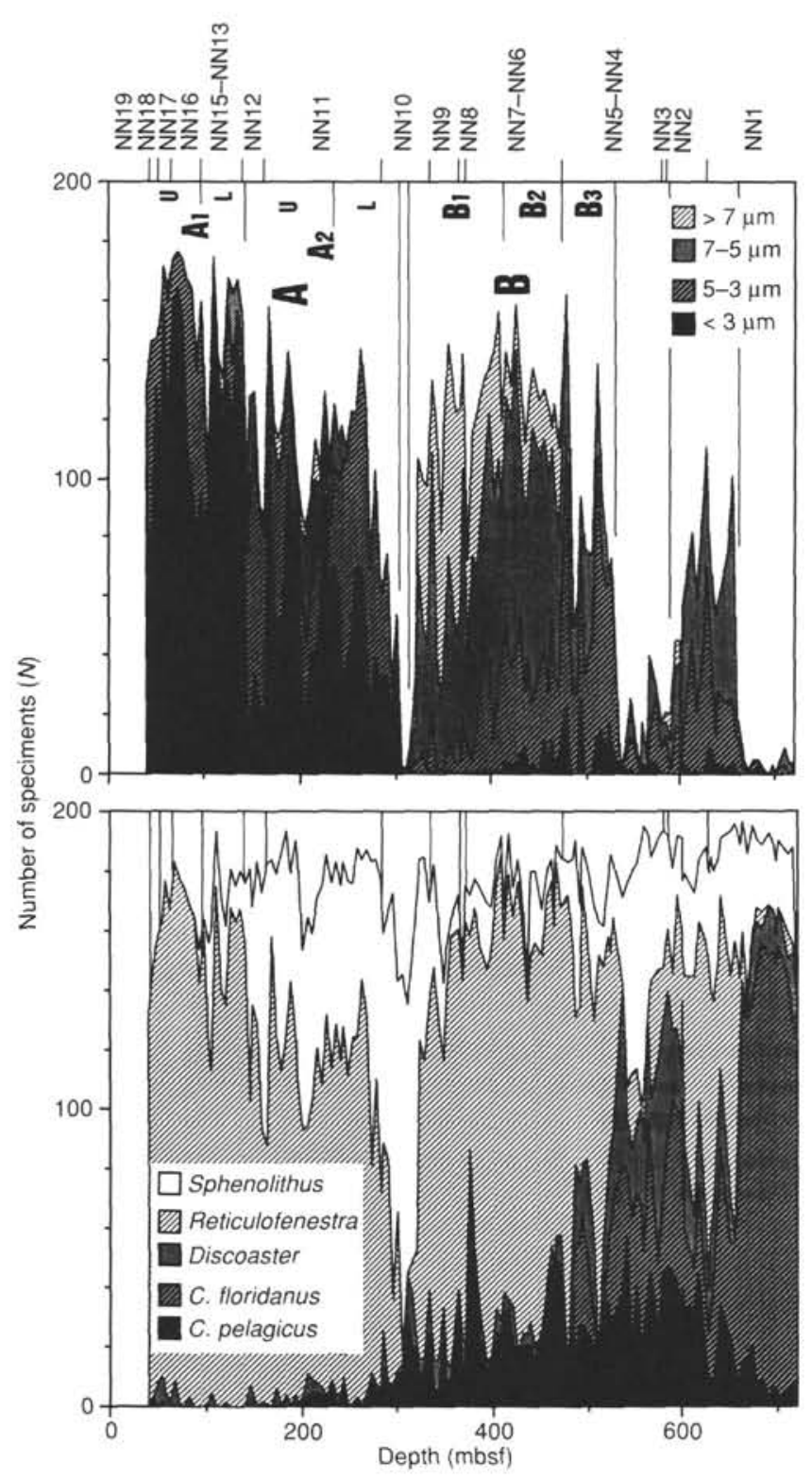

Figure 35. Major trends in nannofossil abundance in the Neogene, in Hole 806B. Sections $A_{1}, A_{2}, B_{1}$, etc., as in Takayama (this volume). Age scale approximate. The largest changes are seen in the late Miocene (within Zone NN10).

reported for the modern Emiliania huxleyi (e.g., Holligan, 1992). It is the alternation between stably structured conditions (thermocline) and mixing (winds, upwelling) that produces the potential for maximum production (cf. Legendre and Le Fevre, 1989).

We have listed, in Figure 34, some of the major events punctuating the history of Neogene oceans, events that are commonly invoked to help explain changes found in the record. The major changes are due to cooling. To what extent specific geographic events-the opening and closing of seaways, the uplift of continental regions-accelerate the process of cooling at specific times is an open question. The effects from spontaneous changes in deep circulation (attendant on relatively minor changes in boundary conditions) may be considered large enough to interfere with proper assignments of ultimate causes. The outstanding example is the upturn in NADW production in the late Miocene, which we discussed. Should the closing of the Indonesian Seaway be held responsible? Or the closing of the Tethys elsewhere? Or simply a cooling in the high latitudes?
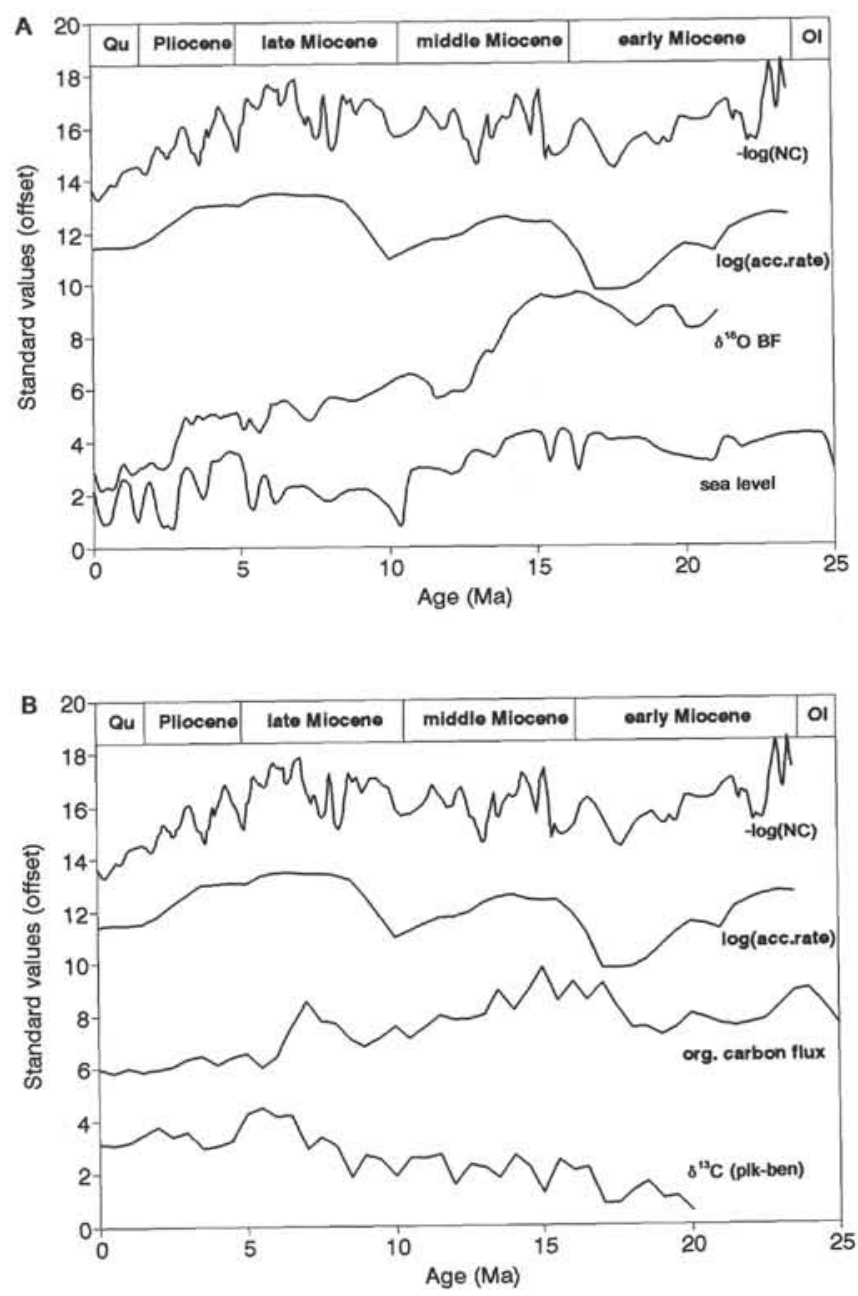

Figure 36. Comparison of trends in proxies of carbonate sedimentation (-log of noncarbonate; $\log$ of accumulation rate) on Ontong Java Plateau, and proxies of climatic change. A. $\delta^{18} \mathrm{O}$ of benthic foraminifers (from Fig. 5) and sea level (from Fig. 6). B. Carbon isotopes (from Fig. 7), plotted as organic carbon flux (equation in Vincent and Berger, 1985), and difference in planktonic and benthic values (nutrient concentration proxy). Arbitrary units, offset for clarity. The graph illustrates that the presently available proxies for sea-level position are of little use in attempting to predict carbonate content and accumulation rate of sediments on Ontong Java Plateau.

We tentatively put forward the hypothesis that the "master modulator" of carbonate sedimentation in the Pacific is the production of NADW, which affects productivity and carbonate dissolution simultaneously, through basin-basin fractionation. Because NADW production is a nonlinear response to climatic forcing in a particular region (the Nordic realm), strong correlations to global proxies of change are not necessary. Beside changing the global distribution of nutrient contents of deep water and the preferred locations for carbonate sedimentation, an increase of NADW production leads to major readjustments in the planetary heat budget. Silica deposition reflects upwelling, carbonate deposition downwelling. Upwelling water cools the surface waters, whereas downwelling implies transport of surface waters from elsewhere-in the case of the North Atlantic from low latitudes into the Nordic realm. Increased carbonate entrapment in the North Atlantic, after the middle Miocene, indicates an increase in the efficiency of the Nordic heat pump which feeds (and feeds on) the Icelandic low-pressure area. Thus, major asymmetries result which affect wind patterns and eolian moisture transport. Carbonate accumulation in the North Atlantic, and the associated late 
Neogene "silica switch" out of it and into the Pacific, are proxies for heat flow into the North Atlantic and out of the Pacific.

Many other mechanisms are at work, of course, besides NADW production, processes that are tied to sea-level change and high-latitude climate. East-west asymmetry (warm-water pileup in the western Pacific) is another important ingredient of sedimentation history on the plateau. Effects from nonlinear responses of terrestrial systems (albedo change from water-ice transition, deforestation due to drought, uplift due to increased erosion from climatic change) greatly complicate matters further.

Thus, once more we return to comparing the record to proxies of climatic change (rather than linking it to postulated climatic change, from poorly defined geographic events). The results of such comparison, unfortunately, are disappointing (Fig. 36). While there is more than a hint of agreement between the carbonate record and the record of accumulation rates, there is little relationship between either of these and the two standard proxies for global change, deep-water $\delta^{18} \mathrm{O}$ and sea level (Fig. 36A). We should expect, for example, that regression should favor an increase in sedimentation rates, because of increased supply of carbonate and nutrient matter from the shelves. Peak accumulation in the middle Miocene does appear at the cooling step (12 to $14 \mathrm{Ma}$ ), but the effect is not particularly striking. Our age scale, and the large amount of smoothing that went into making the rate curve, may be at fault. Unfortunately, biostratigraphic resolution is rather coarse in the interval of interest. The well-documented rate peak in the latest Miocene, which is accompanied by maximum values for carbonate content, has no counterpart in the sea-level curve. Admittedly, this curve has been smoothed (otherwise, regressions or transgressions would be too readily available to produce whatever effect is desired, at any given interval). The sea-level drop near $3 \mathrm{Ma}$, finally, is not reflected in an increase in carbonate accumulation, but in a decrease, which we ascribe to winnowing (at the shallower depths). (The productivity signal, as mentioned, is ambiguous.)

Coherency with the carbon isotope record (Fig. 36B) is somewhat more encouraging. The rate of carbonate sedimentation on the plateau is high when there is a reduction in the size of organic carbon reservoirs, and the maximum accumulation in the late Neogene corresponds to increased nutrient contents in deep water (presumed to be largely from Pacific enrichment through basin-basin fractionation, contingent on NADW production).

The minimum rate of accumulation in the late early Miocene (accompanied by low carbonate values) corresponds to the first peak of the Monterey Carbon Excursion. This period is marked by profound changes in the benthic assemblage (Thomas and Vincent, 1987), and by maximum asymmetry between Atlantic and Pacific, in the $\delta^{13} \mathrm{C}$ record (Miller and Fairbanks, 1985, fig. 4). We suggest that a major reorganization of deep circulation, from an upturn of the volume of NADW production, led to nutrient pileup in the Pacific (enabling efficient coastal upwelling and organic carbon extraction around the North Pacific; see Ingle, 1981) and to a reduction in $\mathrm{pH}$ of deep waters, because of greatly increased $\mathrm{CO}_{2}$ content. This resulted in greatly increased carbonate dissolution.

One way to produce hiatuses in calcareous sequences, in this view, is by chemical erosion, from increased NADW production and corresponding ageing of Pacific deep water. No great changes in ice volume or planetary temperature gradient need accompany such climate-driven events, which depend on the nonlinear response of the hydrography of the Nordic realm (including salinity change in surface waters) to threshold changes in climate. It should be noted that the postulated mechanism is nonanalog to the familiar glacial-interglacial contrast, where cold times are characterized by increased carbonate preservation in the deep Pacific. At some point (which probably has to do with the extent of sea ice in high latitudes), additional cooling does not result in increased NADW production, but decreases it (Berger and Wefer, 1991).
If the NADW hypothesis is accepted, we must ask at which point the postulated "NADW optimum" occurs in our records. We think the optimum is reached near $5 \mathrm{~m}$.y. ago, when productivity is high (as seen in the accumulation rate of shallow sites) and dissolution is great at depth (as seen in the anomalously low rates of Sites 803 and 804). The latest Miocene to early Pliocene dissolution acme which marks the NADW optimum is the carbonate low marked V-W-X in Kaneps (1973; see also Saito et al., 1975), and referred to as Gl17 and NH7 in Barron et al. (1985). It is not directly related to the Messinian Carbon Shift at $6 \mathrm{Ma}$, but comes about $1 \mathrm{~m} . \mathrm{y}$. later, upon completion of the shift (cf. the variables $-\log (\mathrm{NC})$ and organic carbon flux in Fig. 36B). Thus, it does not represent titration of organic carbon introduced to the ocean from erosion.

\section{Problems and Paradoxes}

Our main conclusion in considering the various lines of evidence presented is that both carbonate content and carbonate accumulation rate records are the result of a complex interplay of numerous factors, some global, some local, which greatly complicates conceptual modelling. Yet, the ease with which carbonate stratigraphies correlate over large depth intervals (and distances), and the fact that accumulation rates seem to correlate well along the equatorial Pacific (cf. Mayer et al., 1992) hold out the promise that large-scale processes will be found governing the patterns. Our own favorite master modulator of carbonate sedimentation is the changing intensity of NADW production, that is, Pacific-Atlantic asymmetry. Other processes must also be important, however.

Perhaps the best we can do at this point is to summarize the major problems and paradoxes that have been identified in the Neogene carbonate record on the Ontong Java Plateau, as follows:

1. Carbonate records are parallel over a wide depth range. The "parallelism problem" implies that the lysocline concept may have to be modified. We know that dissolution is important at depth, in modulating carbonate deposition. If patterns in shallow sites are parallel to those from below the lysocline, does that mean that dissolution is also important on the upper plateau? Or is there a "conspiracy" of separate factors acting in concert? These questions must be resolved before the nature of acoustic reflectors can be understood, and the reason why they can be traced over long distances through a large depth range.

2. Dissolution of carbonate cannot explain both carbonate and sedimentation rate patterns. The "loss paradox" arises from the fact that carbonate percentages at different depths are very similar to each other, so similar that the differences are insufficient to account for differences in sedimentation rate, assuming that dissolution produces these differences. The rate differences are depth related; thus, they are most probably determined by dissolution processes. If selective removal of carbonate is not the explanation, removal of noncarbonate must occur simultaneously with dissolution of carbonate. The nature of this process is not understood. It should be noted that this finding is independent of the particular age model adopted, since it is based solely on the comparison of ratios of rates (and ratios of noncarbonate content).

3. Equatorial crossings have little or no effect on carbonate content or sedimentation rate. "Equatorial insensitivity" indicates that equatorial upwelling must be unimportant in biogenic sedimentation on the plateau. If productivity is higher at the equator than elsewhere, as is true farther to the east, we should see an increase of carbonate content, at least in the deeper cores, where the CCD should be depressed according to current models of carbonate sedimentation (Berger, 1978; Farrell and Prell, 1989). We should also see an increase of sedimentation rates at the equator. The information on rates may not be reliable enough to detect the effect directly, but it should still be apparent in the thickness ratios of time-equivalent sections of 
paired records. There is some indication that density is decreased when crossing the equator.

4. There seems to be a general insensitivity of both carbonate and sedimentation rate records to global changes in conditions, as seen in commonly used proxies. Changes in $\delta^{18} \mathrm{O}$ of benthic foraminifers, for example, and sea-level changes (as mapped by sequence stratigraphy), are not clearly correlated with the main parameters of Neogene carbonate sedimentation on the plateau. The apparent "global insensitivity" may have several reasons: (1) the carbonate patterns (especially the rates of sedimentation) are poorly defined; (2) the proxies of global change are poorly defined or poorly chosen; (3) regional processes are entirely predominant, and their history differs substantially from that of global ones. Most likely, elements of all three sets of reasons are applicable.

The issues listed above are of a very general nature. Without a successful attack on these questions, the major patterns of carbonate sedimentation on the plateau will remain enigmatic, as will many phenomena associated with it, such as acoustic reflectors and hiatus formation. Much will be learned from detailed east-west comparisons, using results from Leg 138, and from comparisons with equatorial sedimentation in the Atlantic (for which legs are in the planning stage).

\section{ACKNOWLEDGMENTS}

We are greatly indebted to our shipmates of Leg 130 for generous collaboration and assistance. We especially thank Mitch Lyle for providing logging data in a timely manner. Fay Woodruff and Sam Savin sent background material and data on DSDP Site 289. Wuchang Wei, Johanna Resig, and Bill Sliter read the initial draft of the manuscript and made useful suggestions for improvement. J. Resig also kindly allowed the use of unpublished data. Financial support from the U.S. National Science Foundation (through JOI/USSAC and grants to W.H.B. and R.M.L.) is gratefully acknowledged. W.H.B. also acknowledges support from the University of Bremen for work on Leg 130 materials.

\section{REFERENCES*}

Andrews, J.E., Packham, G., et al., 1975. Init. Repts. DSDP, 30: Washington (U.S. Govt. Printing Office).

Archer, D., 1991. Modeling the calcite lysocline. J. Geophys. Res., 96:17037-17050.

Arrhenius, G., 1952. Sediment cores from the east Pacific. Rep. Swed. DeepSea Exped. 1947-1948, 5:1-227.

Backman, J., 1979. Pliocene biostratigraphy of DSDP Sites 111 and 116 from the North Atlantic Ocean and the age of the Northern Hemisphere Glaciation. Stockholm Contrib. Geol., 32:115-137.

Baldauf, J.G., and Barron, J.A., 1990. Evolution of biosiliceous sedimentation patterns-Eocene through Quaternary: paleoceanographic response to polar cooling. In Bleil, U., and Thiede, J. (Eds.), Geological History of the Polar Oceans: Arctic Versus Antarctic: Dordrecht (Kluwer Academic), 575-607.

Barron, J.A., 1989. The late Cenozoic stratigraphic record and hiatuses of the northeast Pacific: results from the Deep Sea Drilling Project. In Winterer, E.L., Hussong, D.M., and Decker, R.W. (Eds.), The Geology of North America (Vol. N): The Eastern Pacific Ocean and Hawaii. Geol. Soc. Am., 311-322.

Barron, J.A., and Baldauf, J.G., 1989. Tertiary cooling steps and paleoproductivity as reflected by diatoms and biosiliceous sediments. In Berger, W.H., Smetacek, V.S., and Wefer, G. (Eds.), Productivity of the Oceans: Present and Past: New York (Wiley-Interscience), 341-354.

Barron, J.A., Keller, G., and Dunn, D.A., 1985. A multiple microfossil biochronology for the Miocene. In Kennett, J.P. (Ed.), The Miocene Ocean: Paleoceanography and Biogeography. Mem. Geol. Soc. Am., 163:21-36.

Berger, A., Loutre, M.F., and Laskar, J., 1992. Stability of the astronomical frequencies over the Earth's history for paleoclimate studies. Science, $255: 560-566$

Berger, W.H., 1972. Deep-sea carbonates: dissolution facies and age depth constancy. Nature, 236:392-395.

, 1973. Cenozoic sedimentation in the eastern tropical Pacific. Geol. Soc. Am. Bull., 84:1941-1954.
1978. Sedimentation of deep-sea carbonate: maps and models of variations and fluctuations. J. Foraminiferal Res., 8:286-302.

Berger, W.H., and Johnson, T.C., 1976. Deep-sea carbonates: dissolution and mass wasting on Ontong-Java Plateau. Science, 192:785-787.

Berger, W.H., and Keir, R.S., 1984. Glacial-Holocene changes in atmospheric $\mathrm{CO}_{2}$ and the deep-sea record. In Hansen, J.E., and Takahashi, T. (Eds.), Climate Processes and Climate Sensitivity. Am. Geophys. Union, Maurice Ewing Ser., 5:337-351.

Berger, W.H., Kroenke, L.W., Mayer, L.A., Backman, J., Janecek, T.R., Krissek, L., Leckie, M., Lyle, M., and Shipboard Scientific Party, 1992. The record of Ontong Java Plateau: main results of ODP Leg 130. Geol. Soc. Am. Bull., 104:954-972.

Berger, W.H., Kroenke, L.W., Mayer, L.A., and Shipboard Scientific Party, 1991. Ontong Java Plateau, Leg 130: synopsis of major drilling results. In Kroenke, L.W., Berger, W.H., Janecek, T.R., et al., Proc. ODP, Init. Repts., 130: College Station, TX (Ocean Drilling Program), 497-537.

Berger, W.H., and Mayer, L.A., 1978. Deep-sea carbonates: acoustic reflectors and lysocline fluctuations. Geology, 6:11-15.

Berger, W.H., and Spitzy, A., 1988. History of atmospheric $\mathrm{CO}_{2}$ : constraints from the deep-sea record. Paleoceanography, 3:401-411.

Berger, W.H., and Vincent, E., 1986. Deep-sea carbonates: reading the carbonisotope signal. Geol. Rundsch., 75:249-269.

Berger, W.H., and Wefer, G., 1991. Productivity of the glacial ocean: discussion of the iron hypothesis. Limnol. Oceanogr., 36:1899-1918.

Berggren, W.A., 1969. Rates of evolution in some Cenozoic planktonic Foraminifera. Micropaleontology, 15:351-365.

1972. Late Pliocene-Pleistocene glaciation. In Laughton, A.S. Berggren, W.A., et al., Init. Repts. DSDP, 12: Washington (U.S. Govt. Printing Office), 953-963.

Berggren, W.A., Kent, D.V., and Van Couvering, J.A., 1985. The Neogene: Part 2. Neogene geochronology and chronostratigraphy. In Snelling, N.J. (Ed.), The Chronology of the Geological Record. Geol. Soc. London Mem., 10:211-260.

Broecker, W.S., 1973. Factors controlling $\mathrm{CO}_{2}$ content in the oceans and atmosphere. In Woodwell, G.M., and Pecan, E.V. (Eds.), Carbon and the Biosphere. AEC Symp., 30:32-50.

Cifelli, R., 1969. Radiation of Cenozoic planktonic Foraminifera. Syst. Zool., 18:154-168.

DePaolo, D.J., 1986. Detailed record of the Neogene Sr isotopic evolution of seawater from DSDP Site 590B. Geology, 14:103-106.

DePaolo, D.J., and Ingram, B.L., 1985. High-resolution stratigraphy with strontium isotopes. Science, 227:938-941.

Ehrmann, W.U., and Thiede, J., 1985. History of Mesozoic and Cenozoic sediment fluxes to the North Atlantic Ocean. Contrib. Sedimentol. 15:1-109.

Elderfield, H., 1986. Strontium isotope stratigraphy. Palaeogeogr., Palaeoclimatol., Palaeoecol., 57:71-90.

Farrell, J.W., and Prell, W.L., 1989. Climatic change and $\mathrm{CaCO}_{3}$ preservation: an 800,000 year bathymetric reconstruction from the central equatorial Pacific Ocean. Paleoceanography, 4:447-466.

Gardner, J.V., Dean, W.E., Bisagno, L., and Hemphill, E., 1986a. Late Neogene and Quaternary coarse-fraction and carbonate stratigraphies for Site 586 on Ontong-Java Plateau and Site 591 on Lord Howe Rise. In Kennett, J.P., von der Borch, C.C., et al., Init. Repts. DSDP, 90, Pt. 2: Washington (U.S. Govt. Printing Office), 1201-1224.

Gardner, J.V., Nelson, C.S., and Baker, P.A., 1986b. Distribution and character of pale green laminae in sediment from Lord Howe Rise: a probable late Neogene and Quaternary tephrostratigraphic record. In Kennett, J.P., von der Borch, C.C., et al., Init. Repts. DSDP, 90, Pt. 2: Washington (U.S. Govt. Printing Office), 1145-1159.

Gartner, S., 1992. Miocene nannofossil chronology in the North Atlantic, DSDP Site 608. Mar. Micropaleontol., 18:307-331.

Gasperi, J.T., and Kennett, J.P., in press. Isotopic evidence for depth stratification and paleoecology of Miocene planktonic Foraminifera: western equatorial Pacific DSDP Site 289. In Tsuchi, R. (Ed.), Pacific Neogene Events in Time and Space: Tokyo (Univ. of Tokyo).

Grötsch, J., Wu, G., and Berger, W.H., 1991. Carbonate cycles in the Pacific: reconstruction of saturation fluctuations. In Einsele, G., Ricken, W., and Seilacher, A. (Eds.), Cycles and Events in Stratigraphy: Heidelberg (Springer-Verlag), $110-125$.

* Abbreviations for names of organizations and publication titles in ODP reference lists follow the style given in Chemical Abstracts Service Source Index (published by American Chemical Society). 
Haq, B.U., 1973. Transgressions, climatic change and the diversity of calcareous nannoplankton. Mar. Geol., 15:25-30.

, 1984. Paleoceanography: a synoptic overview of 200 million years of ocean history. In Haq, B.U., and Milliman, J.D. (Eds.), Marine Geology and Oceanography of Arabian Sea and Coastal Pakistan: New York (Van Nostrand Reinhold), 201-231.

Haq, B.U., Hardenbol, J., and Vail, P.R., 1987. Chronology of fluctuating sea levels since the Triassic. Science, 235:1156-1167.

Haq, B.U., Worsley, T.R., Burckle, L.H., Douglas, R.G., Keigwin, L.D., Opdyke, N.D., Savin, S.M., Sommer, M.A., Vincent, E., and Woodruff, F., 1980. Late Miocene marine carbon-isotopic shift and synchroneity of some phytoplanktonic biostratigraphic events. Geology, 8:427-431.

Hays, J.D., Saito, T., Opdyke, N.D., and Burckle, L.H., 1969. Plio-Pleistocene sediments of the equatorial Pacific: their paleomagnetic biostratigraphic, and climatic record. Geol. Soc. Am. Bull., 80:1481-1514.

Hebbeln, D., Wefer, G., and Berger, W.H., 1990. Pleistocene dissolution fluctuations from apparent depth of deposition in Core ERDC-127P, westequatorial Pacific. Mar. Geol., 92:165-176.

Herbert, T.D., and Mayer, L.A., 1991. Long climatic time series from sediment physical property measurements. J. Sediment. Petrol., 61: 1089-1108

Herguera, J.C., and Berger, W.H., 1991. Paleoproductivity: glacial to postglacial change in the western equatorial Pacific, from benthic Foraminifera. Geology, 19:1173-1176.

Hermelin, J.O.R., 1989. Pliocene benthic Foraminifera from the Ontong-Java plateau (Western Equatorial Pacific Ocean): faunal response to changing paleoenvironment. Spec. Publ. Cushman Found. Foraminiferal Res., 26:1-143.

Hess, J., Bender, M.L., and Schilling, J.G., 1986. Evolution of the ratio of strontium-87 to strontium-86 in seawater from Cretaceous to Present. Science, 231:979-984.

Hodell, D.A., Elmstrom, K.M., and Kennett, J.P., 1986. Latest Miocene benthic $\delta^{18} \mathrm{O}$ changes, global ice volume, sea level, and the "Messinian salinity crisis." Nature, 320:411-414.

Hodell, D.A., Mueller, P.A., and Garrido, J.R., 1991. Variations in the strontium isotopic composition of seawater during the Neogene. Geology, 19:24-27.

Hodell, D.A., Mueller, P.A., McKenzie, J.A., and Mead, G.A., 1989. Strontium isotope stratigraphy and geochemistry of the late Neogene ocean. Earth Planet. Sci. Lett., 92:165-178.

Holligan, P.M., 1992. Do marine phytoplankton influence global climate? In Falkowski, P.G., and Woodhead, A.D. (Eds.), Primary Productivity and Biogeochemical Cycles in the Sea: New York (Plenum), 487-501.

Hsü, K.J., and Weissert, H.J. (Eds.), 1985. South Atlantic Paleoceanography: Cambridge (Cambridge Univ. Press).

Hussong, D.M., Wipperman, L.K., and Kroenke, L.W., 1979. The crustal structure of the Ontong Java and Manihiki oceanic plateaus. J. Geophys. Res., 84:6003-6010.

Ingle, J.C., Jr., 1981. Origin of Neogene diatomites around the North Pacific rim. In Garrison, R.S., Douglas, R., Pisciotto, K., Isaacs, C., and Ingle, J.C. (Eds.), The Monterey Formation and Related Siliceous Rocks of California. Spec. Publ., Soc. Econ. Paleontol. Mineral., 159-179.

Jansen, E., and Sjøholm, J., 1991. Reconstruction of glaciation over the past 6 million years from ice-borne deposits in the Norwegian Sea. Nature, 349:600-604

Jansen, E., Sjøholm, J., Bleil, U., and Erichsen, J.A., 1990. Neogene and Pleistocene glaciations in the Northern Hemisphere and late MiocenePliocene global ice volume fluctuations: evidence from the Norwegian Sea. In Bleil, U., and Thiede, J. (Eds.), Geological History of the Polar Oceans: Arctic Versus Antarctic: Dordrecht (Kluwer Academic), 677-705.

Johnson, T.C., Hamilton, E.L., and Berger, W.H., 1977. Physical properties of calcareous ooze: control by dissolution at depth. Mar. Geol., 24:259-277.

Kaneps, A., 1973. Carbonate chronology for Pliocene deep-sea sediments. In van Andel, T.H., Heath, G.R., et al., Init. Repts. DSDP, 16: Washington (U.S. Govt. Printing Office), 873-881.

Keigwin, L.D., 1979. Late Cenozoic stable isotope stratigraphy and paleoceanography of DSDP sites from the east equatorial and central North Pacific Ocean. Earth Planet. Sci. Lett., 45:361-382.

Keir, R.S., 1988. On the late Pleistocene ocean geochemistry and circulation. Paleoceanography, 3:413-445.

Keller, G., 1985. Depth stratification of planktonic foraminifers in the Miocene ocean. In Kennett, J.P. (Ed.), The Miocene Ocean: Paleoceanography and Biogeography. Mem. Geol. Soc. Am., 163:177-195.

Keller, G., and Barron, J.A., 1983. Paleoceanographic implications of Miocene deep-sea hiatuses. Geol. Soc. Am. Bull., 94:590-613.
1987. Paleodepth distribution of Neogene deep-sea hiatuses. Paleoceanography, 2:697-713.

Kennett, J.P. (Ed.), 1985. The Miocene Ocean: Paleoceanography and Biogeography. Mem. Geol. Soc. Am., 163.

1986a. Miocene paleoceanography and plankton evolution. In Hsü, K.J. (Ed.), Mesozoic and Cenozoic Oceans. Am. Geophys. Union, Geodyn. Ser., 15:119-122.

1986b. Miocene to early Pliocene oxygen and carbon isotope stratigraphy of the Southwest Pacific, DSDP Leg 90. In Kennett, J.P., von der Borch, C.C., et al., Init. Repts. DSDP, 90, Pt. 2: Washington (U.S. Govt. Printing Office), 1383-1411.

Kennett, J.P., Keller, G., and Srinivasan, M.S., 1985. Miocene planktonic foraminiferal biogeography and paleoceanographic development of the Indo-Pacific region. In Kennett, J.P. (Ed.), The Miocene Ocean: Paleoceanography and Biogeography. Mem. Geol. Soc. Am., 163:197-236.

Kennett, J.P., von der Borch, C.C., et al., 1986. Init. Repts. DSDP, 90, Pt. 1: Washington (U.S. Govt. Printing Office).

Kroenke, L.W., Berger, W.H., Janecek, T.R., et al., 1991. Proc. ODP, Init. Repts., 130: College Station, TX (Ocean Drilling Program).

Legendre, L., and Le Fevre, J., 1989. Hydrodynamical singularities as controls of recycled versus export production in oceans. In Berger, W.H., Smetacek, V.S., and Wefer, G. (Eds.), Productivity of the Ocean: Present and Past: Chichester (John Wiley), 49-63.

Leinen, M., 1979. Biogenic silica accumulation in the central equatorial Pacific and its implications for Cenozoic paleoceanography. Geol. Soc. Am. Bull., 90(2):1310-1376.

Loutit, T.S., and Keigwin, L.D., Jr., 1982. Stable isotope evidence for the latest Miocene sea-level fall in the Mediterranean region. Nature, 300:163-166.

Loutit, T.S., Kennett, J.P., and Savin, S.M., 1984. Miocene equatorial and southwest Pacific paleoceanography from stable isotope evidence. Mar. Micropaleontol., 8:215-233.

Mayer, L., Pisias, N., Janecek, T., and Shipboard Scientific Party, ODP Leg 138, 1992. High-resolution studies of the eastern equatorial Pacific. Eos, $73: 257-262$.

Mayer, L.A., 1991. Extraction of high-resolution carbonate data for paleoclimatic reconstruction. Nature, 352:148-151.

Mayer, L.A., Shipley, T.H., and Winterer, E.L., 1986. Equatorial Pacific seismic reflectors as indicators of global oceanographic events. Science, 233:761-764.

Mayer, L.A., Shipley, T.H., Winterer, E.L., Mosher, D., and Hagen, R.A., 1991 SeaBeam and seismic reflection surveys on the Ontong Java Plateau. In Kroenke, L.W., Berger, W.H., Janecek, T.R., et al., Proc. ODP, Init. Repts., 130: College Station, TX (Ocean Drilling Program), 45-75.

McGowran, B., 1986. Cainozoic oceanic and climatic events: the Indo-Pacific foraminiferal biostratigraphic record. Palaeogeogr., Palaeoclimatol., Palaeoecol., 55:247-265.

McKenzie, J.A., and Oberhänsli, H., 1985. Paleoceanographic expressions of the Messinian salinity crisis. In Hsü, K.J., and Weissert, H.J. (Eds.), South Atlantic Paleoceanography: Cambridge (Cambridge Univ. Press), 99-123.

Miller, K.G., and Fairbanks, R.G., 1985. Oligocene to Miocene carbon isotope cycles and abyssal circulation changes. In Sundquist, E.J., and Broecker, W.S. (Eds.), The Carbon Cycle and Atmospheric $\mathrm{CO}_{2}$ : Natural Variations Archean to Present. Am. Geophys. Union, Geophys. Monogr. Ser., 32:469-486.

Miller, K.G., Fairbanks, R.G., and Mountain, G.S., 1987. Tertiary oxygen isotope synthesis, sea-level history, and continental margin erosion. Paleoceanography, 2:1-19.

Miller, K.G., Feigenson, M.D., Wright, J.D., and Clement, B.M., 1991. Miocene isotope reference section, Deep Sea Drilling Project Site 608: an evaluation of isotope and biostratigraphic resolution. Paleoceanography, 6:33-52.

Moore, T.C., Loutit, T.S., and Greenlee, S.M., 1987. Estimating short-term changes in eustatic sea level. Paleoceanography, 2:625-637.

Parker, F.L., and Berger, W.H., 1971. Faunal and solution patterns of planktonic Foraminifera in surface sediments of the South Pacific. Deep-Sea Res., Pt. A, 18:73-107.

Prentice, M.L., and Matthews, R.K., 1988. Cenozoic ice-volume history: development of a composite oxygen isotope record. Geology, 16:963-966.

Raymo, M.E., Ruddiman, W.F., and Froelich, P.N., 1988. Influence of late Cenozoic mountain building on ocean geochemical cycles. Geology, 16:649-653.

Richter, F.M., and DePaolo, D.J., 1988. Diagenesis and $\mathrm{Sr}$ isotopic evolution of seawater using data from DSDP 590B and 575. Earth Planet. Sci. Lett., 90:382-394. 
Romine, K., and Lombari, G., 1985. Evolution of Pacific circulation in the Miocene: radiolarian evidence from DSDP Site 289. In Kennett, J.P. (Ed.), The Miocene Ocean: Paleoceanography and Biogeography. Mem. Geol. Soc. Am., 163:273-290.

Ruddiman, W.F., Raymo, M.E., Martinson, D.G., Clement B.M., and Backman, J., 1989. Pleistocene evolution: Northern Hemisphere ice sheets and North Atlantic Ocean. Paleoceanography, 4:353-412.

Ruddiman, W.F., Raymo, M. E., and McIntyre, A., 1986. Matuyama 41,000year cycles: North Atlantic and Northern Hemisphere ice sheets. Earth Planet. Sci. Lett., 80:117-129.

Saito, T., Burckle, L.H., and Hays, J.D., 1975. Late Miocene to Pleistocene biostratigraphy of equatorial Pacific sediments. In Saito, T., and Burckle. L.H. (Eds.), Late Neogene Epoch Boundaries. Spec. Publ. Micropaleontol., 1:226-244.

Savin, S.M., Douglas, R.G., and Stehli, F.G., 1975. Tertiary marine paleotemperatures. Geol. Soc. Am. Bull., 86:1499-1510.

Schlanger, S.O., and Douglas, R.G., 1974. The pelagic ooze-chalk-limestone transition and its implication for marine stratigraphy. In Hsü, K.J., and Jenkyns, H.C. (Eds.), Pelagic Sediments: On Land and Under the Sea. Int. Assoc. Sedimentol. Spec. Publ., 1:117-148.

Shackleton, N.J., 1985. Oceanic carbon isotope constraints on oxygen and carbon dioxide in the Cenozoic atmosphere. In Sundquist, E.T., and Broecker, W.S. (Eds.), The Carbon Cycle and Atmospheric $\mathrm{CO}_{2}$ : Natural Variations Archean to Present. Am. Geophys. Union, Geophys. Monogr. Ser., 32:412-417.

Shackleton, N.J., Backman, J., Zimmerman, H., Kent, D.V., Hall, M.A., Roberts, D.G., Schnitker, D., Baldauf, J., Desprairies, A., Homrighausen, R., Huddlestun, P., Keene, J.B., Kaltenback, A.J., Krumsiek, K.A.O., Morton, A.C., Murray, J.W., and Westberg-Smith, J., 1984. Oxygen isotope calibration of the onset of ice-rafting in DSDP Site 552A: history of glaciation in the North Atlantic region. Nature, 307:620-623.

Shackleton, N.J., Berger, A., and Peltier, W.R., 1990. An alternative astronomical calibration of the lower Pleistocene time scale based on ODP Site 677. Trans. R. Soc. Edinburgh, Earth Sci., 81:251-261.

Shackleton, N.J., Imbrie, J., and Pisias, N.G., 1988. The evolution of oceanic oxygen-isotope variability in the North Atlantic over the past three million years. Philos. Trans. R. Soc. London, Ser. B, 318:679-688.

Shackleton, N.J., and Kennett, J.P., 1975. Paleotemperature history of the Cenozoic and the initiation of Antarctic glaciation: oxygen and carbon isotope analyses in DSDP Sites 277,279 and 281. In Kennett, J.P., Houtz, R.E., et al., Init. Repts. DSDP, 29: Washington (U.S. Govt. Printing Office), 743-755.

Shackleton, N.J., and Opdyke, N.D., 1973. Oxygen isotope and paleomagnetic stratigraphy of equatorial Pacific Core V28-238: oxygen isotope temperatures and ice volumes on a $10^{5}$ year and $10^{6}$ year scale. Quat. Res., 3:39-55.

1976. Oxygen-isotope and paleomagnetic stratigraphy of Pacific Core V28-239: late Pliocene to latest Pleistocene. In Cline, R.M., and Hays, J.D. (Eds.), Investigations of Late Quaternary Paleoceanography and Paleoclimatology. Mem. Geol. Soc. Am., 145:449-464.

Shipboard Scientific Party, 1986. Site 586. In Moberly, R., Schlanger, S.O. et al., Init. Repts. DSDP, 89: Washington (U.S. Govt. Printing Office), 213-281.

Tarduno, J.A., Sliter, W.V., Kroenke, L., Leckie, M., Mayer, H., Mahoney, J.J., Musgrave, R., Storey, M., and Winterer, E.L., 1991. Rapid formation of Ontong Java Plateau by Aptian mantle plume volcanism. Science, 254:399-403.

Theyer, F., Vincent, E., and Mayer, L.A., 1989. Sedimentation and paleoceanography of the central equatorial Pacific. In Winterer, E.L., Hussong, D.M., and Decker, R.W. (Eds.), The Geology of North America (Vol. N): The Eastern Pacific Ocean and Hawaii. Geol. Soc. Am., 347-372.

Thiede, J., and Bleil, U. (Eds.), 1990. Geological History of the Polar Oceans: Arctic Versus Antarctic: Dordrecht (Kluwer Academic).

Thomas, E., and Vincent, E., 1987. Equatorial Pacific deep-sea benthic Foraminifera: faunal changes before the middle Miocene polar cooling. Geology, 15:1035-1039.

van Andel, T.H., Heath, G.R., and Moore, T.C., 1975. Cenozoic history and paleoceanography of the central equatorial Pacific Ocean: a regional synthesis of Deep Sea Drilling Project data. Mem. Geol. Soc. Am., 143:1-134.

van Andel, T.H., Thiede, J., Sclater, J.G., and Hay, W.W., 1977. Depositional history of the South Atlantic Ocean during the last 125 million years. J. Geol., 85:651-698.

Vincent, E., and Berger, W.H., 1981. Planktonic Foraminifera and their use in paleoceanography. In Emiliani, C. (Ed.), The Sea (Vol. 7): The Oceanic Lithosphere: New York (Wiley), 1025-1119.

1985. Carbon dioxide and polar cooling in the Miocene: the Monterey Hypothesis. In Sundquist, E., and Broecker, W.S. (Eds.), The Carbon Cycle and Atmospheric $\mathrm{CO}_{2}:$ Natural Variations Archean to Present. Am. Geophys. Union, Geophys. Monogr. Ser., 32:455-468.

Vincent, E., Killingley, J.S., and Berger, W.H., 1980. The Magnetic Epoch-6 carbon shift: a change in the ocean's ${ }^{13} \mathrm{C} /{ }^{12} \mathrm{C}$ ratio 6.2 million years ago. Mar. Micropaleontol., 5:185-203.

Wei, K.-Y., and Kennett, J.P., 1986. Taxonomic evolution of Neogene planktonic Foraminifera and paleoceanographic relations. Paleoceanography, 1:67-84.

Whitman, J.M., 1989. Stable isotope record of Foraminifera from Ontong Java Plateau for the last 6 million years, DSDP Site 586 [Ph.D. dissert.]. Univ. of California, San Diego.

Whitman, J.M., and Berger, W.H., 1992. Pliocene-Pleistocene oxygen isotope record of Site 586, Ontong Java Plateau. Mar. Micropaleontol., 18:171-198.

Winterer, E.L., Riedel, W.R., et al., 1971. Init. Repts. DSDP, 7, Pt. 1: Washington (U.S. Govt. Printing Office).

Woodruff, F., 1985. Changes in Miocene deep-sea benthic foraminiferal distribution in the Pacific Ocean: relationship to paleoceanography. In Kennett, J.P. (Ed.), The Miocene Ocean: Paleoceanography and Biogeography. Mem. Geol. Soc. Am., 163:131-175.

Woodruff, F., and Douglas, R.G., 1981. Response of deep-sea benthic Foraminifera to Miocene paleoclimatic events, DSDP Site 289. Mar. Micropaleontol., 6:617-632.

Woodruff, F., and Savin, S.M., 1991. Mid-Miocene isotope stratigraphy in the deep sea: high-resolution correlations, paleoclimatic cycles, and sediment preservation. Paleoceanography, 6:755-806.

Woodruff, F., Savin, S.M., and Douglas, R.G., 1981. Miocene stable isotope record: a detailed deep Pacific Ocean study and its paleoclimatic implications. Science, 212:665-668.

Wu, G., and Berger, W.H., 1991. Pleistocene $\delta^{18} \mathrm{O}$ records from Ontong-Java Plateau: effects of winnowing and dissolution. Mar. Geol., 96:193-209.

Wu, G., Yasuda, M.K., and Berger, W.H., 1991. Late Pleistocene carbonate stratigraphy on Ontong-Java Plateau in the western equatorial Pacific. Mar Geol., 99:135-150.

Date of initial receipt: 24 July 1992

Date of acceptance: 30 October 1992

Ms 130B-051 